\title{
mRNA and microRNA profiles in the amygdala are relevant to Susceptible and Resilient mice induced by psychological stress
}

\section{Jinyan Sun}

Qingdao University, School of Pharmacy

\section{Yanjun Lu}

Qingdao University, School of Pharmacy

Jiuyong Yang

Qingdao University, School of Pharmacy

Zhenhua Song

Qingdao University, School of Pharmacy

Wei Lu ( $\square$ luwei@qdu.edu.cn )

Qingdao University, School of Pharmacy https://orcid.org/0000-0001-8399-8424

Jin-Hui Wang

University of Chinese Academy of Sciences, Institute of Biophysics

\section{Research article}

Keywords: susceptibility, resilience, neuron, psychological stress, amygdala

Posted Date: March 31st, 2020

DOl: https://doi.org/10.21203/rs.3.rs-18577/v1

License: (1) This work is licensed under a Creative Commons Attribution 4.0 International License.

Read Full License 


\section{Abstract}

Background Severe or prolonged stress increases the risk to develop psychopathologies. An individual's perception of stress exposure varies greatly, as do its consequences. Numerous individuals demonstrate resilience to psychological stress. The mRNA and microRNA profiles of stress susceptibility and resilience induced by psychological stress in the amygdala remain to be elucidated.

Methods Psychological stress to an observer was given by witnessing the attacks of the aggressor on the similar. After five days of psychological stress, the degree of fear memory and anxiety of mice were measured by social interaction test and elevated plus-maze (EPM). mRNA and microRNA profiles were quantified by high-throughput sequencing in amygdala tissues harvested from Control, Susceptible and Resilient mice.

Results In the amygdala from Susceptible mice versus Resilient mice, the upregulation of Peptide, Thyrotropin-releasing hormone, and ECM receptor, Glutamatergic synapse, Cytokine-cytokine receptor interaction, Long-term depression, PI3K-Akt, Oxytocin, GnRH, HIF-1, Estrogen, Calcium signaling pathways may be related to psychological stress-induced susceptibility, and the downregulation may be related to resilience. The downregulation of Adrenergic synapse, Adherens junction, Wnt, Sphingolipid, B cell receptor, CAMP, Rap1, Toll-like receptor signaling pathways may be related to psychological stressinduced susceptibility, and the upregulation may be related to resilience. Results by sequencing mRNA and microRNA profiles are consistent, in which some of them are validated by qRT-PCR and dualluciferase reporter assay.

Conclusion Susceptible and Resilient induced by psychological stresses are caused by the imbalanced regulation of different synapses and signaling pathways in the amygdala.

\section{Background}

Severe or prolonged stress increases the risk to develop psychopathologies such as MDD, PTSD, anxiety disorders, schizophrenia and may even trigger psychotic episodes in susceptible individuals [1-9]. An individual's perception of stress exposure varies greatly, as do its consequences. Stress could rapidly activate the autonomic nervous system (ANS) that causes the release of epinephrine and norepinephrine from the adrenal medulla. Then the hypothalamic-pituitary-adrenal (HPA) axis is activated as well, mediated by glucocorticoid (GC) hormones [10-12]. Limbic and hypothalamic brain structures coordinate emotional, cognitive, neuroendocrine and autonomic inputs, which together determine the magnitude and specificity of an individual's behavioral, neural and hormonal responses to stress [13-15]. Most current studies on stress use physiological stress models, such as SD, bondage, etc. Psychological stress models include cat urine exposure, victimization witness, etc. [16-19]. Compared with a large amount of research literature on physiological stress, there are relatively few studies on psychological stress.

The amygdala is an important center of fear learning and memory, plays a critical role in regulating stress-induced mental disorders [20-23]. During stress, the amygdala changes at the level of molecules, 
cells, and circuits. Evidence indicates that several hormones and neurotransmitter systems(such as the norepinephrine system, the GABAergic system, the serotonin system, the endocannabinoid system, the glucocorticoid system, etc.) were modulated in the amygdala during or after stress stimuli [24-32]. Changes in the hormone and neurotransmitter systems further contribute to the amygdala's plasticity at the cellular and neural circuits levels $[33,34]$. On the other hand, stress-induced neuroinflammation is also involved in the development of related psychiatric disorders. In the amygdala, the signaling pathway of inflammatory responses was activated early (a day after stress) in response to trauma [35]. Healthy individuals with greater social stressor were reported with greater amygdala activity and greater increases in inflammatory activity represented as increased concentrations of IL-6 and CRPs [36, 37]. Another study shows chronic stress (chronic unpredictable mild stress) elevated IL-1 $\beta$ concentrations and reactive oxygen species (ROS), while decreased IL-10 concentration and anti-oxidative superoxide dismutase and glutathione peroxidase [38].

After undergoing psychological stress, stressors can be divided into stress susceptibility and stress resilience according to the different effects of stressors' physical and mental health. Susceptible mice exhibit symptoms such as fear memory, anxiety, and depression, whereas resilient mice fail to show these changes $[39,40]$. Resilience can be thought of as a measure of the ability of an organism to adapt and to withstand challenges to its stability [41]. Molecular profiles of stress susceptibility and resilience induced by psychological stress need be addressed. To achieve this goal, we use an animal model of social defeat in the resident/intruder paradigm [39, 42-46]. Psychological stress in social interactions may be more close to real life than stress caused by electrical stimulations [44-46]. To mimic psychological stress, an observer was arranged around to witness attacks of the aggressor to the similar. Therefore, cellular and molecular profiles related to susceptibility and resilience induced by psychological stress in the amygdala will be our research focus, as it remains not to be systemically studied. It is worth noting that many studies have been focused on the genetics of stress-related disorders as well as genetic factors associated with vulnerability to stresses and disorder occurrence [32, 47-49].

To assess the molecular profile in the amygdala related to susceptibility and resilience induced by psychological stress, our strategies are as follows. The mice in the experimental group were subject to psychological stress, while the mice in the control group were not given any stress. In the mouse model of social defeat, psychological stress to each of the observers was achieved by watching the similar being attacked. The index for evaluating the susceptibility or resilience of mice after psychological stress is to measure the degree of fear of memory and anxiety of mice. After five days of psychological stress, the degree of fear memory and anxiety of mice were measured by social interaction test and elevated plusmaze (EPM). If the experimental group of mice express susceptibility or resilience, we will harvest their amygdala tissues within 24 hours. mRNA and microRNA profiles were analyzed by high-throughput sequencing from Susceptible mice and Resilient mice induced by psychological stress as well as Control mice. Through joint analyses and comparisons of three groups of mRNAs and microRNAs, we expect to figure out genes associated with stress susceptibility and resilience in the amygdala. We also expect to develop new therapeutic strategies by this analysis. 


\section{Methods}

\section{Experimental animals}

C57BL/6J mice and CD-1 mice were obtained from Beijing Vital River Laboratory Animal Technology Co., Ltd. and Qingdao Daren Fortune Animal Technology Co., Ltd. The feeding conditions used in this experiment were by specific pathogen-free conditions. Mice were kept under controlled conditions $(22 \pm$ $2{ }^{\circ} \mathrm{C}$, daylight between 7:00-19:00, relative humidity, $55 \pm 5 \%$ ). All experiments were performed under the guidelines and regulations of the Qingdao University Experimental Animal Care and Use Committee. Concerning Golden 's protocol, male 5-week-old C57BL/6J mice were used as subjects, and male 15week-old CD1 mice were used as aggressivors [50]. All procedures were carried out under an approved Home Office project license (number PPL 80/2578) and in accordance with the Animals (Scientific Procedures) Act, 1986 (UK) (amended 2013). All sections of this report adhere to the ARRIVE Guidelines for reporting animal research [51]. A completed ARRIVE guidelines checklist is included in Checklist S1.

\section{Psychological stresses}

Witnessing of the same species being attacked is a way to give psychological stress, leading to anxietylike, and avoidence behaviors[18, 19]. Before the psychological stress paradigm, aggressive CD1 mice were selected by detection of their aggressive behavior [50]. The adaptation period for C57 mice is 7 days before the psychological stress paradigm (Fig. 1a). In the adaptation period, C57 mice live in normal cages. And the CD1 mice were placed on one side of a special squirrel cage $(32 \times 16 \times 16 \mathrm{~cm})$ separated by a transparent and perforated acrylic plate in the middle, and the other side was left for the witness group of mice (C57 mice), which could see the CD1 mice attack and bite another C57 mice, arriving psychological stress. Followed the adaptation period, C57 mice were screened using elevated cross-maze detection and social avoidance detection (details later). Mice with dwell time in the open arms of the maze above $2 \%$ and a social avoidance check ratio above 0.5 were selected, considered without innate anxiety-like and avoidance behavior. These mice were divided into Control group $(n=15)$ and Observe group $(\mathrm{n}=26)$ randomly.

In the next five days, the Observe group undergo psychological stress experiments. Each Observe mouse was placed on the other side of the CD1 cage with a transparent partition, and another C57 mice were placed in the same side of the CD1 mouse. The Observe mice was able to see the other C57 mice being attacked by the CD1 mice through the transparent partition in the middle, subjected to psychological stress (Fig. 1b). The duration of psychological stress in the Observe mice was determined based on the number of attacks on the CD1 mice by 5 times of backbiting C57 mice. Psychological stress were conducted every morning and afternoon, for five days. The index for evaluating the susceptibility or resilience of mice after psychological stress is to measure the degree of fear memory and anxiety behavior.

\section{Elevated plus-maze detection}


After the psychological stress experiment, we performed elevated plus-maze (EPM) test on the observe and control mice on day 6 to detecte the anxiety level of the mice. The EPM tests were performed in a quiet, dark, and no irritation environment. All experiments are performed from 08: 00-14: 00. The EPM is composed of two opposite open arms $(30 \times 5 \mathrm{~cm})$, two opposite closed arms $(30 \times 5 \times 15.25 \mathrm{~cm})$, and a central area $(5 \times 5 \mathrm{~cm}), 40 \mathrm{~cm}$ above the ground. The spontaneous movement trajectory of mice in the elevated cross-maze and the time spent in each arm were recorded within 5 minutes. The percentage of time that the mice stay in the open arm as a percentage of the total time reflected the anxiety level of the mouse. The shorter the time that the mice stayed in the open arm, the more anxious the mice were. Before the start of the psychological stress modeling anxious mice with an open arm staying time less than $2 \%$ were deleted.

\section{Social avoidance detection}

The social avoidance detection was performed in an open-field area $(50 \times 50 \mathrm{~cm})$, which included a small removable transparent cage $(10 \times 10 \mathrm{~cm}) .5 \mathrm{~cm}$ around this small cage was defined as communication area (Fig. 1C). CD1 mouse was put into the small cage or not. The detection of fear memory of C57 mice to $C D 1$ was based on fewer time spent in the communication area when CD1 in the small cage. The ratio of the time that C57 mice stayed in the communication area with CD1 mice in the small cage to the time that $\mathrm{C} 57$ mice stayed in the communication area without CD1 mice was recorded. The smaller ratio reflected the avoidance behavior of C57 to CD1 mice. Before the start of the psychological stress modeling, C57 mice with social avoidance detection ratio less than 0.5 , indicating innate fear of CD1 mice, were deleted.

\section{Susceptible and Resilient categories detection}

Based on the results of the social avoidance detection, we divided the Observe mice into three categories: Susceptible, Resilient and Atypical, of which only Susceptible and Resilient were used in the subsequent experiments. After the psychological stress test, the Observe mice whose ratio decreased by more than $20 \%$ and the ratio of less than 1 were defined as Susceptible. The mice whose ratio decreased by less than $20 \%$ or increased and the ratio greater than 1 were defined as Resilient. The other Observe mice were defined as Atypical.

\section{RNA purification from amygdala tissues}

After the behavioral tests were completed, we took both sides of the amygdala from Susceptible, Resilient, and Control mice. Firstly, mouse was anesthetized with $0.1 \mathrm{ml} / 10 \mathrm{~g}$ intraperitoneal injection of $4 \%$ chloral hydrate. After the mice are fully anesthetized, perfused with $4{ }^{\circ} \mathrm{C}$ normal saline through the left atrium, and decapitated. The entire brain was isolated and put into liquid nitrogen. Then the amygdaloid area was dissected quickly and placed into a pre-cooled RNase free EP tube containing RNAwait storage solution (Solarbio, Beijing, China). After infiltration at $4{ }^{\circ} \mathrm{C}$ overnight, the tissue was transferred from the RNAwait solution to another empty RNase free EP tube, stored at $-80^{\circ} \mathrm{C}$. For subsequent sequencing and post-sequence verification, amygdaloid tissue of each group was sent to Beijing Genomics Institute for high-throughput sequencing. The total RNA concentration, RNA integrity value, and ratio of $28 \mathrm{~S}$ to $18 \mathrm{~S}$ 
ribosomal RNA were measured with a 2100 bioanalyzer (Agilent Technology, USA), and quality control was performed with RNA 6000 nano reagent port 1. Samples with total RNA greater than $10 \mu \mathrm{g}$, concentrations greater than $200 \mathrm{ng} / \mu \mathrm{l}$, RIN greater than 8, 28S / $18 \mathrm{~s}$ greater than 2 were selected to construct mRNA and microRNA libraries. In Susceptible, Resilient, and Control groups, amygdala tissue that meets these conditions was used for high-throughput sequencing, with correlation coefficients above 0.8 .

\section{RNA sequencing}

Total RNA from each sample was isolated by Trizol reagent (LifeTechnologies, Carsbad, CA, USA; [48]). mRNAs were isolated from total RNA with oligo(dT) method and fragmented. Then first strand cDNA and second strand cDNA were synthesized. cDNA fragments were purified and resolved with EB buffer for end reparation and single nucleotide $A$ (adenine) addition. After that, the cDNA fragments were linked with adapters. Those cDNA fragments with suitable size were selected for the PCR amplification.

18-30 nt RNAs were isolated from total RNAs by polyacrylamide gel electrophoresis. They were applied to construct a microRNA sequencing library. RNAs ligated to 5囚-RNA adapter by T4 RNA ligase were sizefractionated and 36-50 nucleotide fractions were excised. The precipitated RNAs were ligated to 3囚-RNA adapter by T4 RNA ligase and size-fractionated, and then 62-75 nucleotide fraction (small RNA + adaptors) was excised. To produce the templates enough for the sequencing, small RNAs ligated with adaptors were subjected to RT-PCR. Products were purified and collected by gel purification for highthroughput sequencing.

Qualities of mRNA and microRNA libraries were evaluated by 2100 Bioanalyzer (Agilent Technologies, CA USA). Their quantities were verified by ABI StepOnePlus Real-Time PCR System. Their sequencings were done by Illumina HiseqTM 2500 platform (Illumina Inc., San Diego, CA USA). In two libraries, the average reading length was about $100 \mathrm{bp}$ (pair-end) and 49 bp (single-end), respectively.

\section{Bioinformatics for mRNA}

Original image data was transformed into raw data or raw reads by base calling. Dynamic Trim Perl script implemented in the SolexaQA package was done to control the quality of raw sequencing data. Reads with adapters, unknown bases more than $10 \%$ as well as $50 \%$ bases with a low-quality score (PHRED score 5) were removed. The remained "clean reads" were mapped to the mouse genome reference sequence (UCSC mm10) by TopHat v1.0.12 incorporated Bowtie v0.11.3 software to perform alignments. The maximum allowable mismatch was set to three for each read in the alignment and mapping. To calculate the gene expression level, the sole reads uniquely aligned to genes were used. Fragments Per Kilobase Million (FPKM) were used for gene expression. Genes in low expression levels $(F P K M<0.5)$ were removed for further analysis.

The DEseq2 package was used to screen differential expressed genes (DEGs) between two groups with biological replicates, e.g., Susceptible versus Control, Resilient versus Control, Susceptible versus Resilient [52]. A threshold to identify DEGs was fold-change above 2 and P-value less than 0.05. Pathway 
enrichment analysis in DEGs association with physiological or biochemical processes was conducted. Hypergeometric tests implemented in tool WebGestalt (version 2) and canonical pathways from the Kyoto Encyclopedia of Genes and Genomes (KEGG) database were used in these enrichment analyses. Compared with the whole genome background, the enriched metabolic pathways or signal transduction pathways in DEGs would be identified in the analyses. P-values in hypergeometric tests were adjusted by the Benjamini-Hochberg method. Pathways with adjusted p-values less than 0.05 were thought to be significant enrichments.

\section{Bioinformatics for microRNA}

Adaptor sequences, low-quality reads, and contaminants in 49nt-tags from Hiseq sequencing were removed. The remained credible clean reads were aligned to Genbank database and Rfam database with blast or bowtie software to further remove reads of noncoding RNA, such as ribosomal RNAs, transfer RNAs, small nuclear RNAs, small nucleolar RNAs and repeat RNA. To obtain microRNA count, high-quality clean reads ranging in 18-25 nt were matched to the known microRNA precursor of corresponding species in miRBase. microRNAs, which were tags aligned to microRNA precursor in miRBase with no mismatch as well as mature microRNA in miRBase with at least $16 \mathrm{nt}$ overlap allowing offset, would be counted to get the expression of identified microRNAs. For the remained reads without any annotation, Miredp was used to predict potential novel microRNAs and its stem-loop structure [53,54]. To correct biased results from low expression, microRNAs with reading counts less than 5 were discarded in differential expression analysis.

Algorithm based on negative binomial distribution and biology duplicate samples was used to compare the known or novel microRNA expression in Susceptible versus Control, Resilient versus Control, Susceptible versus Resilient. The threshold used to identify differential expression of microRNAs was fold-change larger than 2 and P-value less than 0.001. RNAhybrid, Targetscan and miRanda are three microRNA target prediction methods for predicting gene targets of differentially expressed microRNAs.

\section{Integrated microRNA/mRNA network analysis}

Through bioinformatics analysis, the correlation between differentially expressed microRNAs and their corresponding target mRNAs was found. Although there are several exceptions, in theory, microRNAs are inversely related to the mRNAs they target. Integrate differentially expressed microRNAs and mRNA data sets to identify potential target genes regulated by microRNAs. In our analysis, microRNAs and mRNAs should be reversed simultaneously. mRNAs should be obtained by predicting the target genes of microRNAs in RNAhybrid, Targetscan or miRanda. Cytoscape software (San Diego, CA USA) was used to visualize an interactive network of differentially expressed microRNAs and simultaneously differentially expressed target mRNAs.

\section{Quantitative RT-PCR for the validations of mRNA and microRNA}


Quantitative real-time RT-PCR (qRT-PCR) by the SYBR Green technique was used to analyze 24 mRNAs and 15 microRNAs that were involved in cell function. Supplementary Table One (Table S1) shows the primers used. Briefly, real-time PCR was performed with ChamQTM Universal SYBR qPCR Master Mix. Total RNA was extracted from the amygdala using Trizol kit. The HiScript $\triangle$ RT SuperMix kit and miR-X miRNA First-Strand Synthesis kit (Clontech, 638315, CA, USA) were used to reverse transcribe mRNA and microRNA into cDNA, respectively. For real-time PCR of mRNA and microRNA, in a $20 \mu$ reaction system, $1 \mu \mathrm{l} \mathrm{cDNA}$ was used as a template, $0.4 \mu \mathrm{l}$ per primer $(10 \mathrm{nmol} / \mathrm{l}), 10 \mu \mathrm{l} 2 \times \mathrm{qPCR}$ main components and $8.2 \mu \mathrm{lddH_{2 }} O$ to amplify the cDNA. The program was set to start real-time PCR at $95^{\circ} \mathrm{C}$ for 30 seconds, then perform 40 denaturations at $95^{\circ} \mathrm{C}$ for 10 seconds, anneal and extend at $60^{\circ} \mathrm{C}$ for 30 seconds, melting curve at $95^{\circ} \mathrm{C}$ for 15 seconds, $60^{\circ} \mathrm{C}$ for 60 seconds, and $95^{\circ} \mathrm{C}$ for 15 seconds (ChamQTM Universal SYBR qPCR Master Mix). The relative expression levels of mRNA in tissues were normalized to the internal reference gene GAPDH. The relative expression levels of miRNA in tissues were normalized to U6 small nucleolar RNA. qRT-PCR runs were repeated in three replications. The results were calculated with the $2^{-\triangle \Delta C t}$ method.

\section{Dual luciferase reporter assay to identify targeting relationship between mRNAs and microRNAs}

The vector used is the psiCHECKTM-2 plasmid, which can detect changes in the expression level of the gene of interest inserted into the reporter gene. In this vector, the reporter gene is Renilla luciferase, with Firefly luciferase as the control gene, a fragment containing the target site of the target gene of about $200 \mathrm{bp}$ is inserted into a polyclonal downstream of the Renilla luciferase translation stop codon. The site, constructed as a wild-type vector. The synthetic microRNA mimic and the constructed vector containing the target gene are co-transfected into 293T cells. If the microRNA has a regulatory effect on the target mRNA, the expression of Renilla luciferase containing the target mRNA will decrease. First, total RNA was extracted from any area of C57BL / 6 mouse brain tissue using Trizol kit, and mRNA was reverse transcribed into cDNA using HiScript III RT SuperMix kit. Then use 2xPhanta Max Master Mix to amplify about $200 \mathrm{bp}$ fragments containing the target site of the target gene. The amplified product is purified and recovered according to a common DNA product purification kit. Digest with Xhol / Notl, run the digested product on $1.5 \%$ agarose gel electrophoresis, cut the digested band with the correct molecular weight under UV light, and cut the agarose gel containing the digested band Recover according to the agarose gel DNA recovery kit instructions. The psiCHECKTM-2 plasmid was similarly digested and recovered. A T4 DNA Ligase kit was used to ligate the digested vector plasmid and the digested target gene to construct a wild-type vector plasmid containing the target gene. The ligated wild-type vector plasmid is added to competent cells for transformation, and the obtained bacterial solution is sent to a sequencing company for sequencing verification. For the correct bacterial solution, the plasmid was extracted with a plasmid mini-extraction kit, and the obtained plasmid was a wild-type vector.

The target gene fragment of the wild-type vector is mutated to a microRNA-binding site to construct a mutant vector. The microRNA should not regulate the mutated mRNA, so when the mutant vector plasmid and mimic are co-transfected into 293T cells, the expression of Renilla luciferase in the mutant vector is 
not affected by the added mimic. Based on the wild-type vector plasmid, upstream and downstream mutant primers were designed to make the target gene fragment mutate for PCR amplification, and amplified using Phanta Max Super-Fidelity DNA Polymerase Kit. Add $1 \mu$ of Dpnl to the above PCR product to digest. The digested product was subjected to $1.5 \%$ agarose gel electrophoresis, and a band of the correct molecular weight after digestion was cut under a UV lamp. The agarose gel block containing the digested band was recovered according to the instructions of the agarose gel DNA recovery kit. The recovered product was homologously reconstituted into a mutant vector plasmid using Exnase II. Similarly, the ligated wild-type vector plasmid is added to competent cells for transformation, and the obtained bacterial solution is sent to a sequencing company for sequencing verification. For the correct bacterial solution, the plasmid was extracted with the plasmid mini-kit, and the obtained plasmid was a mutant vector.

In a 24-well plate, $5 \times 104$ HEK293T cells were plated per well and cultured in DMEM containing $10 \%$ FBS. After 24 hours, these cells were co-transfected with $50 \mathrm{ng}$ psiCHECK2-wild-type or mutant reporter plasmid, $50 \mathrm{nM}$ microRNA mimic, or microRNA-NC with Lipofectamine 2000 transfection reagent (Ink,Carsbad[CAUSA). After $6 \mathrm{~h}$ of transfection, the medium in each well of the 24-well plate was aspirated, $500 \mu \mathrm{l}$ of fresh medium was added, and the culture was continued. After 24 hours, the firefly and Renilla luciferase activities were evaluated by the Dual-Glo® luciferase assay system (Promega $\triangle \mathrm{CAT}$ ). Each treatment was done in the triplicates from three independent experiments.

\section{Statistical analyses}

When analyzing high-throughput sequencing results, the DESeq2 package was used to preliminarily process the raw data of mRNA and microRNA expression profiles, respectively. The behavioral test data, qRT-PCR data, and data from the double luciferase reporter gene detection experiment were all expressed by means \pm SEM. Pearson correlation coefficient was used to evaluate the relationship between microRNA and target predicted mRNA expression. The unpaired t-test was used to statistically compare the molecular biological data (qPCR and dual-luciferase reporter gene detection data) of Control and Susceptible, Control and Resilient, and Susceptible and Resilient mice. Since the behavioral experimental data on emotions will vary greatly, one-way analysis of variance is used to compare the behavioral test data between the groups, and the paired t-test is used to test the behavioral data of each group of mice before and after psychological stress training. Analyze and compare. At the same time, the StudentNewman-Keuls test was used to analyze and compare groups before and after stress training. Three asterisks show $p<0.001$, two asterisks show $p<0.01$, one asterisk show $p<0.05$, and the difference is statistically significant.

\section{Results}

\section{Susceptibility and resilience caused by psychological stress}

C57 mice were placed in adjacent rooms of a residential dwelling of CD1 mice, two of which were separated by transparent partitions. C57 mice observed similar mice being physically attacked by 
aggressive permanent CD1 mice. This C57 observation mouse experienced psychological stress. After experiencing these psychological stresses twice a day for 5 consecutive days, mice in the observation group were behaviorally tested to determine their fear memory and anxiety status for CD1 mice. Evaluate the degree of fear memory and anxiety of a mouse to determine whether the mouse is susceptible to stress. C57 mice's fear memory formation for CD1 mice was judged by their degree of avoidance of aggressive CD1 mouse containers on Day 6 and fewer entry into the interaction zone. The ratio of the residence time of $\mathrm{C} 57$ mice in the communication area with and without CD1 mice in small cages was measured and compared among the three groups. C57 mice's anxiety formation for CD1 mice was judged by their degree of exploration of the open arms in the elevated cross-maze on Day 6 . The percentage of the total time that C57 mice stayed in the open arms was measured and compared among the three groups. After the psychological stress experiment, the ratio of the residence time of some C57 mice in the communication area was significantly reduced compared with that before the stress experiment, and the percentage of the total time that these $\mathrm{C} 57$ mice stayed in the open arms was also significantly reduced compared with that before the stress experiment. However, the ratio of the residence time of the other $\mathrm{C} 57$ mice in the communication area did not change significantly compared with that before the stress experiment, and the percentage of the total time that these C57 mice stayed in the open arms also did not change significantly compared with that before the stress experiment. This indicates that psychological stress can cause susceptibility and resilience. Susceptible mice showed fear memory and anxiety-like behaviors, and Resilient mice did not show fear memory and anxiety-like behaviors.

Figure 2a shows the locus of movement of Control, Resilient, and Susceptible mice with and without CD1 mice during social interaction on day 6 . Susceptible mice developed a fear of CD1 mice, while Resilient mice did not fear CD1 mice after psychological stress. Figure 2b and Fig. 2c show the ratio of the residence time of control, resilient, and susceptible mice in the small cage to the time spent in the communication area on day 0 and day 6 , respectively. Figure $2 b$ shows the ratio of the residence time of Control, Resilient, and Susceptible mice in the communication zone with and without CD1 attackers in the small cages on days 0 and 6 . Values in Susceptible mice are $1.36 \pm 0.09$ before psychological stress and $0.77 \pm 0.04(p<0.0001, n=10$, paired t-test) after psychological stress. Values in Resilient mice are $1.16 \pm$ 0.06 before psychological stress and $1.36 \pm 0.05(p=0.0228, n=13$, paired t-test $)$ after psychological stress. Values in Control mice are $1.20 \pm 0.08$ before psychological stress and $1.24 \pm 0.09(p=0.7015, n=$ 15 , paired t-test) after psychological stress. Compared with no statistical difference among three groups at day $0(p=0.2225, F=1.569$, Total $d f=37$, one-way ANOVA), there is significant difference among three groups after the stress $(p<0.0001, F=17.22$, Total $d f=37$, one-way ANOVA $)$. These data indicate that psychological stress can induce some C57 mice to exhibit fear-avoidance behaviors on CD1 mice. However, most C57 mice showed resilience after psychological stress and did not have the fear avoidance behavior of CD1 mice.

Figure 3a shows the motion trajectory of Control, Resilient and Susceptible mice on the elevated crossmaze before psychological stress (day 0 ) and after psychological stress (day 6). Values of staying in open arms for Control, Resilient and Susceptible at day 0 are $13.94 \pm 1.88,13.24 \pm 1.56$ and $13.24 \pm 1.71$, respectively ( $F i g .3 B, p=0.9450, F=0.05670$, Total $d f=37$, one-way ANOVA). Values of staying in open 
arms for Control, Resilient and Susceptible at day 6 are $13.77 \pm 1.83,12.65 \pm 1.69$ and $5.39 \pm 1.45$, respectively (Fig. 3C, $p=0.0054, F=6.075$, Total $d f=37$, one-way ANOVA). These data indicate that psychological stress can induce anxiety-like behavior in some C57 mice, while most C57 mice do not have anxiety-like behavior after psychological stress.

\section{Overall qualities of RNA-Sequencing dataset}

Three mice were taken from each group for high throughput sequencing, and mRNA and microRNA profiles in the amygdala tissue of each mouse were analyzed. Filter low-quality reads and adaptor from RNAs of $55.53 \sim 58.8 \mathrm{Mb}$ raw sequence reads (100 bp) in mRNA library Illumina sequencing, $44.21 \sim$ 45.25 Mb clean reads from each library were mapped, i.e., $88.23 \sim 93.65 \%$ of total reads from mouse genome equivalently for samples (Table S2). Totals about 29,336,157 31,336,586 raw tag counts were produced in small RNA library. After filtering reads with low quality and adaptor, we got clean tag counts in 27,074,072 29,339,909(Table S3). The distribution of these clean small RNA reads varied in 10-44 nucleotides each library, in which the most abundant lengths were 22 nucleotides (Fig. S1). High-quality clean reads larger than 18 nucleotides were mapped to the mouse genome. Genome-matched reads were divided into different categories of small RNAs based on their biogenesis and annotation (Fig. S2). The most abundant RNA category from each library was microRNA. These transcriptome and small RNA sequencing data with high qualities were used to further analysis.

\section{Study on differential expression of amygdala mRNA in three groups of mice}

The total RNAs were sequenced to quantify the mRNA in the amygdala and calculate its FPKM value. Except for low expression level $(F P K M<0.5)$, other genes were analyzed for their differential expression by DESeq2. After mapping reads referred to the mouse genome, $13,693(13,654,13,689)$ mRNAs from clean-read sequences with high quality included $6802(6722,6667)$ of upregulated mRNAs and $6864(6916,7001)$ of downregulated mRNAs while comparing Susceptible versus Control, Resilient versus Control and Susceptible versus Resilient. The criterion for confirming the differential expression of genes was the ratio of their FPKM values above 2 fold. In other words, if the ratio of their FPKM changed above 2 folds between Susceptible versus Control, between Resilient versus Control or between Susceptible versus Resilient, the differential expression of mRNAs was warranted.

Taken out those genes in low expression, we found that 33 mRNAs reached the 2 fold ratio of Susceptible mice to Control mice in their FPKM values, in which 24 mRNAs were downregulated and 9 mRNAs were upregulated (Table S4, Fig. 4a). Then the KEGG database was used to conduct pathway enrichment analysis on the differentially expressed genes that were screened out and enriched into pathways related to physiological and biochemical processes. Table S5 presents signaling pathways identified by KEGG function analysis based on DEGs data in Susceptible versus Control. Figure 5a presents a bubble chart of KEGG pathway enrichment analysis of differentially expressed genes in the amygdala of Susceptible and Control mice. Table 1 presents these upregulated and downregulated genes related to synapses and 
signaling pathways in the amygdala from Susceptible versus Control mice. Among the genes related to synapses, the top line represents those genes that encode synapse elements, while the bottom line represents genes that encode signaling pathways that regulate synapses. Among genes related to signaling pathway, the top line represents genes encoding molecules constituting the signaling pathway, and the bottom line represents genes encoding molecules that regulate the signal pathway. In terms of the signaling pathways that regulate synapse functions, the downregulated genes in the amygdala in Susceptible mice include Cd86. Based on bioinformatics for mRNA-guided protein translation (KEGG database), this downregulated gene in Susceptible mice encodes Toll-like receptor signaling pathway. Also in Cell adhesion molecules, the downregulated genes include Cd86 and Cldn23, encode Immune system. In Tight junction, the downregulated genes include Cldn23, which plays a major role in tight junction-specific obliteration.

\section{Table 1}

Signaling pathways identified by KEGG based on DEGs data of BLA in Susceptible versus Control

\begin{tabular}{|c|c|c|c|}
\hline KEGG Entry & Term & count & Genes \\
\hline \multirow[t]{2}{*}{ mmu04514 } & Cell adhesion molecules (CAMs) & 2 & \\
\hline & & & $\begin{array}{l}\text { Cd86(CD86 antigen) } \downarrow, C l d n 23 \text { (claudin } \\
23) \downarrow\end{array}$ \\
\hline \multirow[t]{2}{*}{ mmu04620 } & Toll-like receptor signaling & 1 & \\
\hline & & & Cd86(CD86 antigen) $\downarrow$ \\
\hline mmu04530 & Tight junction & 1 & Cldn23(claudin 23) $\downarrow$ \\
\hline
\end{tabular}

Our study showed that 113 mRNAs had the 2 fold ratio of Resilient mice to Control mice in FPKM values, in which 68 mRNAs are downregulated and 45 mRNAs are upregulated (Table S6, Fig. 4b). Table S7 presents signaling pathways identified by KEGG function analysis based on DEGs data in Resilient versus Control. Figure 5b presents a bubble chart of KEGG pathway enrichment analysis of differentially expressed genes in the amygdala of Resilient and Control mice. Table 2 presents these upregulated and downregulated genes related to synapses and signaling pathways in the amygdala from Resilient versus Control mice. The upregulated genes related to synapse elements in the amygdala from Resilient mice include Trhr, Itga10 and Scn7a. These upregulated genes in Resilient mice encode structural proteins of building up Adrenergic synapse, Thyrotropin-releasing hormone and ECM receptors. The downregulated genes related to synapse elements in the amygdala from Resilient mice include Gabre. This downregulated gene in Resilient mice encodes structural proteins of building up GABAergic synapse. The upregulated genes related to signaling pathways of regulating synapses in the amygdala from Resilient mice include Cyp2c55. This upregulated gene in Resilient mice encodes structural proteins of building up Serotonergic synapse. The downregulated genes related to signaling pathways of regulating synapses in 
the amygdala from Resilient mice include Pla2g4e. This downregulated gene in Resilient mice encodes structural proteins of building up Serotonergic and Glutamatergic synapses. In terms of the signaling pathways that regulate synapse functions, the downregulated genes in the amygdala in Resilient mice include Ntrk1, Ngfr, H2-T10, Pla2g4e, Eno1b and Ccr6. These downregulated genes in Resilient mice encode MAPK, Neurotrophin, Ras, PI3K-Akt, Fc epsilon RI, Rap1, HIF-1, Oxytocin, GnRH, VEGF and Chemokine signaling pathways. On the other hand, the upregulated genes include Esr2, Itga10, Hspa1b, Hspa1a, Dio3, Trhr and Traf1. These upregulated genes encode Estrogen, MAPK, PI3K-Akt, Calcium, TNF, NF-kappa B and Thyroid hormone signaling pathways. Also in Cell adhesion molecules, the downregulated genes include H2-Q8 and H2-T10, the upregulated genes include $\mathrm{Cd} 6$, encode Immune system. In Inflammatory mediator regulation of TRP channels, the downregulated genes include Ntrk1 and Pla2g4e, the upregulated genes include Cyp2c55, encode Inflammatory mediator. In Cytokinecytokine receptor interaction, the downregulated genes include Ccr6 and Ngfr, mediate cell survival and neural cell death. In Long-term depression, the downregulated genes include Pla2g4e. 
Table 2

Signaling pathways identified by KEGG based on DEGs data of BLA in Resilient versus Control

\begin{tabular}{|c|c|c|c|}
\hline KEGG Entry & Term & count & Genes \\
\hline \multirow[t]{2}{*}{ mmu04915 } & \multirow{2}{*}{$\begin{array}{l}\text { Estrogen signaling } \\
\text { pathway }\end{array}$} & \multirow[t]{2}{*}{3} & Esr2(estrogen receptor 2 (beta) $) \uparrow$, \\
\hline & & & $\begin{array}{l}\text { Hspa1b (heat shock protein } 1 \mathrm{~A}(\mathrm{Hspa} 1 \mathrm{a}) \text {, heat } \\
\text { shock protein } 1 \mathrm{~B}) \uparrow, \text { Hspa1a (heat shock protein } \\
1 \mathrm{~A}) \uparrow\end{array}$ \\
\hline \multirow[t]{2}{*}{ mmu04010 } & \multirow[t]{2}{*}{$\begin{array}{l}\text { MAPK signaling } \\
\text { pathway }\end{array}$} & \multirow[t]{2}{*}{4} & $\begin{array}{l}\text { Ntrk1 (neurotrophic tyrosine kinase, receptor, type } \\
\text { 1) } \downarrow \text {, }\end{array}$ \\
\hline & & & 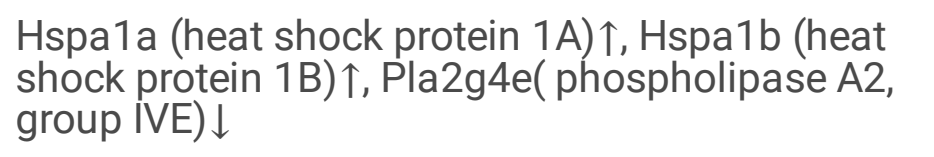 \\
\hline \multirow[t]{2}{*}{ mmu04514 } & \multirow{2}{*}{$\begin{array}{l}\text { Cell adhesion } \\
\text { molecules (CAMs) }\end{array}$} & \multirow[t]{2}{*}{3} & \\
\hline & & & $\begin{array}{l}\text { Cd6(CD6 antigen) } \uparrow, \mathrm{H} 2-\mathrm{Q} 8 \text { (histocompatibility } 2, \mathrm{Q} \\
\text { region locus } 8) \downarrow, \mathrm{H} 2-\mathrm{T} 10 \text { (histocompatibility } 2, \mathrm{~T} \\
\text { region locus } 10) \downarrow\end{array}$ \\
\hline mmu04722 & $\begin{array}{l}\text { Neurotrophin } \\
\text { signaling pathway }\end{array}$ & 2 & $\begin{array}{l}\mathrm{Ngfr} \text { (nerve growth factor receptor (TNFR } \\
\text { superfamily, member 16)) } \downarrow \text {, Ntrk1 (neurotrophic } \\
\text { tyrosine kinase, receptor, type } 1 \text { ) } \downarrow\end{array}$ \\
\hline \multirow[t]{2}{*}{ mmu04726 } & \multirow[t]{2}{*}{ Serotonergic synapse } & \multirow[t]{2}{*}{2} & \\
\hline & & & $\begin{array}{l}\text { Cyp2c55(cytochrome P450, family 2, subfamily c, } \\
\text { polypeptide } 55 \text { ) } \text {, Pla2g4e( phospholipase A2, } \\
\text { group IVE) } \downarrow\end{array}$ \\
\hline \multirow[t]{2}{*}{ mmu04014 } & \multirow{2}{*}{$\begin{array}{l}\text { Ras signaling } \\
\text { pathway }\end{array}$} & \multirow[t]{2}{*}{2} & H2-T10(histocompatibility 2, T region locus 10 ) $\downarrow$, \\
\hline & & & $\begin{array}{l}\text { Ngfr (nerve growth factor receptor (TNFR } \\
\text { superfamily, member 16)) } \downarrow\end{array}$ \\
\hline mmu04080 & $\begin{array}{l}\text { Neuroactive ligand- } \\
\text { receptor interaction }\end{array}$ & 2 & $\begin{array}{l}\text { Gabre (gamma-aminobutyric acid (GABA) A } \\
\text { receptor, subunit epsilon) } \downarrow \text {, Trhr (thyrotropin } \\
\text { releasing hormone receptor) } \uparrow\end{array}$ \\
\hline mmu04151 & $\begin{array}{l}\text { PI3K-Akt signaling } \\
\text { pathway }\end{array}$ & 2 & 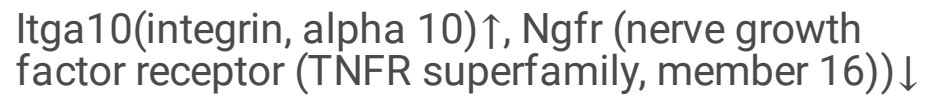 \\
\hline mmu04020 & $\begin{array}{l}\text { Calcium signaling } \\
\text { pathway }\end{array}$ & 1 & Trhr (thyrotropin releasing hormone receptor) $\uparrow$ \\
\hline \multirow[t]{2}{*}{ mmu04664 } & \multirow{2}{*}{$\begin{array}{l}\text { Fc epsilon RI } \\
\text { signaling pathway }\end{array}$} & 1 & \\
\hline & & & Pla2g4e( phospholipase A2, group IVE) $\downarrow$ \\
\hline
\end{tabular}

Note: $\uparrow$ indicates up-regulation in the tissue of BLA from Intruder versus control mice, whereas $\downarrow$ represents down-regulation. 


\begin{tabular}{|c|c|c|c|}
\hline KEGG Entry & Term & count & Genes \\
\hline mmu04015 & $\begin{array}{l}\text { Rap1 signaling } \\
\text { pathway }\end{array}$ & 1 & $\begin{array}{l}\text { Ngfr (nerve growth factor receptor (TNFR } \\
\text { superfamily, member 16)) } \downarrow\end{array}$ \\
\hline mmu04668 & $\begin{array}{l}\text { TNF signaling } \\
\text { pathway }\end{array}$ & 1 & Traf1(TNF receptor-associated factor 1$) \uparrow$ \\
\hline \multirow[t]{2}{*}{ mmu04066 } & HIF-1 signaling & 1 & \\
\hline & & & Eno1b (enolase 1B, retrotransposed) $\downarrow$ \\
\hline \multirow[t]{2}{*}{ mmu04064 } & NF-kappa B signaling & 1 & \\
\hline & potingug & & Traf1(TNF receptor-associated factor 1$) \uparrow$ \\
\hline mmu04727 & GABAergic synapse & 1 & $\begin{array}{l}\text { Gabre (gamma-aminobutyric acid (GABA) A } \\
\text { receptor, subunit epsilon) } \downarrow\end{array}$ \\
\hline \multirow[t]{2}{*}{ mmu04921 } & $\begin{array}{l}\text { Oxytocin signaling } \\
\text { pathway }\end{array}$ & 1 & \\
\hline & & & Pla2g4e( phospholipase A2, group IVE) $\downarrow$ \\
\hline mmu04723 & $\begin{array}{l}\text { Retrograde } \\
\text { endocannabinoid } \\
\text { signaling }\end{array}$ & 1 & $\begin{array}{l}\text { Gabre (gamma-aminobutyric acid (GABA) A } \\
\text { receptor, subunit epsilon) } \downarrow\end{array}$ \\
\hline \multirow[t]{2}{*}{ mmu04917 } & Prolactin signaling & 1 & \\
\hline & & & Esr2(estrogen receptor 2 (beta) $) \uparrow$ \\
\hline \multirow[t]{2}{*}{ mmu04919 } & Thyroid hormone & 1 & \\
\hline & & & Dio3(deiodinase, iodothyronine type III) $\uparrow$ \\
\hline \multirow[t]{2}{*}{ mmu04912 } & GnRH signaling & 1 & \\
\hline & & & Pla2g4e( phospholipase A2, group IVE) $\downarrow$ \\
\hline \multirow[t]{2}{*}{ mmu04370 } & VEGF signaling & 1 & \\
\hline & & & Pla2g4e( phospholipase A2, group IVE) $\downarrow$ \\
\hline \multirow[t]{2}{*}{ mmu04724 } & Glutamatergic & 1 & \\
\hline & & & Pla2g4e( phospholipase A2, group IVE) $\downarrow$ \\
\hline mmu04062 & $\begin{array}{l}\text { Chemokine signaling } \\
\text { pathway }\end{array}$ & 1 & Ccr6(chemokine (C-C motif) receptor 6) $\downarrow$ \\
\hline mmu05032 & Morphine addiction & 1 & $\begin{array}{l}\text { Gabre (gamma-aminobutyric acid (GABA) A } \\
\text { receptor, subunit epsilon) } \downarrow\end{array}$ \\
\hline
\end{tabular}

Note: $\uparrow$ indicates up-regulation in the tissue of BLA from Intruder versus control mice, whereas $\downarrow$ represents down-regulation. 


\begin{tabular}{|c|c|c|c|}
\hline KEGG Entry & Term & count & Genes \\
\hline mmu05033 & Nicotine addiction & 1 & $\begin{array}{l}\text { Gabre (gamma-aminobutyric acid (GABA) A } \\
\text { receptor, subunit epsilon) } \downarrow\end{array}$ \\
\hline \multirow[t]{2}{*}{ mmu04750 } & \multirow{2}{*}{$\begin{array}{l}\text { Inflammatory } \\
\text { mediator regulation of } \\
\text { TRP channels }\end{array}$} & \multirow[t]{2}{*}{3} & $\begin{array}{l}\text { Ntrk1 (neurotrophic tyrosine kinase, receptor, type } \\
\text { 1) } \downarrow\end{array}$ \\
\hline & & & $\begin{array}{l}\text { Cyp2c55(cytochrome P450, family 2, subfamily c, } \\
\text { polypeptide } 55 \text { ) } \uparrow, P l a 2 g 4 \text { ( } \text { (phospholipase A2, group } \\
\text { IVE) } \downarrow\end{array}$ \\
\hline mmu04060 & $\begin{array}{l}\text { Cytokine-cytokine } \\
\text { receptor interaction }\end{array}$ & 2 & $\begin{array}{l}\text { Ccr6(chemokine (C-C motif) receptor 6) } \downarrow \text {,Ngfr } \\
\text { (nerve growth factor receptor (TNFR superfamily, } \\
\text { member 16)) } \downarrow\end{array}$ \\
\hline \multirow[t]{2}{*}{ mmu04730 } & \multirow[t]{2}{*}{ Long-term depression } & 1 & \\
\hline & & & Pla2g4e( phospholipase A2, group IVE) $\downarrow$ \\
\hline \multirow[t]{2}{*}{ mmu04261 } & \multirow[t]{2}{*}{$\begin{array}{l}\text { Adrenergic signaling } \\
\text { in cardiomyocytes }\end{array}$} & \multirow[t]{2}{*}{1} & $\begin{array}{l}\text { Scn7a( sodium channel, voltage-gated, type VII, } \\
\text { alpha) } \uparrow\end{array}$ \\
\hline & & & $\begin{array}{l}\text { sodium channel, voltage-gated, type VII, } \\
\text { alpha(Scn7a) }\end{array}$ \\
\hline mmu04512 & $\begin{array}{l}\text { ECM-receptor } \\
\text { interaction }\end{array}$ & 1 & Itga10(integrin, alpha 10$) \uparrow$ \\
\hline $\begin{array}{l}\text { Note: } \uparrow \text { indi } \\
\text { represents } c\end{array}$ & $\begin{array}{l}\text { up-regulation in the } \\
\text {-regulation. }\end{array}$ & le of & A from Intruder versus control mice, whereas $\downarrow$ \\
\hline
\end{tabular}

Furthermore, our study showed that 108 mRNAs had the 2 fold ratio of Susceptible mice to Resilient mice in FPKM values, in which 52 mRNAs are downregulated and 56 mRNAs are upregulated (Table S8, Fig. 4c). Table S9 presents signaling pathways identified by KEGG function analysis based on DEGs data in Susceptible versus Resilient. Figure 5c presents a bubble chart of KEGG pathway enrichment analysis of differentially expressed genes in amygdala of Susceptible and Resilient mice. Table 3 presents these upregulated and downregulated genes related to synapses and signaling pathways in the amygdala from Susceptible versus Resilient mice. The upregulated genes related to synapse elements in the amygdala include Oprm1, Vwf, Col6a3, Sv2c and Trhr. These upregulated genes encode structural proteins of building up Peptide, Thyrotropin-releasing hormone and ECM receptors. The downregulated genes related to synapse elements in the amygdala include Scn7a. This downregulated gene encodes structural proteins of building up Adrenergic synapse. The upregulated genes related to signaling pathways of regulating synapses in the amygdala include Pla2g4e. This upregulated gene encodes structural proteins of building up Serotonergic and Glutamatergic synapses. The downregulated genes related to signaling pathways of regulating synapses in the amygdala include Cyp2c55. This downregulated gene encodes structural proteins of building up Serotonergic synapse. In terms of the signaling pathways that regulate synapse functions, the downregulated genes in the amygdala include Grk1, Rac3 and Cd86. These 
downregulated genes encode Chemokine, VEGF, Fc epsilon RI, Ras, MAPK, Wnt, Sphingolipid, B cell receptor, cAMP, Rap1, Toll-like receptor and Axon guidance signaling pathways. On the other hand, the upregulated genes include Ccr1, Ccr6, Oprm1, Trhr, Ccl9, Pla2g4e, Vwf, Col6a3, Robo3 and Eno1b. These upregulated genes encode Chemokine, VEGF, Fc epsilon RI, Ras, MAPK, PI3K-Akt, Oxytocin, GnRH, HIF-1, Estrogen, Calcium and Axon guidance signaling pathways. Also in Cell adhesion molecules, the downregulated genes include Cd6 and Cd86, the upregulated genes include LOC547349 and H2-T10, encode Immune system. In Inflammatory mediator regulation of TRP channels, the downregulated genes include Cyp2c55, the upregulated genes include Pla2g4e, encode Inflammatory mediator. In Adherens junction, the downregulated genes include Rac3. In Cytokine-cytokine receptor interaction, the upregulated genes include Ccr1, Ccr6, LOC100861978 and Ccl9. In Long-term depression, the upregulated genes include Pla2g4e. In Cytosolic DNA-sensing pathway, the downregulated genes include Trex1. 
Table 3

Signaling pathways identified by KEGG based on DEGs data of BLA in Susceptible versus Resilient

\begin{tabular}{|c|c|c|c|}
\hline KEGG Entry & Term & count & Genes \\
\hline \multirow[t]{2}{*}{ mmu04062 } & \multirow[t]{2}{*}{$\begin{array}{l}\text { Chemokine } \\
\text { signaling pathway }\end{array}$} & \multirow[t]{2}{*}{5} & $\begin{array}{l}\text { Ccr1 (chemokine (C-C motif) receptor } 1) \uparrow, \\
\text { Ccr6(chemokine (C-C motif) receptor } 6) \uparrow\end{array}$ \\
\hline & & & $\begin{array}{l}\text { Grk1 (G protein-coupled receptor kinase 1) } \downarrow \text {, } \\
\text { LOC100861978(c-C motif chemokine 27-like) } \uparrow, \\
\text { Ccl9(chemokine (C-C motif) ligand 9) } \uparrow\end{array}$ \\
\hline \multirow[t]{2}{*}{ mmu04514 } & \multirow{2}{*}{$\begin{array}{l}\text { Cell adhesion } \\
\text { molecules (CAMs) }\end{array}$} & \multirow[t]{2}{*}{4} & \\
\hline & & & $\begin{array}{l}\text { Cd6(CD6 antigen) } \downarrow, \text { Cd86(CD86 antigen) } \downarrow \text {, } \\
\text { LOC547349(MHC class I family member) } \uparrow, \text { H2- } \\
\text { T10(histocompatibility 2, T region locus 10) } \uparrow\end{array}$ \\
\hline \multirow[t]{2}{*}{ mmu04370 } & \multirow{2}{*}{$\begin{array}{l}\text { VEGF signaling } \\
\text { pathway }\end{array}$} & \multirow[t]{2}{*}{2} & \\
\hline & & & $\begin{array}{l}\text { Rac3(RAS-related C3 botulinum substrate } 3) \downarrow \text {, } \\
\text { Pla2g4e (phospholipase A2, group IVE) } \uparrow\end{array}$ \\
\hline \multirow[t]{2}{*}{ mmu04664 } & \multirow{2}{*}{$\begin{array}{l}\text { Fc epsilon RI } \\
\text { signaling pathway }\end{array}$} & \multirow[t]{2}{*}{2} & \\
\hline & & & $\begin{array}{l}\text { Rac3(RAS-related C3 botulinum substrate } 3) \downarrow \text {, } \\
\text { Pla2g4e( phospholipase A2, group IVE) } \uparrow\end{array}$ \\
\hline \multirow[t]{2}{*}{ mmu04360 } & \multirow[t]{2}{*}{ Axon guidance } & \multirow[t]{2}{*}{2} & Robo3(roundabout guidance receptor 3) $\uparrow$ \\
\hline & & & Rac3(RAS-related C3 botulinum substrate 3 ) $\downarrow$, \\
\hline \multirow[t]{2}{*}{ mmu04726 } & \multirow{2}{*}{$\begin{array}{l}\text { Serotonergic } \\
\text { synapse }\end{array}$} & \multirow[t]{2}{*}{2} & \\
\hline & & & $\begin{array}{l}\text { Cyp2c55(cytochrome P450, family } 2 \text {, subfamily c, } \\
\text { polypeptide } 55) \downarrow \text {, Pla2g4e (phospholipase A2, group } \\
\text { IVE) } \uparrow\end{array}$ \\
\hline \multirow[t]{2}{*}{ mmu04014 } & \multirow{2}{*}{$\begin{array}{l}\text { Ras signaling } \\
\text { pathway }\end{array}$} & \multirow[t]{2}{*}{2} & \\
\hline & & & $\begin{array}{l}\text { Rac3(RAS-related C3 botulinum substrate } 3) \downarrow \text {, } \\
\text { Pla2g4e( phospholipase A2, group IVE) } \uparrow\end{array}$ \\
\hline \multirow[t]{2}{*}{ mmu04010 } & \multirow{2}{*}{$\begin{array}{l}\text { MAPK signaling } \\
\text { pathway }\end{array}$} & \multirow[t]{2}{*}{2} & \\
\hline & & & $\begin{array}{l}\text { Rac3(RAS-related C3 botulinum substrate } 3) \downarrow \text {, } \\
\text { Pla2g4e( phospholipase A2, group IVE) } \uparrow\end{array}$ \\
\hline mmu04080 & $\begin{array}{l}\text { Neuroactive ligand- } \\
\text { receptor interaction }\end{array}$ & 2 & 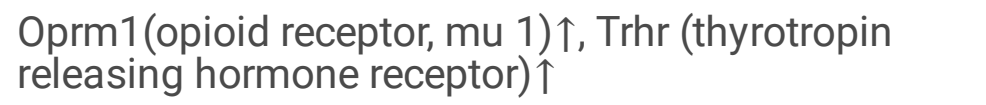 \\
\hline mmu04151 & $\begin{array}{l}\text { PI3K-Akt signaling } \\
\text { pathway }\end{array}$ & 2 & \\
\hline
\end{tabular}

Note: $\uparrow$ indicates up-regulation in the tissue of BLA from Intruder versus control mice, whereas $\downarrow$ represents down-regulation. 


\begin{tabular}{|c|c|c|c|}
\hline KEGG Entry & Term & count & Genes \\
\hline & & & $\begin{array}{l}\text { Vwf (Von Willebrand factor) } \uparrow, \text { Col6a3( collagen, type } \\
\text { VI, alpha } 3) \uparrow\end{array}$ \\
\hline \multirow[t]{2}{*}{ mmu04310 } & \multirow{2}{*}{$\begin{array}{l}\text { Wnt signaling } \\
\text { pathway }\end{array}$} & 1 & \\
\hline & & & Rac3(RAS-related C3 botulinum substrate 3 ) $\downarrow$ \\
\hline \multirow[t]{2}{*}{ mmu04071 } & \multirow{2}{*}{$\begin{array}{l}\text { Sphingolipid } \\
\text { signaling pathway }\end{array}$} & 1 & \\
\hline & & & Rac3(RAS-related C3 botulinum substrate 3 ) $\downarrow$ \\
\hline \multirow[t]{2}{*}{ mmu04921 } & \multirow{2}{*}{$\begin{array}{l}\text { Oxytocin signaling } \\
\text { pathway }\end{array}$} & 1 & \\
\hline & & & Pla2g4e( phospholipase A2, group IVE) $\uparrow$ \\
\hline \multirow[t]{2}{*}{ mmu04662 } & \multirow{2}{*}{$\begin{array}{l}\text { B cell receptor } \\
\text { signaling pathway }\end{array}$} & 1 & \\
\hline & & & Rac3(RAS-related C3 botulinum substrate 3) $\downarrow$ \\
\hline \multirow[t]{2}{*}{ mmu04912 } & \multirow{2}{*}{$\begin{array}{l}\text { GnRH signaling } \\
\text { pathway }\end{array}$} & 1 & \\
\hline & & & Pla2g4e( phospholipase A2, group IVE) $\uparrow$ \\
\hline \multirow[t]{2}{*}{ mmu04066 } & \multirow{2}{*}{$\begin{array}{l}\text { HIF-1 signaling } \\
\text { pathway }\end{array}$} & 1 & \\
\hline & & & Eno1b (enolase 1B, retrotransposed) $\uparrow$ \\
\hline \multirow[t]{2}{*}{ mmu04724 } & \multirow{2}{*}{$\begin{array}{l}\text { Glutamatergic } \\
\text { synapse }\end{array}$} & 1 & \\
\hline & & & Pla2g4e( phospholipase A2, group IVE) $\uparrow$ \\
\hline \multirow[t]{2}{*}{ mmu04024 } & \multirow{2}{*}{$\begin{array}{l}\text { cAMP signaling } \\
\text { pathway }\end{array}$} & 1 & \\
\hline & & & Rac3(RAS-related C3 botulinum substrate 3 ) $\downarrow$ \\
\hline \multirow[t]{2}{*}{ mmu04015 } & \multirow{2}{*}{$\begin{array}{l}\text { Rap1 signaling } \\
\text { pathway }\end{array}$} & 1 & \\
\hline & & & Rac3(RAS-related C3 botulinum substrate 3 ) $\downarrow$ \\
\hline mmu04915 & $\begin{array}{l}\text { Estrogen signaling } \\
\text { pathway }\end{array}$ & 1 & Oprm1 (opioid receptor, mu 1) $\uparrow$ \\
\hline mmu04020 & $\begin{array}{l}\text { Calcium signaling } \\
\text { pathway }\end{array}$ & 1 & Trhr (thyrotropin releasing hormone receptor) $\uparrow$ \\
\hline \multirow[t]{2}{*}{ mmu04620 } & \multirow{2}{*}{$\begin{array}{l}\text { Toll-like receptor } \\
\text { signaling pathway }\end{array}$} & 1 & \\
\hline & & & Cd86(CD86 antigen) $\downarrow$ \\
\hline mmu04512 & $\begin{array}{l}\text { ECM-receptor } \\
\text { interaction }\end{array}$ & 3 & $\begin{array}{l}\text { Vwf (Von Willebrand factor) } \uparrow, \text { Col6a3(collagen, type } \\
\text { VI, alpha } 3) \uparrow, S v 2 c(\text { synaptic vesicle glycoprotein } 2 \mathrm{c}) \uparrow\end{array}$ \\
\hline
\end{tabular}

Note: $\uparrow$ indicates up-regulation in the tissue of BLA from Intruder versus control mice, whereas $\downarrow$ represents down-regulation. 


\begin{tabular}{|c|c|c|c|}
\hline KEGG Entry & Term & count & Genes \\
\hline \multirow[t]{2}{*}{ mmu04060 } & \multirow[t]{2}{*}{$\begin{array}{l}\text { Cytokine-cytokine } \\
\text { receptor interaction }\end{array}$} & \multirow[t]{2}{*}{4} & $\begin{array}{l}\text { Ccr1 (chemokine (C-C motif) receptor } \\
\text { 1) } \uparrow, C c r 6 \text { (chemokine (C-C motif) receptor } 6) \uparrow\end{array}$ \\
\hline & & & $\begin{array}{l}\text { LOC100861978(c-C motif chemokine 27- } \\
\text { like) } \uparrow, C c 19 \text { (chemokine (C-C motif) ligand 9) } \uparrow\end{array}$ \\
\hline \multirow[t]{2}{*}{ mmu04750 } & \multirow{2}{*}{$\begin{array}{l}\text { Inflammatory } \\
\text { mediator regulation } \\
\text { of TRP channels }\end{array}$} & \multirow[t]{2}{*}{2} & \\
\hline & & & $\begin{array}{l}\text { Cyp2c55(cytochrome P450, family 2, subfamily c, } \\
\text { polypeptide } 55 \text { ) } \downarrow \text {, Pla2g4e (phospholipase A2, group } \\
\text { IVE) } \uparrow\end{array}$ \\
\hline \multirow[t]{2}{*}{ mmu04520 } & \multirow[t]{2}{*}{ Adherens junction } & \multirow[t]{2}{*}{1} & \\
\hline & & & Rac3(RAS-related C3 botulinum substrate 3 ) $\downarrow$ \\
\hline \multirow[t]{2}{*}{ mmu04730 } & \multirow{2}{*}{$\begin{array}{l}\text { Long-term } \\
\text { depression }\end{array}$} & \multirow[t]{2}{*}{1} & \\
\hline & & & Pla2g4e (phospholipase A2, group IVE) $\uparrow$ \\
\hline \multirow[t]{2}{*}{ mmu04623 } & \multirow{2}{*}{$\begin{array}{l}\text { Cytosolic DNA- } \\
\text { sensing pathway }\end{array}$} & \multirow[t]{2}{*}{1} & \\
\hline & & & Trex 1 (three prime repair exonuclease 1 ) $\downarrow$ \\
\hline mmu04261 & $\begin{array}{l}\text { Adrenergic signaling } \\
\text { in cardiomyocytes }\end{array}$ & 1 & $\begin{array}{l}\text { Scn7a(sodium channel, voltage-gated, type VII, } \\
\text { alpha) } \downarrow\end{array}$ \\
\hline
\end{tabular}

\section{qRT-PCR to verify mRNA results}

We ran quantitative qRT-PCR from amygdala tissues that had been used for mRNA sequencing to validate our data above. The expressions of Cd86, Lst1, Iqgap3, Rpl10a and Lrrcc1 are lowered as well as the expressions of Gimap9, Lhx9 and Fibcd1 are elevated in Susceptible mice, compared to Control mice (Fig. 6). The expressions of Gabre, Abhd1, Fam227b and Ngfr are lowered as well as the expressions of Hspa1b, Slc37a2 and Dok3 are elevated in Resilient mice, compared to Control mice (Fig. 7). The expressions of Lrrcc1 and Cd86 are lowered as well as the expressions of Tgoln2, Amd2, Abhd1, Pla2g4e, Zfp729a, Oprm1 and Fam227b are elevated in Susceptible mice, compared to Resilient mice (Fig. 8). These consistent results achieved by mRNA sequencing and qRT-PCR analysis validate our study.

Based on the functional relationship between mRNAs and microRNAs, microRNAs affects the level of mRNAs in cells. mRNAs can be degrade by microRNAs with their dicers binding and weaken their translations. If the downregulation of mRNAs in the amygdala for susceptibility and resilience is caused by microRNAs, their correspondent microRNAs are upregulated, or vice versa. To validate mRNA changes in our study, we quantitatively analyzed microRNA profiles by their sequencings in amygdala tissues from the mice with Susceptible mice, Resilient mice and Control mice. 


\section{Study on differential expression of microRNA in amygdala of three groups of mice}

The profile of microRNAs is given in Table S10 if their expressions change above 2 folds in Susceptible mice versus Control mice, in which certain microRNAs are upregulated or downregulated. Based on the RNAhybrid, Targetscan and miRanda databases, this predicted target mRNAs match the measures by microRNA sequencing. Table 4 presents the altered microRNAs and their predicted-target mRNAs from Susceptible mice and Control mice. Table 5 presents the altered mRNAs and their correspondent microRNAs from Susceptible mice and Control mice. We bulid interactive networks about microRNAs and overlapped mRNAs for Susceptible mice and Control mice, which were based on three databases (Fig. 9). By reading Tables S11, 4 and 5, we found the microRNAs and their target mRNAs are matched well.

Table 4

The changed miRNAs predict target mRNAs in Susceptible versus Control

\begin{tabular}{|c|c|c|c|}
\hline miRNAs & $\begin{array}{l}\text { The predicted target mRNAs that } \\
\text { match DEGs in transcriptome* }\end{array}$ & miRNAs & $\begin{array}{l}\text { The predicted target mRNAs that } \\
\text { match DEGs in transcriptome * }\end{array}$ \\
\hline $\begin{array}{l}\text { miR- } \\
451 \mathrm{a} \uparrow\end{array}$ & 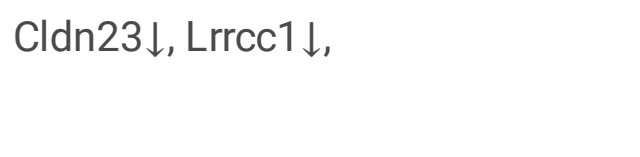 & $\begin{array}{l}\text { miR- } \\
665- \\
3 p \downarrow\end{array}$ & Dok3个, \\
\hline $\begin{array}{l}\text { miR- } \\
10 \mathrm{~b}- \\
5 \mathrm{p} \uparrow\end{array}$ & Cldn23\, & $\begin{array}{l}\text { miR- } \\
3968 \downarrow\end{array}$ & Noxred1个, \\
\hline $\begin{array}{l}\text { miR- } \\
34 \mathrm{~b}- \\
5 \mathrm{p} \uparrow\end{array}$ & Vmn2r30 & $\begin{array}{l}\text { miR- } \\
297 c- \\
5 p \downarrow\end{array}$ & Sumf2个, \\
\hline $\begin{array}{l}\text { miR- } \\
202- \\
5 p \uparrow\end{array}$ & 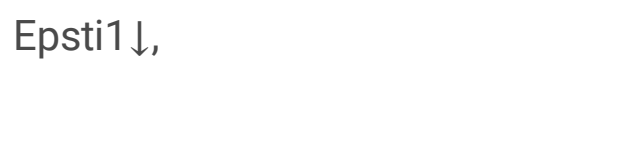 & $\begin{array}{l}\operatorname{miR-} \\
551 b- \\
3 p \downarrow\end{array}$ & Fibcd1个, \\
\hline $\begin{array}{l}\text { miR- } \\
199 a- \\
3 p \uparrow\end{array}$ & 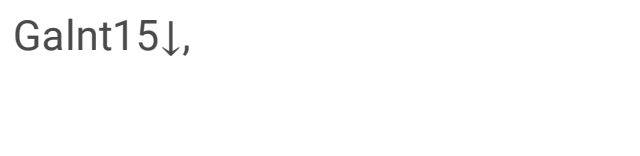 & $\begin{array}{l}\operatorname{miR-} \\
669 \mathrm{c}^{-} \\
5 \mathrm{p} \downarrow\end{array}$ & Plac9b $\uparrow$ \\
\hline $\begin{array}{l}\text { miR- } \\
211- \\
5 p \uparrow\end{array}$ & 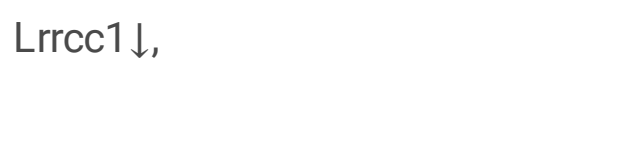 & $\begin{array}{l}\text { miR- } \\
34 b- \\
3 p \uparrow\end{array}$ & Iqgap3\} $\\
$\hline
\end{tabular}


Table 5

The changed mRNAs predict target miRNAs in Susceptible versus Control

\begin{tabular}{|c|c|c|c|}
\hline $\begin{array}{l}\text { Geng } \\
\text { Symbol }\end{array}$ & $\begin{array}{l}\text { The predicted target miRNAs that } \\
\text { match DEGs in transcriptome * }\end{array}$ & $\begin{array}{l}\text { Geng } \\
\text { Symbol }\end{array}$ & $\begin{array}{l}\text { The predicted target miRNAs that } \\
\text { match DEGs in transcriptome * }\end{array}$ \\
\hline Cldn23 $\downarrow$ & miR-451a $\uparrow$, miR-10b-5p $\uparrow$, & Dok3 $\uparrow$ & miR-665-3p $\downarrow$ \\
\hline 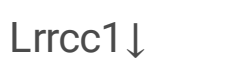 & miR-451a $\uparrow$, miR-211-5p $\uparrow$ & Noxred1 $\uparrow$ & miR-3968\, \\
\hline 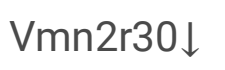 & miR-34b-5p & Sumf $2 \uparrow$ & miR-297c-5p $\downarrow$ \\
\hline Epsti1】 & miR-202-5p & Fibcd1个 & miR-551b-3p $\downarrow$ \\
\hline Galnt15 & miR-199a-3p $\uparrow$ & Plac9b $\uparrow$ & miR-669c-5p $\downarrow$ \\
\hline Iqgap3\ & miR-34b-3p $\uparrow$ & & \\
\hline
\end{tabular}

The profile of microRNAs is given in Table S12 if their expressions change above 2 folds in Resilient mice versus Control mice, in which certain microRNAs are upregulated or downregulated. Based on the RNAhybrid, Targetscan and miRanda databases, this predicted target mRNAs match the measures by microRNA sequencing. Table 6 presents the altered microRNAs and their predicted-target mRNAs from Resilient mice and Control mice. Table 7 presents the altered mRNAs and their correspondent microRNAs from Resilient mice and Control mice. We bulid interactive networks about microRNAs and overlapped mRNAs for Resilient mice and Control mice, which were based on three databases (Fig. 10). By reading Tables S13, 6 and 7, we found the microRNAs and their target mRNAs are matched well. 
Table 6

The changed miRNAs predict target mRNAs in Resilient versus Control

\begin{tabular}{|c|c|c|c|}
\hline miRNAs & $\begin{array}{l}\text { The predicted target mRNAs that } \\
\text { match DEGs in transcriptome * }\end{array}$ & miRNAs & $\begin{array}{l}\text { The predicted target mRNAs that } \\
\text { match DEGs in transcriptome * }\end{array}$ \\
\hline $\begin{array}{l}\text { let-7b- } \\
3 p \downarrow\end{array}$ & 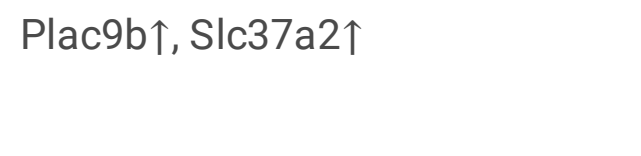 & $\begin{array}{l}\text { miR- } \\
199 b- \\
3 p \uparrow\end{array}$ & Ccr6 $\downarrow$, Tmprss $4 \downarrow$, Lpp $\downarrow$, Abhd1 $\downarrow$ \\
\hline $\begin{array}{l}\text { miR- } \\
107- \\
3 p \downarrow\end{array}$ & 4930473A02Rik $\uparrow$ & $\begin{array}{l}\operatorname{miR}- \\
206- \\
3 p \uparrow\end{array}$ & 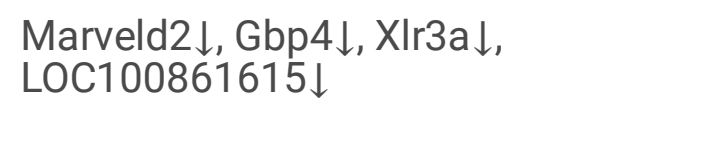 \\
\hline $\begin{array}{l}\text { miR- } \\
107- \\
5 p \downarrow\end{array}$ & Lhx9个 & $\begin{array}{l}\operatorname{miR}- \\
211- \\
5 p \uparrow\end{array}$ & $\begin{array}{l}\text { Scube2 } \downarrow, 4930555 \text { G01Rik } \downarrow \text {, } \\
\text { Fam227b } \downarrow \text {, Abhd1 } \downarrow\end{array}$ \\
\hline $\begin{array}{l}\text { miR- } \\
124- \\
5 p \downarrow\end{array}$ & 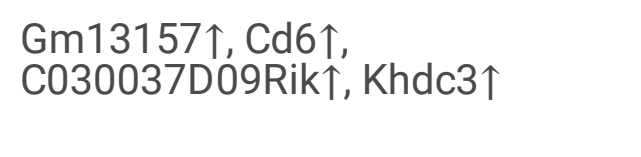 & $\begin{array}{l}\text { miR- } \\
375- \\
3 p \uparrow\end{array}$ & Arhgap33os $\downarrow$, Tgoln2 $\downarrow$ \\
\hline $\begin{array}{l}\text { miR- } \\
1249- \\
3 p \downarrow\end{array}$ & Slc37a2 $2 \uparrow$, Krt $\uparrow 2, C d 6 \uparrow, \operatorname{Lrrc} 48 \uparrow$ & $\begin{array}{l}\operatorname{miR-} \\
378 d \uparrow\end{array}$ & $\begin{array}{l}\text { Arhgef37 } 1, \text { F630042J09Rik } \downarrow \text {, } \\
\text { Tmprss4 } 4 \text {, Fam227b } \downarrow \text {, Serpina3f } \downarrow, H 2- \\
\text { Q5 } \downarrow\end{array}$ \\
\hline $\begin{array}{l}\text { miR- } \\
129 b- \\
5 p \downarrow\end{array}$ & Mybpc1个, Esr2, Trhr $\uparrow$ & $\begin{array}{l}\operatorname{miR}- \\
429- \\
3 p \uparrow\end{array}$ & 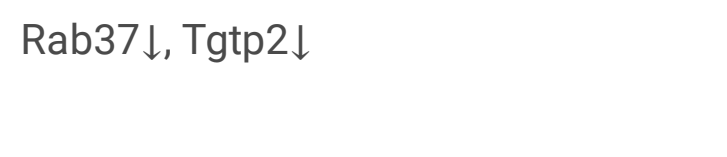 \\
\hline $\begin{array}{l}\text { miR- } \\
1306- \\
5 p \downarrow\end{array}$ & 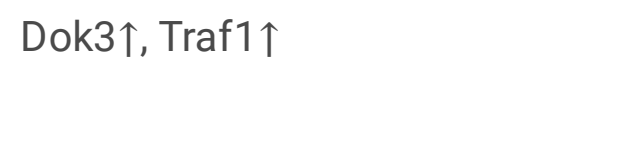 & $\begin{array}{l}\operatorname{miR}- \\
448- \\
3 p \uparrow\end{array}$ & Gbp4 $\downarrow$, Insrr $\downarrow, 4930555 G 01$ Rik $\downarrow$ \\
\hline $\begin{array}{l}\text { miR- } \\
130 \mathrm{~b}- \\
3 p \downarrow\end{array}$ & $\mathrm{Hbb}-\mathrm{bs} \uparrow$ & $\begin{array}{l}\operatorname{miR}- \\
451 \mathrm{a} \uparrow\end{array}$ & Lpp $\downarrow$ \\
\hline $\begin{array}{l}\text { miR- } \\
133 a- \\
3 p \downarrow\end{array}$ & $\operatorname{Itga} 10 \uparrow$ & $\begin{array}{l}\operatorname{miR}- \\
467 \mathrm{~b}- \\
5 \mathrm{p} \uparrow\end{array}$ & H2-T10』 \\
\hline $\begin{array}{l}\text { miR- } \\
134- \\
5 p \downarrow\end{array}$ & 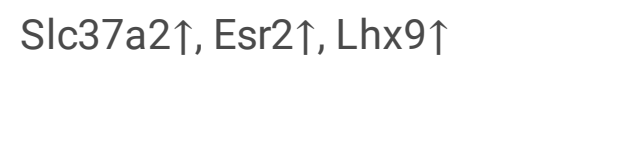 & $\begin{array}{l}\operatorname{miR}- \\
7070- \\
3 p \uparrow\end{array}$ & $\begin{array}{l}\text { B3gnt9 } \downarrow, Z f p 729 a \downarrow, \text { Ngfr } \downarrow \text {, Insrr } \downarrow \text {, } \\
\text { Arhgap33os } \downarrow, \text { A530016L24Rik }\end{array}$ \\
\hline $\begin{array}{l}\text { miR- } \\
15 a- \\
3 p \downarrow\end{array}$ & 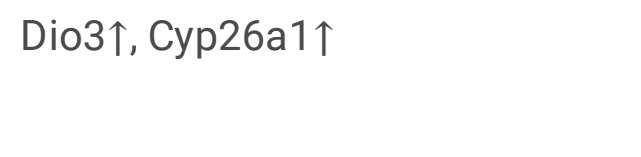 & $\begin{array}{l}\operatorname{miR}- \\
879- \\
5 p \uparrow\end{array}$ & 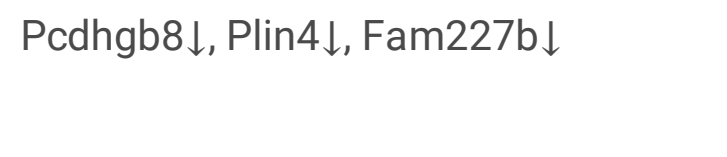 \\
\hline $\begin{array}{l}\text { miR- } \\
187- \\
5 p \downarrow\end{array}$ & 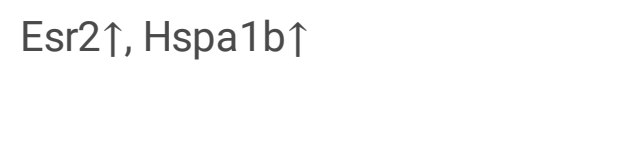 & $\begin{array}{l}\text { miR- } \\
6958- \\
3 p \downarrow\end{array}$ & 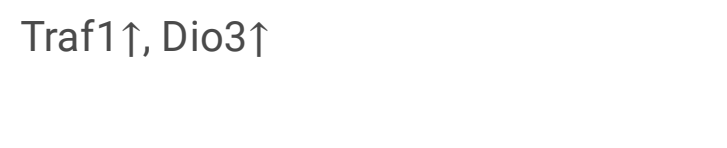 \\
\hline
\end{tabular}

Note: $\uparrow$ indicates up-regulation in the tissue of BLA from Resilient versus Control mice, whereas $\downarrow$ represents down-regulation. 


\begin{tabular}{|c|c|c|c|}
\hline miRNAs & $\begin{array}{l}\text { The predicted target mRNAs that } \\
\text { match DEGs in transcriptome * }\end{array}$ & miRNAs & $\begin{array}{l}\text { The predicted target mRNAs that } \\
\text { match DEGs in transcriptome * }\end{array}$ \\
\hline $\begin{array}{l}\text { miR- } \\
20 \mathrm{~b}- \\
5 \mathrm{p} \downarrow\end{array}$ & 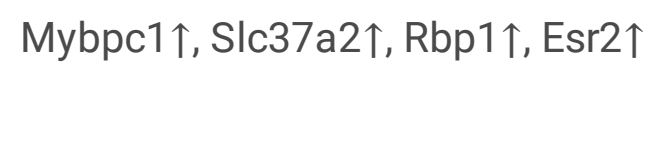 & $\begin{array}{l}\text { miR- } \\
702- \\
3 p \downarrow\end{array}$ & Dio3个 \\
\hline $\begin{array}{l}\text { miR- } \\
219 a- \\
5 p \downarrow\end{array}$ & Awat2 $\uparrow$ & $\begin{array}{l}\text { miR- } \\
7069- \\
3 p \downarrow\end{array}$ & 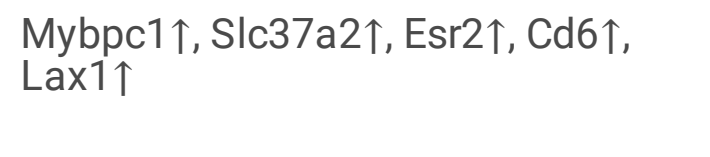 \\
\hline $\begin{array}{l}\operatorname{miR-} \\
219 c^{-} \\
3 p \downarrow\end{array}$ & 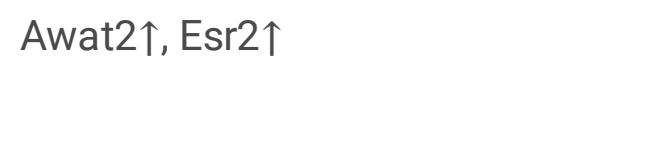 & $\begin{array}{l}\operatorname{miR}- \\
758- \\
3 p \downarrow\end{array}$ & 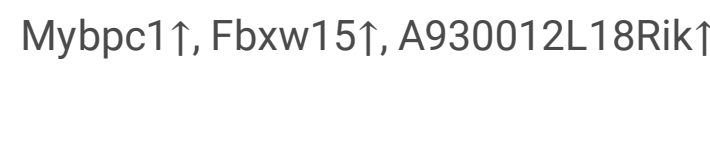 \\
\hline $\begin{array}{l}\text { miR- } \\
27 b- \\
5 p \downarrow\end{array}$ & 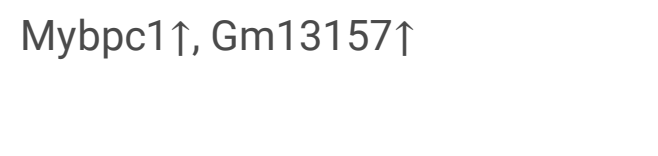 & $\begin{array}{l}\text { miR- } \\
764- \\
3 p \downarrow\end{array}$ & Nlrp5-ps $\uparrow$ \\
\hline $\begin{array}{l}\text { miR- } \\
296- \\
3 p \downarrow\end{array}$ & Nlrp5-ps $\uparrow$ & $\begin{array}{l}\operatorname{miR}-7 b- \\
3 p \downarrow\end{array}$ & 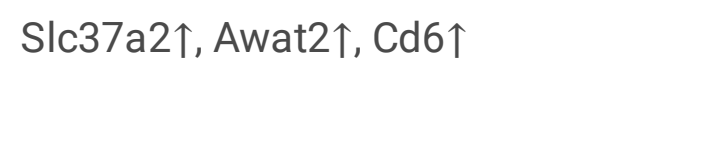 \\
\hline $\begin{array}{l}\text { miR- } \\
298- \\
3 p \downarrow\end{array}$ & 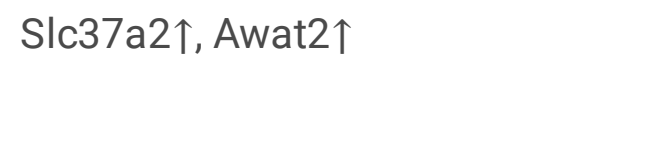 & $\begin{array}{l}\operatorname{miR}- \\
874- \\
3 p \downarrow\end{array}$ & Mybpc $1 \uparrow$ \\
\hline $\begin{array}{l}\text { miR- } \\
298- \\
5 p \downarrow\end{array}$ & $\mathrm{Cd} 6 \uparrow$ & $\begin{array}{l}\operatorname{miR}-93- \\
3 p \downarrow\end{array}$ & Glt8d2个 \\
\hline $\begin{array}{l}\operatorname{miR}- \\
29 c-3 p \downarrow\end{array}$ & 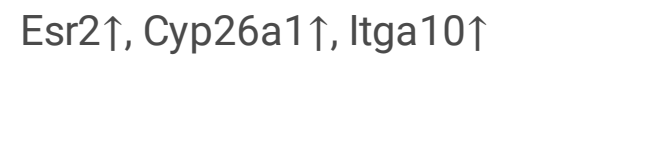 & $\begin{array}{l}\text { miR- } \\
99 a- \\
3 p \downarrow\end{array}$ & 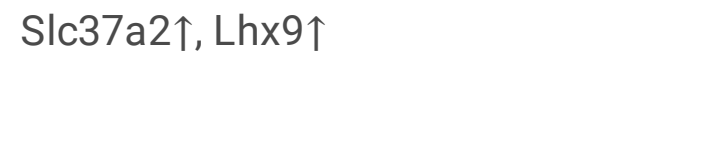 \\
\hline $\begin{array}{l}\text { miR- } \\
300- \\
3 p \downarrow\end{array}$ & Nlrp5-ps $\uparrow$ & $\begin{array}{l}\operatorname{miR}- \\
532- \\
3 p \downarrow\end{array}$ & $\operatorname{Lax} 1 \uparrow, \operatorname{Scn} 7 a \uparrow$ \\
\hline $\begin{array}{l}\operatorname{miR-} \\
301 b- \\
3 p \downarrow\end{array}$ & Slc37a2؟ & $\begin{array}{l}\text { miR- } \\
539- \\
3 p \downarrow\end{array}$ & Cdkn1c $\uparrow, R b p 1 \uparrow, E s r 2 \uparrow$ \\
\hline $\begin{array}{l}\text { miR- } \\
3065- \\
5 p \downarrow\end{array}$ & Dio3个 & $\begin{array}{l}\text { miR- } \\
5620- \\
5 p \downarrow\end{array}$ & Сур2c55个 \\
\hline $\begin{array}{l}\text { miR- } \\
3069- \\
3 p \downarrow\end{array}$ & 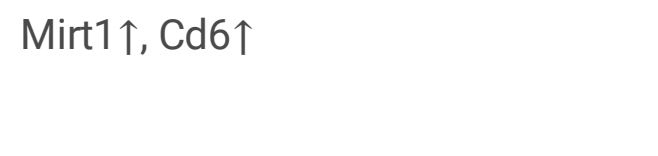 & $\begin{array}{l}\operatorname{miR}- \\
665- \\
3 p \downarrow\end{array}$ & 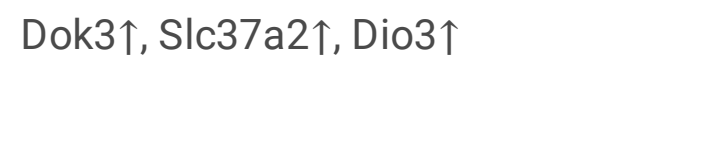 \\
\hline $\begin{array}{l}\text { miR- } \\
3074- \\
5 \mathrm{p} \downarrow\end{array}$ & Ugt1a6a $\uparrow$, Esr $2 \uparrow$ & $\begin{array}{l}\operatorname{miR}- \\
668- \\
5 \mathrm{p} \downarrow\end{array}$ & 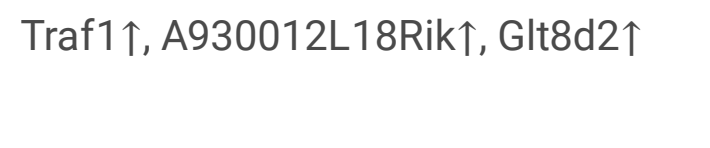 \\
\hline
\end{tabular}

Note: $\uparrow$ indicates up-regulation in the tissue of BLA from Resilient versus Control mice, whereas $\downarrow$ represents down-regulation. 


\begin{tabular}{|c|c|c|c|}
\hline miRNAs & $\begin{array}{l}\text { The predicted target mRNAs that } \\
\text { match DEGs in transcriptome * }\end{array}$ & miRNAs & $\begin{array}{l}\text { The predicted target mRNAs that } \\
\text { match DEGs in transcriptome * }\end{array}$ \\
\hline $\begin{array}{l}\text { miR- } \\
3095- \\
3 p \downarrow\end{array}$ & Awat $2 \uparrow$ & $\begin{array}{l}\text { miR- } \\
669 f- \\
5 p \downarrow\end{array}$ & Awat $2 \uparrow$ \\
\hline $\begin{array}{l}\text { miR- } \\
320- \\
3 p \downarrow\end{array}$ & Awat $2 \uparrow$ & $\begin{array}{l}\operatorname{miR}- \\
671- \\
5 p \downarrow\end{array}$ & 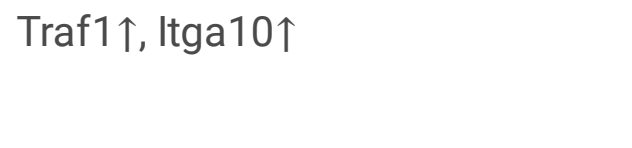 \\
\hline $\begin{array}{l}\text { miR- } \\
338- \\
3 p \downarrow\end{array}$ & Hbb-bs $\uparrow$, Lax $1 \uparrow$ & $\begin{array}{l}\operatorname{miR}- \\
676- \\
5 \mathrm{p} \downarrow\end{array}$ & Scn7a $\uparrow$ \\
\hline $\begin{array}{l}\text { miR- } \\
344 f- \\
3 p \downarrow\end{array}$ & Hbb-bs $\uparrow$, Nlrp5-ps $\uparrow, T r h r \uparrow$ & $\begin{array}{l}\operatorname{miR}- \\
431- \\
3 p \downarrow\end{array}$ & 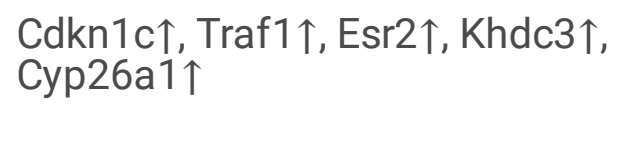 \\
\hline $\begin{array}{l}\text { miR- } \\
34 a- \\
5 p \downarrow\end{array}$ & Traf1 $\uparrow$ & $\begin{array}{l}\operatorname{miR}- \\
448- \\
5 p \downarrow\end{array}$ & 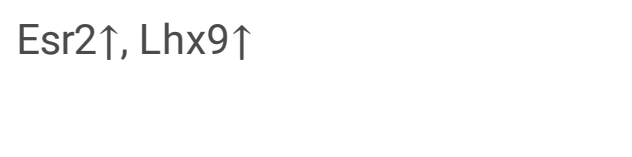 \\
\hline $\begin{array}{l}\text { miR- } \\
3535 \downarrow\end{array}$ & Hspa1b $\uparrow$ & $\begin{array}{l}\text { miR- } \\
486 b- \\
5 p \downarrow\end{array}$ & Slc39a2 $\uparrow$ \\
\hline $\begin{array}{l}\text { miR- } \\
362- \\
5 p \downarrow\end{array}$ & 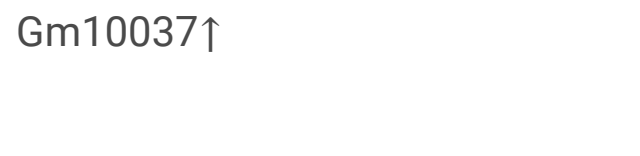 & $\begin{array}{l}\operatorname{miR}- \\
490- \\
3 p \downarrow\end{array}$ & 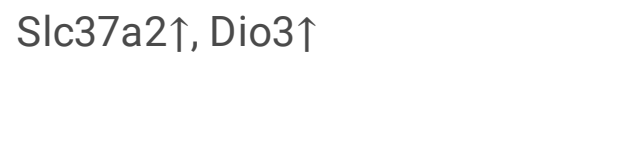 \\
\hline $\begin{array}{l}\text { miR- } \\
376 a- \\
3 p \downarrow\end{array}$ & Dio3个 & $\begin{array}{l}\text { miR- } \\
497 a- \\
5 p \downarrow\end{array}$ & 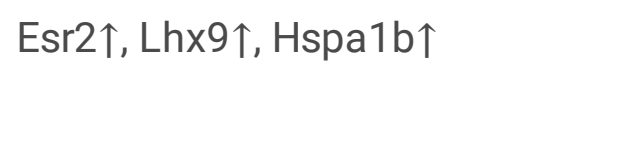 \\
\hline $\begin{array}{l}\operatorname{miR}- \\
378 \mathrm{c} \downarrow\end{array}$ & 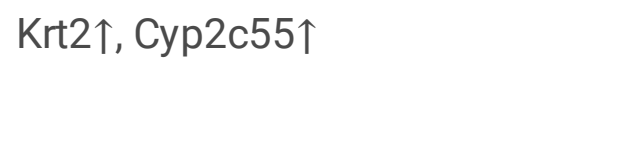 & $\begin{array}{l}\mathrm{miR}- \\
423- \\
5 \mathrm{p} \downarrow\end{array}$ & 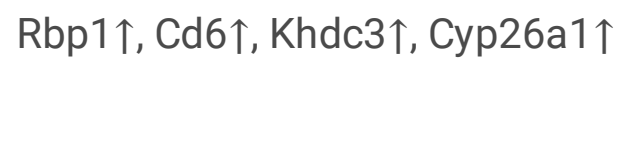 \\
\hline $\begin{array}{l}\operatorname{miR}- \\
3968 \downarrow\end{array}$ & \multicolumn{3}{|l|}{ Traf1 $\uparrow, \mathrm{Cd} 6 \uparrow$} \\
\hline $\begin{array}{l}\text { Note: } \uparrow \\
\text { represel }\end{array}$ & $\begin{array}{l}\text { ates up-regulation in the tissue } \\
\text { own-regulation. }\end{array}$ & from $\mathrm{R}$ & ient versus Control mice, whereas \\
\hline
\end{tabular}


Table 7

The changed mRNAs predict target miRNAs in Resilient versus Control

\begin{tabular}{|c|c|c|c|}
\hline Geng Symbol & $\begin{array}{l}\text { The predicted target miRNAs that match } \\
\text { DEGs in transcriptome * }\end{array}$ & Geng Symbol & $\begin{array}{l}\text { The predicted } \\
\text { target } \\
\text { miRNAs that } \\
\text { match DEGs } \\
\text { in } \\
\text { transcriptome } \\
\text { * }\end{array}$ \\
\hline 4930473A02Rik $\uparrow$ & miR-107-3p $\downarrow$ & 4930555G01Rik $\downarrow$ & $\begin{array}{l}\text { mmu-miR- } \\
211-5 p \uparrow \\
\text { mmu-miR- } \\
448-3 p \uparrow\end{array}$ \\
\hline A930012L18Rik $\uparrow$ & miR-668-5p $\downarrow$, miR-758-3p $\downarrow$ & A530016L24Rik $\downarrow$ & $\begin{array}{l}\text { mmu-miR- } \\
7070-3 p \uparrow\end{array}$ \\
\hline Awat $2 \uparrow$ & $\begin{array}{l}\text { miR-3095-3p } \downarrow \text {, miR-320-3p } \downarrow \text {, miR-7b-3p } \downarrow \text {, } \\
\text { miR-298-3p } \downarrow \text {, miR-219c-3p } \downarrow \text {, miR-669f- } \\
5 p \downarrow \text {, miR-219a-5p } \downarrow\end{array}$ & Abhd1 $\downarrow$ & $\begin{array}{l}\text { mmu-miR- } \\
211-5 p \uparrow \\
\text { mmu-miR- } \\
199 b-3 p \uparrow\end{array}$ \\
\hline C030037D09Rik $\uparrow$ & miR-124-5p $\downarrow$ & Arhgap33os $\downarrow$ & $\begin{array}{l}\text { mmu-miR- } \\
375-3 p \uparrow \\
\text { mmu-miR- } \\
7070-3 p \uparrow\end{array}$ \\
\hline Cd6个 & $\begin{array}{l}\text { miR-7b-3p } \downarrow \text {, miR-3069-3p } \downarrow \text {, miR-124-5p } \downarrow \text {, } \\
\text { miR-7069-3p } \downarrow \text {, miR-3968 } \downarrow \text {, miR-423-5p } \downarrow \text {, } \\
\text { miR-1249-3p } \downarrow \text {, miR-298-5p } \downarrow\end{array}$ & Arhgef37\ & $\begin{array}{l}\text { mmu-miR- } \\
378 d \uparrow\end{array}$ \\
\hline Cdkn1c $\uparrow$ & miR-539-3p $\downarrow$, miR-431-3p $\downarrow$ & B3gnt9 $\downarrow$ & $\begin{array}{l}\text { mmu-miR- } \\
7070-3 p \uparrow\end{array}$ \\
\hline 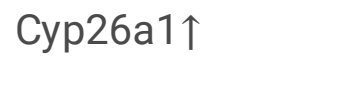 & $\begin{array}{l}\text { miR-15a-3p } \downarrow \text {, miR-29c-3p } \downarrow \text {, miR-423-5p } \downarrow \text {, } \\
\text { miR-431-3p } \downarrow\end{array}$ & 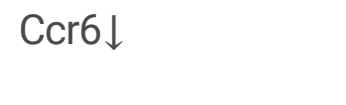 & $\begin{array}{l}\text { mmu-miR- } \\
199 \mathrm{~b}-3 \mathrm{p} \uparrow\end{array}$ \\
\hline Сур2c55个 & miR-5620-5p $\downarrow$, miR-378c $\downarrow$ & F630042J09Rik $\downarrow$ & $\begin{array}{l}\text { mmu-miR- } \\
378 \mathrm{~d} \uparrow\end{array}$ \\
\hline Dio3个 & $\begin{array}{l}\text { miR-702-3p } \downarrow \text {, miR-15a-3p } \downarrow \text {, miR-490-3p } \downarrow \text {, } \\
\text { miR-6958-3p } \downarrow \text {, miR-376a-3p } \downarrow \text {, miR-3065- } \\
5 p \downarrow \text {, miR-665-3p } \downarrow\end{array}$ & Fam227b $\downarrow$ & $\begin{array}{l}\text { mmu-miR- } \\
211-5 p \uparrow \\
\text { mmu-miR- } \\
879-5 p \uparrow \\
\text { mmu-miR- } \\
378 d \uparrow\end{array}$ \\
\hline
\end{tabular}

Note: $\uparrow$ indicates up-regulation in the tissue of BLA from Resilient versus Control mice, whereas $\downarrow$ represents down-regulation. 


\begin{tabular}{|c|c|c|c|}
\hline Geng Symbol & $\begin{array}{l}\text { The predicted target miRNAs that match } \\
\text { DEGs in transcriptome * }\end{array}$ & Geng Symbol & $\begin{array}{l}\text { The predicted } \\
\text { target } \\
\text { miRNAs that } \\
\text { match DEGs } \\
\text { in } \\
\text { transcriptome } \\
\text { * }\end{array}$ \\
\hline Dok3个 & miR-1306-5p $\downarrow$, miR-665-3p $\downarrow$ & Gbp4 $\downarrow$ & $\begin{array}{l}\text { mmu-miR- } \\
448-3 p \uparrow \\
\text { mmu-miR- } \\
206-3 p \uparrow\end{array}$ \\
\hline Esr2个 & $\begin{array}{l}\text { miR-134-5p } \downarrow \text {, miR-448-5p } \downarrow \text {, miR-20b-5p } \downarrow \text {, } \\
\text { miR-7069-3p } \downarrow \text {, miR-497a-5p } \downarrow \text {, miR-29c- } \\
\text { 3p } \downarrow \text {, miR-539-3p } \downarrow \text {, miR-431-3p } \downarrow \text {, miR- } \\
\text { 129b-5p } \downarrow \text {, miR-219c-3p } \downarrow \text {, miR-187-5p } \downarrow \text {, } \\
\text { miR-3074-5p } \downarrow\end{array}$ & $\mathrm{H} 2-\mathrm{Q}$ 5 $\downarrow$ & $\begin{array}{l}\text { mmu-miR- } \\
378 d \uparrow\end{array}$ \\
\hline Fbxw15个 & miR-758-3p $\downarrow$ & H2-T10 $\downarrow$ & $\begin{array}{l}\text { mmu-miR- } \\
467 b-5 p \uparrow\end{array}$ \\
\hline Glt8d2个 & miR-668-5p $\downarrow$, miR-93-3p $\downarrow$ & Insrr $\downarrow$ & $\begin{array}{l}\text { mmu-miR- } \\
448-3 p \uparrow \\
\text { mmu-miR- } \\
7070-3 p \uparrow\end{array}$ \\
\hline Gm10037个 & miR-362-5p $\downarrow$ & LOC100861615 $\downarrow$ & $\begin{array}{l}\text { mmu-miR- } \\
206-3 p \uparrow\end{array}$ \\
\hline 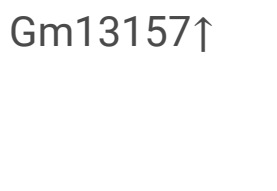 & miR-124-5p $\downarrow$, miR-27b-5p $\downarrow$ & Lpp $\downarrow$ & $\begin{array}{l}\text { mmu-miR- } \\
451 \mathrm{a} \uparrow, \mathrm{mmu}- \\
\text { miR-199b- } \\
3 \mathrm{p} \uparrow\end{array}$ \\
\hline $\mathrm{Hbb}-\mathrm{bs} \uparrow$ & miR-130b-3p $\downarrow$, miR-338-3p $\downarrow$, miR-344f-3p $\downarrow$ & Marveld2 $\downarrow$ & $\begin{array}{l}\text { mmu-miR- } \\
206-3 p \uparrow\end{array}$ \\
\hline Hspa1b $\uparrow$ & miR-497a-5p $\downarrow$, miR-3535 $\downarrow$, miR-187-5p $\downarrow$ & $\mathrm{Ngfr} \downarrow$ & $\begin{array}{l}\text { mmu-miR- } \\
7070-3 p \uparrow\end{array}$ \\
\hline Itga10 $\uparrow$ & miR-29c-3p $\downarrow$, miR-133a-3p $\downarrow$, miR-671-5p $\downarrow$ & Pcdhgb8 $\downarrow$ & $\begin{array}{l}\text { mmu-miR- } \\
879-5 p \uparrow\end{array}$ \\
\hline Khdc3个 & miR-124-5p $\downarrow$, miR-423-5p $\downarrow$, miR-431-3p $\downarrow$ & Plin4 $\downarrow$ & $\begin{array}{l}\text { mmu-miR- } \\
879-5 p \uparrow\end{array}$ \\
\hline Krt2 $2 \uparrow$ & miR-1249-3p $\downarrow$, miR-378c $\downarrow$ & Rab37\ & $\begin{array}{l}\text { mmu-miR- } \\
429-3 p \uparrow\end{array}$ \\
\hline 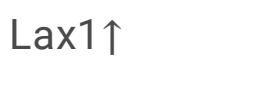 & miR-532-3p $\downarrow$, miR-7069-3p $\downarrow$, miR-338-3p $\downarrow$ & Scube2 $\downarrow$ & $\begin{array}{l}\text { mmu-miR- } \\
211-5 p \uparrow\end{array}$ \\
\hline
\end{tabular}




\begin{tabular}{|c|c|c|c|}
\hline Geng Symbol & $\begin{array}{l}\text { The predicted target miRNAs that match } \\
\text { DEGs in transcriptome * }\end{array}$ & Geng Symbol & $\begin{array}{l}\text { The predicted } \\
\text { target } \\
\text { miRNAs that } \\
\text { match DEGs } \\
\text { in } \\
\text { transcriptome } \\
\text { * }\end{array}$ \\
\hline Lhx9个 & $\begin{array}{l}\operatorname{miR}-134-5 p \downarrow \text {, miR-448-5p } \downarrow \text {, miR-497a-5p } \downarrow \text {, } \\
\text { miR-107-5p } \uparrow, \text { miR-99a-3p } \downarrow\end{array}$ & Serpina3f $\downarrow$ & $\begin{array}{l}\text { mmu-miR- } \\
378 d \uparrow\end{array}$ \\
\hline Lrrc48 $\uparrow$ & miR-1249-3p $\downarrow$ & 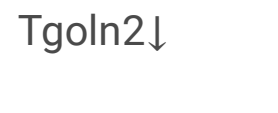 & $\begin{array}{l}\text { mmu-miR- } \\
375-3 p \uparrow\end{array}$ \\
\hline Mirt1 $\uparrow$ & miR-3069-3p $\downarrow$ & 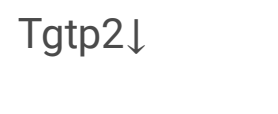 & $\begin{array}{l}\mathrm{mmu}-\mathrm{miR}- \\
429-3 \mathrm{p} \uparrow\end{array}$ \\
\hline Mybpc1个 & $\begin{array}{l}\text { miR-874-3p } \downarrow \text {, miR-20b-5p } \downarrow \text {, miR-7069-3p } \downarrow \text {, } \\
\text { miR-27b-5p } \downarrow \text {, miR-129b-5p } \downarrow \text {, miR-758-3p }\end{array}$ & Tmprss4 $\downarrow$ & $\begin{array}{l}\text { mmu-miR- } \\
378 d \uparrow, m m u- \\
\text { miR-199b- } \\
3 p \uparrow\end{array}$ \\
\hline Nlrp5-ps $\uparrow$ & $\begin{array}{l}\text { miR-344f-3p } \downarrow \text {, miR-300-3p } \downarrow \text {, miR-764-3p } \downarrow \text {, } \\
\text { miR-296-3p } \downarrow\end{array}$ & $\mathrm{XIr} 3 \mathrm{a} \downarrow$ & $\begin{array}{l}\text { mmu-miR- } \\
206-3 p \uparrow\end{array}$ \\
\hline Plac9b $\uparrow$ & let-7b-3p $\downarrow$ & Zfp729a $\downarrow$ & $\begin{array}{l}\text { mmu-miR- } \\
7070-3 p \uparrow\end{array}$ \\
\hline $\mathrm{Rbp} 1 \uparrow$ & miR-20b-5p $\downarrow$, miR-423-5p $\downarrow$, miR-539-3p $\downarrow$ & 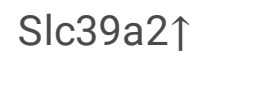 & $\begin{array}{l}\text { miR-486b- } \\
5 p \downarrow\end{array}$ \\
\hline Scn7a $\uparrow$ & miR-532-3p $\downarrow$, miR-676-5p $\downarrow$ & Traf1 $\uparrow$ & 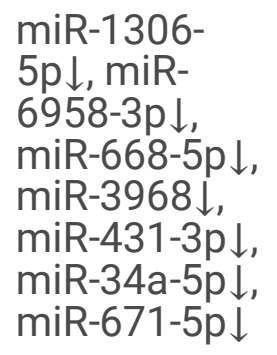 \\
\hline Slc37a2؟ & $\begin{array}{l}\text { miR-134-5p } \downarrow \text {, miR-7b-3p } \downarrow \text {, miR-490-3p } \downarrow \text {, } \\
\text { miR-301b-3p } \downarrow \text {, miR-20b-5p } \downarrow \text {, miR-7069- } \\
3 p \downarrow \text {, miR-298-3p } \downarrow \text {, miR-1249-3p } \downarrow \text {, let-7b- } \\
3 p \downarrow \text {, miR-99a-3p } \downarrow \text {, miR-665-3p } \downarrow\end{array}$ & Trhr $\uparrow$ & $\begin{array}{l}\operatorname{miR}-344 f- \\
3 p \downarrow, \text { miR- } \\
129 b-5 p \downarrow\end{array}$ \\
\hline Ugt1a6a & miR-3074-5p $\downarrow$ & & \\
\hline
\end{tabular}

The profile of microRNAs is given in Table S14 if their expressions change above 2 folds in Susceptible mice versus Resilient mice, in which certain microRNAs are upregulated or downregulated. Based on the RNAhybrid, Targetscan and miRanda databases, this predicted target mRNAs match the measures by 
microRNA sequencing. Table 8 presents the altered microRNAs and their predicted-target mRNAs from Susceptible mice and Resilient mice. Table 9 presents the altered mRNAs and their correspondent microRNAs from Susceptible mice and Resilient mice. We bulid interactive networks about microRNAs and overlapped mRNAs for Susceptible mice and Resilient mice, which were based on three databases (Fig. 11). By reading Tables S15, 8 and 9, we found the microRNAs and their target mRNAs are matched well. Consistent results by jointly sequencing mRNAs and microRNAs validate our analyses and strengthen our conclusion. 
Table 8

The changed miRNAs predict target mRNAs in Susceptible versus Resilient

\begin{tabular}{|c|c|c|c|}
\hline miRNAs & $\begin{array}{l}\text { The predicted target mRNAs that } \\
\text { match DEGs in transcriptome * }\end{array}$ & miRNAs & $\begin{array}{l}\text { The predicted target mRNAs that } \\
\text { match DEGs in transcriptome * }\end{array}$ \\
\hline $\begin{array}{l}\text { let-7a-1- } \\
3 p \downarrow\end{array}$ & Tagap $\uparrow$, & $\begin{array}{l}\text { miR- } \\
10 \mathrm{~b}- \\
5 \mathrm{p} \uparrow\end{array}$ & Ehd4】 \\
\hline $\begin{array}{l}\text { miR- } \\
151- \\
3 p \downarrow\end{array}$ & 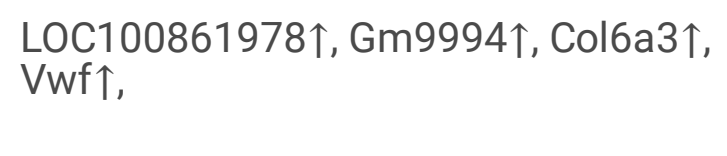 & $\begin{array}{l}\operatorname{miR-} \\
181 \mathrm{c}- \\
3 \mathrm{p} \uparrow\end{array}$ & Bhlhe22 $\downarrow$, Grk1 $\downarrow$ \\
\hline $\begin{array}{l}\text { miR- } \\
199 \mathrm{~b}- \\
3 p \downarrow\end{array}$ & 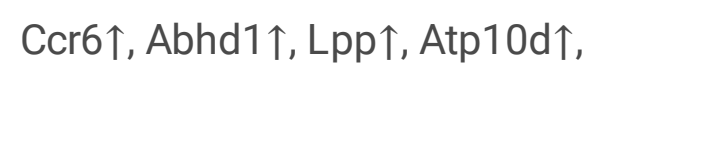 & $\begin{array}{l}\operatorname{miR}- \\
187- \\
3 \mathrm{p} \uparrow\end{array}$ & Msln $\downarrow$, Muc6 $\downarrow$, Ehd4 $\downarrow$ \\
\hline $\begin{array}{l}\text { miR- } \\
211- \\
5 p \downarrow\end{array}$ & 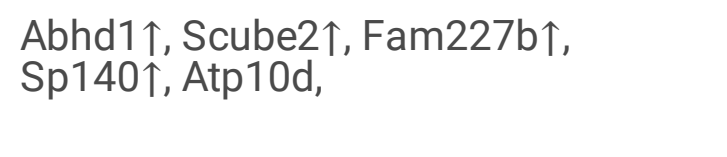 & $\begin{array}{l}\operatorname{miR}- \\
187- \\
5 p \uparrow\end{array}$ & Tmem71 $\downarrow, 2610035 D 17 R i k \downarrow$ \\
\hline $\begin{array}{l}\operatorname{miR}-24- \\
3 p \downarrow\end{array}$ & $\begin{array}{l}\text { Tgoln2 } 2 \uparrow, \text { Pla2g4e } \uparrow, \text { Alas } 2 \uparrow, \text { Oprm1 } \uparrow, \\
\text { Alad } \uparrow, \text { Atp10d } \uparrow,\end{array}$ & $\begin{array}{l}\text { miR- } \\
199 a- \\
3 p \uparrow\end{array}$ & 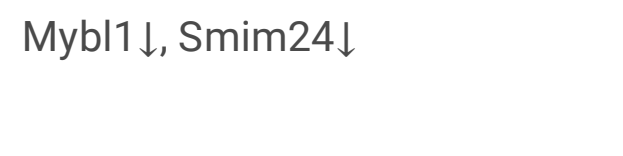 \\
\hline $\begin{array}{l}\text { miR- } \\
3065- \\
5 p \downarrow\end{array}$ & 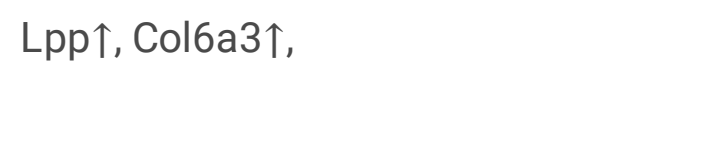 & $\begin{array}{l}\text { miR- } \\
199 a- \\
5 p \uparrow\end{array}$ & Tnni1 $\downarrow$, Vmn2r32 $\downarrow$ \\
\hline $\begin{array}{l}\text { miR- } \\
339- \\
5 p \downarrow\end{array}$ & 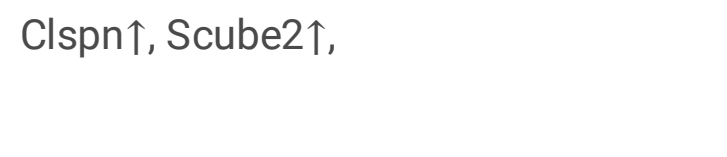 & $\begin{array}{l}\operatorname{miR}- \\
19 b- \\
3 p \uparrow\end{array}$ & Ptchd4】 \\
\hline $\begin{array}{l}\operatorname{miR-} \\
378 d \downarrow\end{array}$ & 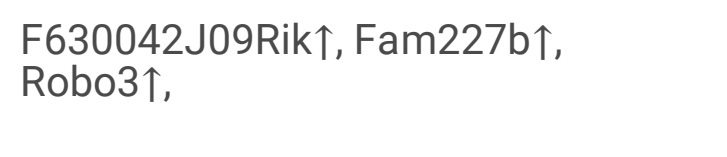 & $\begin{array}{l}\text { miR- } \\
200 \mathrm{c}- \\
3 \mathrm{p} \uparrow\end{array}$ & Grk1 $1, \mathrm{Cd} 6 \downarrow$ \\
\hline $\begin{array}{l}\operatorname{miR}- \\
467 \mathrm{~h} \downarrow\end{array}$ & 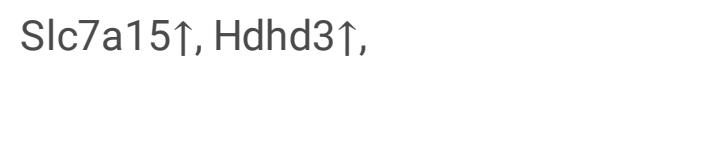 & $\begin{array}{l}\operatorname{miR}- \\
202- \\
5 p \uparrow\end{array}$ & 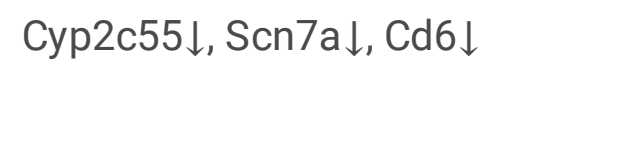 \\
\hline $\begin{array}{l}\text { miR- } \\
541- \\
3 p \downarrow\end{array}$ & 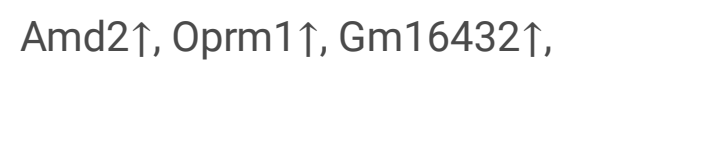 & $\begin{array}{l}\mathrm{miR}- \\
20 \mathrm{~b}- \\
5 \mathrm{p} \uparrow\end{array}$ & 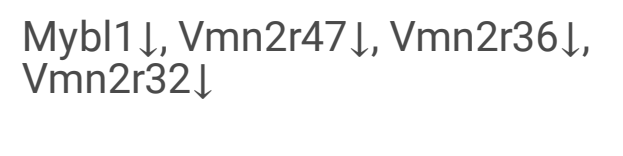 \\
\hline $\begin{array}{l}\text { miR- } \\
669 c^{-} \\
5 p \downarrow\end{array}$ & 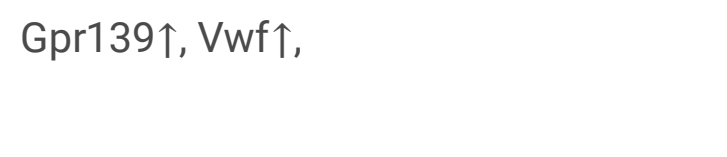 & $\begin{array}{l}\operatorname{miR}- \\
210- \\
3 p \uparrow\end{array}$ & Rad54b $\downarrow$ \\
\hline $\begin{array}{l}\text { miR- } \\
673- \\
5 p \downarrow\end{array}$ & 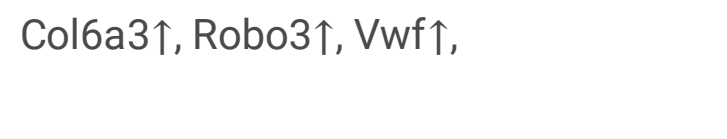 & $\begin{array}{l}\text { miR- } \\
219 a- \\
5 p \uparrow\end{array}$ & Npcd $\downarrow$ \\
\hline
\end{tabular}

Note: $\uparrow$ indicates up-regulation in the tissue of BLA from Susceptible versus Resilient mice, $\downarrow$ represents down-regulation. 


\begin{tabular}{|c|c|c|c|}
\hline miRNAs & $\begin{array}{l}\text { The predicted target mRNAs that } \\
\text { match DEGs in transcriptome * }\end{array}$ & miRNAs & $\begin{array}{l}\text { The predicted target mRNAs that } \\
\text { match DEGs in transcriptome * }\end{array}$ \\
\hline $\begin{array}{l}\text { miR- } \\
7019- \\
3 p \downarrow\end{array}$ & Clspn $\uparrow$, & $\begin{array}{l}\text { miR- } \\
219 b- \\
5 p \uparrow\end{array}$ & 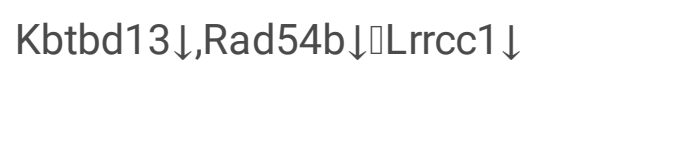 \\
\hline $\begin{array}{l}\text { miR- } \\
7070- \\
3 p \downarrow\end{array}$ & 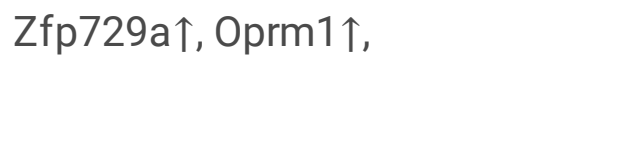 & $\begin{array}{l}\text { miR- } \\
27 b- \\
5 p \uparrow\end{array}$ & Tnni1 $\downarrow, G m 13157 \downarrow$ \\
\hline $\begin{array}{l}\text { miR- } \\
879- \\
5 p \downarrow\end{array}$ & 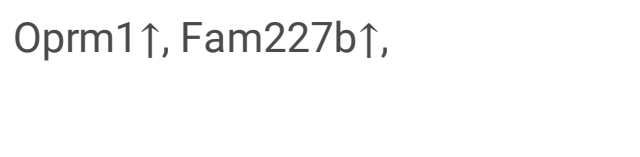 & $\begin{array}{l}\text { miR- } \\
296- \\
3 p \uparrow\end{array}$ & 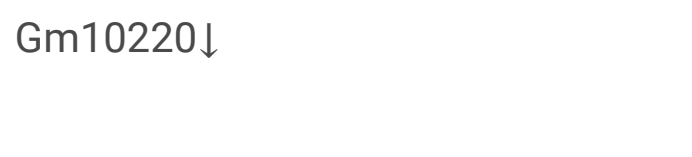 \\
\hline $\begin{array}{l}\operatorname{miR}-93- \\
3 p \uparrow\end{array}$ & Glt8d2 $\downarrow$,Pter $\downarrow$ & $\begin{array}{l}\text { miR- } \\
297 c^{-} \\
5 p \uparrow\end{array}$ & Muc6 $\downarrow$ \\
\hline $\begin{array}{l}\text { miR- } \\
764- \\
3 p \uparrow\end{array}$ & Muc6 $\downarrow, G r k 1 \downarrow$ & $\begin{array}{l}\text { miR- } \\
298- \\
5 \mathrm{p} \uparrow\end{array}$ & Psrc1 $\downarrow, C d 6 \downarrow$ \\
\hline $\begin{array}{l}\text { miR- } \\
758- \\
3 p \uparrow\end{array}$ & 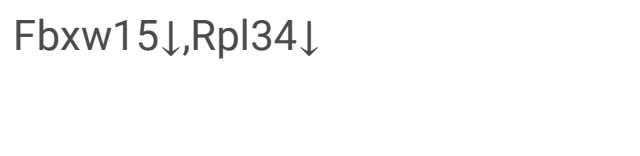 & $\begin{array}{l}\text { miR- } \\
3069- \\
3 p \uparrow\end{array}$ & $\mathrm{Cd} 6 \downarrow, \mathrm{Vmn} 2 \mathrm{r} 51 \downarrow$ \\
\hline $\begin{array}{l}\text { miR- } \\
466 \mathrm{k} \uparrow\end{array}$ & Cd6 $\downarrow$ & $\begin{array}{l}\operatorname{miR}- \\
344 f- \\
3 p \uparrow\end{array}$ & Trhr $\downarrow$ \\
\hline $\begin{array}{l}\operatorname{miR-} \\
466 n- \\
5 p \uparrow\end{array}$ & Pter $\downarrow$ & $\begin{array}{l}\text { miR- } \\
34 \mathrm{~b}- \\
5 \mathrm{p} \uparrow\end{array}$ & Tnni1 $\downarrow, V m n 2 r 30 \downarrow$ \\
\hline $\begin{array}{l}\text { miR- } \\
483- \\
5 p \uparrow\end{array}$ & Trim68 $\downarrow, C d 6 \downarrow$ & $\begin{array}{l}\text { miR- } \\
362- \\
5 p \uparrow\end{array}$ & 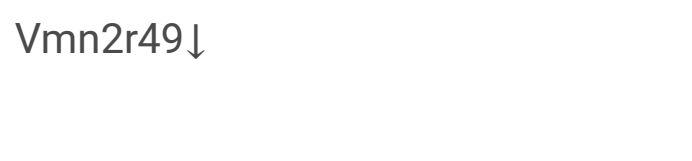 \\
\hline $\begin{array}{l}\text { miR- } \\
532- \\
5 p \uparrow\end{array}$ & Psrc $1 \downarrow, M y b \mid 1 \downarrow \square N p c d \downarrow \square$ Ptchd $4 \downarrow$ & $\begin{array}{l}\operatorname{miR}- \\
378 \mathrm{c} \uparrow\end{array}$ & Сyp2c55」,Krt2 $\downarrow \square T r i m 68 \downarrow \square V m n 2 r 30 \downarrow$ \\
\hline $\begin{array}{l}\text { miR- } \\
700- \\
3 p \uparrow\end{array}$ & Pter $\downarrow, M u c 6 \downarrow$ & $\begin{array}{l}\text { miR- } \\
431- \\
3 p \uparrow\end{array}$ & Bhlhe22 $\downarrow, G r k 1 \downarrow \square C d k n 1 \mathrm{c} \downarrow$ \\
\hline $\begin{array}{l}\operatorname{miR}- \\
665- \\
3 p \uparrow\end{array}$ & Slc25a47\ & $\begin{array}{l}\text { miR- } \\
423- \\
5 p \uparrow\end{array}$ & Bhlhe22 $\downarrow, C d 6 \downarrow$ \\
\hline $\begin{array}{l}\text { Note: } \uparrow \mathrm{i} \\
\text { represer }\end{array}$ & $\begin{array}{l}\text { ates up-regulation in the tissue } \\
\text { own-regulation. }\end{array}$ & m Sus & ible versus Resilient mice, $\downarrow$ \\
\hline
\end{tabular}


Table 9

The changed mRNAs predict target miRNAs in Susceptible versus Resilient

\begin{tabular}{|c|c|c|c|}
\hline Geng Symbol & $\begin{array}{l}\text { The predicted target } \\
\text { miRNAs that match DEGs } \\
\text { in transcriptome * }\end{array}$ & Geng Symbol & $\begin{array}{l}\text { The predicted target miRNAs } \\
\text { that match DEGs in } \\
\text { transcriptome * }\end{array}$ \\
\hline Abhd1 $\uparrow$ & $\begin{array}{l}\operatorname{miR}-199 b-3 p \downarrow \text {, miR-211- } \\
5 p \downarrow\end{array}$ & 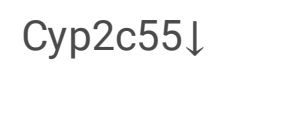 & miR-378c $\uparrow, m i R-202-5 p \uparrow$ \\
\hline Alad $\uparrow$ & 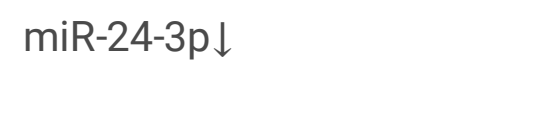 & Tnni1 $\downarrow$ & $\begin{array}{l}\operatorname{miR}-34 b-5 p \uparrow, \text { miR-199a-5p, } \\
\text { miR-27b-5p } \uparrow\end{array}$ \\
\hline Alas $2 \uparrow$ & $\mathrm{miR}-24-3 p \downarrow$ & Scn7a $\downarrow$ & miR-202-5p $\uparrow$ \\
\hline Amd $2 \uparrow$ & miR-541-3p $\downarrow$ & Psrc1 $\downarrow$ & miR-532-5p $\uparrow, m i R-298-5 p \uparrow$ \\
\hline Atp10d $\uparrow$ & $\begin{array}{l}\text { miR-24-3p } \downarrow \text {, miR-199b-3p } \downarrow \\
\text { miR-211-5p } \downarrow\end{array}$ & Slc25a47 $\downarrow$ & miR-665-3p $\uparrow$ \\
\hline Ccr6个 & miR-199b-3p $\downarrow$ & 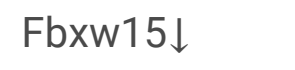 & $\operatorname{miR}-758-3 p \uparrow$ \\
\hline Clspn $\uparrow$ & $\begin{array}{l}\operatorname{miR}-7019-3 p \downarrow \text {, miR-339- } \\
5 p \downarrow\end{array}$ & Krt2 $\downarrow$ & $\operatorname{miR}-378 c \uparrow$ \\
\hline Col6a3 $\uparrow$ & $\begin{array}{l}\text { miR-673-5p } \downarrow, \text { miR-3065- } \\
5 p \downarrow, \text { miR-151-3p } \downarrow\end{array}$ & Mybl1 $\downarrow$ & $\begin{array}{l}\text { miR-532-5p } \uparrow, \text { miR-199a-3p } \uparrow \\
\text { miR-20b-5p }\end{array}$ \\
\hline F630042J09Rik $\uparrow$ & $\operatorname{miR}-378 d \downarrow$ & Trim68\ & miR-378c $\uparrow, m i R-483-5 p \uparrow$ \\
\hline Fam227b $\uparrow$ & $\begin{array}{l}\text { miR-378d } \downarrow \text {, miR-211-5p } \downarrow \\
\text { miR-879-5p } \downarrow\end{array}$ & Bhlhe22 $\downarrow$ & $\begin{array}{l}\text { miR-181c-3p } \uparrow, \text { miR-423-5p } \uparrow \\
\text { miR-431-3p }\end{array}$ \\
\hline Gm16432个 & miR-541-3p $\downarrow$ & Glt8d2\ & miR-93-3p $\uparrow$ \\
\hline Gm9994^ & miR-151-3p $\downarrow$ & Smim24】 & $\operatorname{miR}-199 a-3 p \uparrow$ \\
\hline Gpr139؟ & miR-669c-5p $\downarrow$ & $M s \ln \downarrow$ & miR-187-3p $\uparrow$ \\
\hline Hdhd $3 \uparrow$ & $\mathrm{miR}-467 \mathrm{~h} \downarrow$ & Rpl34」 & miR-758-3p $\uparrow$ \\
\hline LOC100861978 & miR-151-3p $\downarrow$ & 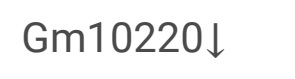 & $\operatorname{miR}-296-3 p \uparrow$ \\
\hline Lpp $\uparrow$ & $\begin{array}{l}\operatorname{miR}-3065-5 p \downarrow, \text { miR-199b- } \\
3 p \downarrow\end{array}$ & Npcd $\downarrow$ & miR-532-5p $\uparrow, m i R-219 a-5 p \uparrow$ \\
\hline 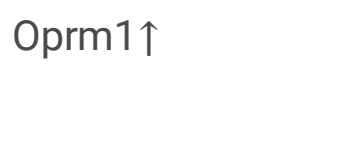 & $\begin{array}{l}\operatorname{miR}-24-3 p \downarrow \text {, miR-541-3p } \downarrow \text {, } \\
\text { miR-7070-3p } \downarrow \text {, miR-879- } \\
5 p \downarrow\end{array}$ & Pter $\downarrow$ & $\begin{array}{l}\text { miR-466n-5p } \uparrow, \text { miR-93-3p } \uparrow \\
\text { miR-700-3p } \uparrow\end{array}$ \\
\hline Pla2g4e $\uparrow$ & miR-24-3p $\downarrow$ & 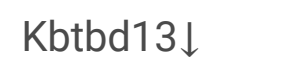 & $\operatorname{miR}-219 b-5 p \uparrow$ \\
\hline 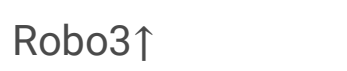 & miR-673-5p $\downarrow$, miR-378d $\downarrow$ & Tmem71』 & miR-187-5p $\uparrow$ \\
\hline
\end{tabular}

Note: $\uparrow$ indicates up-regulation in the tissue of BLA from Susceptible versus Resilient mice, whereas $\downarrow$ represents down-regulation. 


\begin{tabular}{|c|c|c|c|}
\hline Geng Symbol & $\begin{array}{l}\text { The predicted target } \\
\text { miRNAs that match DEGs } \\
\text { in transcriptome * }\end{array}$ & Geng Symbol & $\begin{array}{l}\text { The predicted target miRNAs } \\
\text { that match DEGs in } \\
\text { transcriptome * }\end{array}$ \\
\hline Scube $2 \uparrow$ & miR-339-5p $\downarrow$, miR-211-5p $\downarrow$ & Muc6 $\downarrow$ & 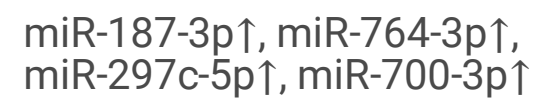 \\
\hline Slc7a15个 & $\mathrm{miR}-467 \mathrm{~h} \downarrow$ & Ehd4 $\downarrow$ & miR-10b-5p $\uparrow,-m i R-187-3 p \uparrow$ \\
\hline Sp140个 & miR-211-5p $\downarrow$ & 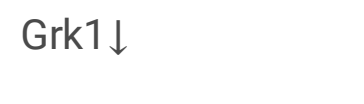 & 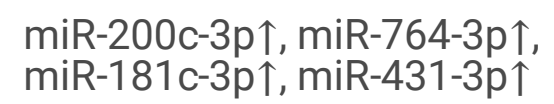 \\
\hline Tagap $\uparrow$ & 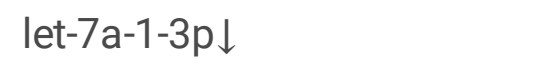 & Trhr $\downarrow$ & miR-344f-3p $\uparrow$ \\
\hline Tgoln2 $2 \uparrow$ & $\operatorname{miR}-24-3 p \downarrow$ & Ptchd4」 & $\operatorname{miR}-532-5 p \uparrow, m i R-19 b-3 p \uparrow$ \\
\hline$V w f \uparrow$ & $\begin{array}{l}\text { miR-673-5p } \downarrow \text {, miR-151-3p } \downarrow \text {, } \\
\text { miR-669c-5p } \downarrow\end{array}$ & Vmn2r49 & miR-362-5p $\uparrow$ \\
\hline Zfp729a $\uparrow$ & miR-7070-3p $\downarrow$ & $\operatorname{Rad54b\downarrow }$ & miR-219b-5p $\uparrow, m i R-210-3 p \uparrow$ \\
\hline 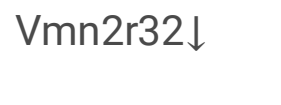 & $\begin{array}{l}\operatorname{miR}-199 a-5 p \uparrow, \text { miR-20b- } \\
5 p \uparrow\end{array}$ & 2610035D17Rik $\downarrow$ & $\operatorname{miR}-187-5 p \uparrow$ \\
\hline Vmn2r30 & $\operatorname{miR}-378 c \uparrow, \operatorname{miR}-34 b-5 p \uparrow$ & Cd6】 & 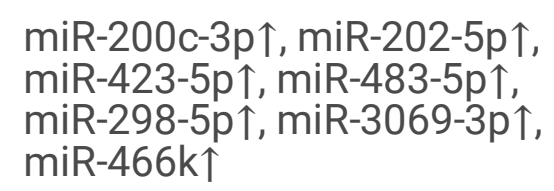 \\
\hline 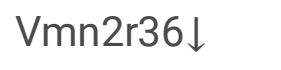 & miR-20b-5p $\uparrow$ & 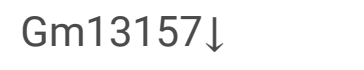 & miR-27b-5p $\uparrow$ \\
\hline Vmn2r47 $\downarrow$ & $\operatorname{miR}-20 b-5 p \uparrow$ & 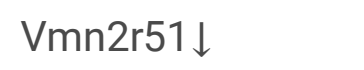 & miR-3069-3p $\uparrow$ \\
\hline 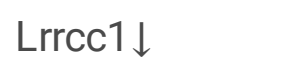 & miR-219b-5p $\uparrow$ & Cdkn1c $\downarrow$ & miR-431-3p $\uparrow$ \\
\hline
\end{tabular}

\section{qRT-PCR to verify microRNA results}

To validate the data by sequencing microRNA analysis, we ran qRT-PCR from amygdala tissues that had been used for microRNA sequencing. we choose 15 microRNAs to conduct qRT-PCR, including miR-451a, miR-34b-5p, miR-34b-3p, miR-211-5p and let-7a-1-3p in Susceptible mice versus Control mice (Fig. 12a), miR-99a-3p, miR-134-5p, miR-532-5p, miR-497a-5p and miR-211-5p in Resilient mice versus Control mice (Fig. 12b) as well as miR-378d, miR-211-5p, miR-24-3p, miR-199a-3p and miR-34b-5p in Susceptible mice versus Resilient mice (Fig. 12c). Consistent to data by high-throughput sequencing, these microRNAs are significantly changed in qRT-PCR analysis from Susceptible mice versus Control mice, Resilient mice versus Control mice as well as Susceptible mice versus Resilient mice (Fig. 12). Their predicted target mRNAs match the altered mRNAs (Tables $4 \sim 9,11,13,15$ ). Consistent results from analyses by microRNA sequencing and qRT-PCR analysis support the validation of our study. 


\section{Tgoln2 and Pla2g4e mRNA are the targets of microRNA-24- $3 p$}

To validate the silicon prediction in Tables $4 \sim 9$, we selected miRNA-24-3p to examine whether it targeted to Tgoln2 and Pla2g4e by qRT-PCR and dual-luciferase reporter assay. The inverse correlations are seen between Tgoln2 and miRNA-24-3p (Fig. 13a) as well as between Pla2g4e and miRNA-24-3p (Fig. 13c) from qRT-PCR analyses. In the dual-luciferase report assay, we constructed luciferase reporter plasmids, which contained the wild-type or the mutant of the predicted binding sites of microRNAs in mRNAs Tgoln2 and Pla2g4e. Such reporter constructs were transfected into HEK293T cells. The relative activities of luciferase reporter for Tgoln2 and Pla2g4e mRNA are significantly lowered by the mimics of miRNA-24$3 p$, but not negative control (Fig. 13b/13d), which are reversed by mutating the binding sites of miRNA24-3p. These results support that Tgoln2 and Pla2g4e mRNA are the direct targets of miRNA-24-3p, which is consistent with our bioinformatics analyses in the prediction of microRNA target genes.

\section{Discussion}

Stress types include physical stress versus psychological stress as well as acute severe stress versus chronic mild stress [31, 32, 48, 55]. After undergoing psychological stress, stressors can be divided into stress susceptibility and stress resilience according to the different effects of stressors' physical and mental health. Susceptible mice exhibit symptoms such as fear memory, anxiety, and depression, whereas resilient mice fail to show these changes $[39,40]$. Identifying the molecular mechanisms that lead some individuals to become susceptible to stress and others resilient is essential for developing effective treatments and, ultimately, preventing the emergence of fear of memory and anxiety [56]. In the present study, we focus on analyzing mRNA and microRNA profiles in the amygdala from the mice treated by psychological stress.

Susceptible mice compared to Resilient mice, the upregulated genes related to synapse elements in the amygdala include Oprm1, Vwf, Col6a3, Sv2c and Trhr, encode structural proteins of building up Peptide, Thyrotropin-releasing hormone and ECM receptors. The downregulated genes related to synapse elements in the amygdala include Scn7a, encodes structural proteins of building up Adrenergic synapse. The upregulated genes related to signaling pathways of regulating synapses in the amygdala include Pla2g4e, encodes structural proteins of building up Serotonergic and Glutamatergic synapses. The downregulated genes related to signaling pathways of regulating synapses in the amygdala include Cyp2c55, encodes structural proteins of building up Serotonergic synapse. In terms of the signaling pathways that regulate synapse functions, the downregulated genes in the amygdala include Grk1, Rac3 and Cd86, encode Chemokine, VEGF, Fc epsilon RI, Ras, MAPK, Wnt, Sphingolipid, B cell receptor, cAMP, Rap1, Toll-like receptor and Axon guidance signaling pathways. On the other hand, the upregulated genes include Ccr1, Ccr6, Oprm1, Trhr, Ccl9, Pla2g4e, Vwf, Col6a3, Robo3 and Eno1b, encode Chemokine, VEGF, Fc epsilon RI, Ras, MAPK, PI3K-Akt, Oxytocin, GnRH, HIF-1, Estrogen, Calcium and Axon guidance signaling pathways. Also in Cell adhesion molecules, the downregulated genes include Cd6 and Cd86, the 
upregulated genes include LOC547349 and H2-T10, encode Immune system. In Inflammatory mediator regulation of TRP channels, the downregulated genes include Cyp2c55, the upregulated genes include Pla2g4e, encode Inflammatory mediator. In Adherens junction, the downregulated genes include Rac3. In Cytokine-cytokine receptor interaction, the upregulated genes include Ccr1, Ccr6, LOC100861978 and Cc19. In Long-term depression, the upregulated genes include Pla2g4e. In Cytosolic DNA-sensing pathway, the downregulated genes include Trex1. The data indicate that the upregulation of Peptide, Thyrotropinreleasing hormone and ECM receptor, Glutamatergic synapse, Cytokine-cytokine receptor interaction, Long-term depression, PI3K-Akt, Oxytocin, GnRH, HIF-1, Estrogen, Calcium signaling pathways in the amygdala may be related to psychological stress-induced susceptibility, and the downregulation may be related to resilience. The downregulation of Adrenergic synapse, Adherens junction, Wnt, Sphingolipid, B cell receptor, cAMP, Rap1, Toll-like receptor signaling pathways in the amygdala may be related to psychological stress-induced susceptibility, and the upregulation may be related to resilience.

In addition to analyzing the downregulation or upregulation of gene expression in specific signaling pathways, the imbalanced expression of genes in signaling pathways may be related to susceptibility and resilience. The data show that except for the expression of all genes in some signal pathways are downregulated or upregulated, genes in other signal pathways are partially upregulated and partially downregulated. For example, Serotonergic synapse, Cell adhesion molecules, Inflammatory mediator regulation of TRP channels, Chemokine, VEGF, Fc epsilon RI, Ras, MAPK, Axon guidance signaling pathways, this imbalanced expression may play a role in susceptibility caused by psychological stress. In the amygdala brain region, the expression of some genes in some signaling pathways is upregulated and the expression of other genes is downregulated in psychologically stressed mice, indicating that the molecular regulatory network in these pathways is imbalanced. In other words, the upregulation and downregulation of gene expression between multiple signaling pathways and in a single signaling pathway imbalances the molecular regulatory network within the amygdala, resulting in neuronal dysfunction in the amygdala. In summary, the upregulated genes of encoding synapse elements may strengthen the formation and transmission of synapses for susceptibility. The imbalance of signaling pathways may be involved in susceptibility.

In terms of the validation of our study and result, after the high throughput sequencing of mRNAs and microRNAs, We verified some mRNAs and microRNAs with qRT-PCR and analyzed the interaction between mRNAs and microRNAs. Our results indicate that the changed expression of mRNAs matches the changed expression of microRNAs well in high-throughput sequencing(Tables $4 \sim 9$ ). Some genes with their altered expressions in high throughput sequencing have been confirmed by qRT-PCR analysis (Fig. 6 $\sim 8$ and 12). Furthermore, dual-luciferase report analysis has confirmed direct interactions between mRNA Tgoln2 and miRNA-24p-3p as well as between Pla2g4e and miRNA-24p-3p (Fig. 13). In a word, we are confident in our results, because is better than previous analyses in either microRNAs or mRNAs.

To the best of our knowledge, no study has yet reported an association between Tgoln2(Pla2g4e) and susceptibility. The research report shows, Tgoln2 encodes a transmembrane protein primarily localized to the trans-Golgi network (TGN), an important protein sorting station in the cell [57]. Tgoln2 is of particular 
interest because it was identified in a microarray expression study as having a consistently up-regulated expression pattern in the brains of suicide completers as compared to controls [58]. Pla2g4e belongs to cytosolic phospholipase A2 (cPLA2), which selectively catalyzes the hydrolysis of the sn-2 site of the glycerol portion of the membrane phospholipid to break the ester bond [59]. It is considered to be related to neural structure and function, a neurobehavioral disorder in research [60]. Some literature suggests that this gene may be a risk gene for panic disorder [61], there is also some literature indicating that there is a certain relationship between the occurrence of depression [62]. Cytosolic phospholipase A2 is closely related to axonal proliferation and excitotoxic damage under pathological conditions [63]. Various pathological changes in CNS disease lead to increased expression of CPLA2 and increased activity [63]. CPLA2 is involved in oxidative stress and inflammatory response in a variety of neurodegenerative diseases [62]. In normal brain cells, PLA2 regulation achieves a balance between the conversion of arachidonic acid to a pro-inflammatory mediator and reintegration into the membrane. Without strictly regulating PLA2 activity, a disproportionate pro-inflammatory mediator is produced. The resulting induced oxidative stress and neuroinflammation are similar to neurological diseases such as Alzheimer's disease, epilepsy, etc. [59, 63].

We found the changes of certain genes have not been observed in previous analyses[64-67], including Oprm1, Vwf, Col6a3, Sv2c, Trhr, Scn7a, Pla2g4e, Cyp2c55, Grk1, Rac3, Cd86, Ccr1, Ccr6, Ccl9, Robo3, Eno1b, Cd6, LOC547349, H2-T10, LOC100861978 and Trex1. The changes in the expression of these genes in the amygdala may be due to susceptibility and resilience.

\section{Conclusions}

We paid attention to analyze and compare the profiles of mRNA and microRNAs in the amygdala from Susceptible and Resilient mice, which helps to figure out molecules that are involved in susceptibility and resilience. Susceptible and Resilient induced by psychological stresses are caused by the imbalanced regulation of different synapses and signaling pathways in the amygdala. Therefore, studying the molecular expression profile in the amygdala of psychologically stressed mice can help understand the role of the amygdala in stress-induced susceptibility and resilience, and new targets can be found in the amygdala brain area that can be used to treat stress disorders.

\section{Abbreviations}

CAMP

Cyclic adenosine monophosphate

CRPs

Complex Regional Pain syndrome

ECM

Extracellular Matrix

GABAergic

$\mathrm{Y}$-aminobutyrate 
GnRH

Gonadotropin Releasing Hormone

HIF-1

Hypoxia Inducible Factor-1

IL-1 $\beta$

Interleukin-1 $\beta$

IL-6

Interleukin-6

IL-10

Interleukin-10

MAPK

Mitogen Activated Protein Kinase

MDD

Major Depressive Disorder

NF-kappa B

Nuclear Factor-kappa B

PTSD

Post-Traumatic Stress Disorder

TNF

Tumor Necrosis Factor-

TRP

Transient Receptor Potential

VEGF

Vascular Endothelial Growth Factor

\section{Declarations}

\section{Ethics approval and consent to participate}

All procedures were carried out under an approved Home Office project license (number PPL 80/2578) and in accordance with the Animals (Scientific Procedures) Act, 1986 (UK) (amended 2013).

\section{Consent for publication}

Not applicable

\section{Availability of data and materials}

The datasets supporting the conclusions of this article are included within the article and its additional files. 
The authors declare that they have no competing interests.

\section{Funding}

This work was supported by Natural Science Foundation in Shandong China [ZR2017BC067] to Wei Lu; Natural Science Foundation in Shandong China [ZR2017BC033] and National Natural Science Foundation in China [31801953 and 31701073] to Zhenhua Song. These funding were role in the analysis of data and in writing the manuscript. This work was also supported by the National Key R\&D Program of China [2016YFC1307101] and Natural Science Foundation in China [81671071 and 81471123] to Jin-Hui Wang. These funding were role in the design of the study and in the collection of data. Zhenhua Song contributed to experiments and data analyses. Wei Lu and Jin-Hui Wang contributed to concept, project design and paper writing.

\section{Authors' contributions}

JYS, YJL, JYY and ZHS contributed to experiments and data analyses. WL and JHW contributed to concept, project design and paper writing. All authors read and approved the final manuscript.

\section{Acknowledgements}

Not applicable

\section{References}

1. Swaab DF, Bao AM, and Lucassen PJ. The stress system in the human brain in depression and neurodegeneration. Ageing Res Rev. 2005;4:141-94.

2. Bremner JD, Elzinga B, Schmahl C, and Vermetten E. Structural and functional plasticity of the human brain in posttraumatic stress disorder. Prog Brain Res. 2008;167:171-86.

3. Heim C, Newport DJ, Mletzko T, Miller AH, and Nemeroff CB. The link between childhood trauma and depression: insights from HPA axis studies in humans. Psychoneuroendocrinology. 2008;33:693-710.

4. Risch N, Herrell R, Lehner T, Liang KY, Eaves L, Hoh J, et al. Interaction between the serotonin transporter gene (5-HTTLPR), stressful life events, and risk of depression: a meta-analysis. JAMA. 2009;301:2462-71.

5. Mitra R, Jadhav S, McEwen BS, Vyas A, and Chattarji S. Stress duration modulates the spatiotemporal patterns of spine formation in the basolateral amygdala. Proc Natl Acad Sci U S A. 2005;102:9371-6.

6. Pryce CR, Aubert Y, Maier C, Pearce PC, and Fuchs E. The developmental impact of prenatal stress, prenatal dexamethasone and postnatal social stress on physiology, behaviour and neuroanatomy of primate offspring: studies in rhesus macaque and common marmoset. Psychopharmacology (Berl). 2011;214:33-53. 
7. Sinclair D, Fullerton JM, Webster MJ, and Weickert CS. Glucocorticoid Receptor 1B and 1C mRNA Transcript Alterations in Schizophrenia and Bipolar Disorder, and Their Possible Regulation by GR Gene Variants. Plos One. 2012;7.

8. Sinclair D, Tsai SY, Woon HG, and Weickert CS. Abnormal glucocorticoid receptor mRNA and protein isoform expression in the prefrontal cortex in psychiatric illness. Neuropsychopharmacology. 2011;36:2698-709.

9. Lucassen PJ, Pruessner J, Sousa N, Almeida OF, Van Dam AM, Rajkowska G, et al. Neuropathology of stress. Acta Neuropathol. 2014;127:109-35.

10. Joels $M$, Sarabdjitsingh RA, and Karst $H$. Unraveling the time domains of corticosteroid hormone influences on brain activity: rapid, slow, and chronic modes. Pharmacol Rev. 2012;64:901-38.

11. Herman JP, Figueiredo H, Mueller NK, Ulrich-Lai Y, Ostrander MM, Choi DC, et al. Central mechanisms of stress integration: hierarchical circuitry controlling hypothalamo-pituitary-adrenocortical responsiveness. Front Neuroendocrinol. 2003;24:151-80.

12. Tasker JG and Herman JP. Mechanisms of rapid glucocorticoid feedback inhibition of the hypothalamic-pituitary-adrenal axis. Stress. 2011;14:398-406.

13. de Kloet ER, Joels M, and Holsboer F. Stress and the brain: from adaptation to disease. Nat Rev Neurosci. 2005;6:463-75.

14. Lucassen PJ, Heine VM, Muller MB, van der Beek EM, Wiegant VM, De Kloet ER, et al. Stress, depression and hippocampal apoptosis. CNS Neurol Disord Drug Targets. 2006;5:531-46.

15. Holsboer F. The corticosteroid receptor hypothesis of depression. Neuropsychopharmacology. 2000;23:477-501.

16. Grigoruta M, Martinez-Martinez A, Dagda RY, and Dagda RK. Psychological Stress Phenocopies Brain Mitochondrial Dysfunction and Motor Deficits as Observed in a Parkinsonian Rat Model. Mol Neurobiol. 2019.

17. Grigoruta M, Vargas-Caraveo A, Vazquez-Mayorga E, Castillo-Michel HA, Diaz-Sanchez AG, ReyesHerrera J, et al. Blood mononuclear cells as speculum of emotional stress analyzed by synchrotron infrared spectroscopy and a nootropic drug. Spectrochim Acta A Mol Biomol Spectrosc. 2018;204:475-483.

18. Du K, Lu W, Sun Y, Feng J, and Wang JH. mRNA and miRNA profiles in the nucleus accumbens are related to fear memory and anxiety induced by physical or psychological stress. J Psychiatr Res. 2019;118:44-65.

19. Sun Y, Lu W, Du K, and Wang JH. microRNA and mRNA profiles in the amygdala are relevant to fear memory induced by physical or psychological stress. J Neurophysiol. 2019;122:1002-1022.

20. LeDoux JE. Emotion circuits in the brain. Annu Rev Neurosci. 2000;23:155-84.

21. Prakash N, Stark CJ, Keisler MN, Luo L, Der-Avakian A, and Dulcis D. Serotonergic plasticity in the dorsal raphe nucleus characterizes susceptibility and resilience to anhedonia. J Neurosci. 2019.

22. Davis M and Whalen PJ. The amygdala: vigilance and emotion. Mol Psychiatry. 2001;6:13-34. 
23. Davis $M$, Rainnie $D$, and Cassell M. Neurotransmission in the rat amygdala related to fear and anxiety. Trends Neurosci. 1994;17:208-14.

24. Hatfield T and McGaugh JL. Norepinephrine infused into the basolateral amygdala posttraining enhances retention in a spatial water maze task. Neurobiol Learn Mem. 1999;71:232-9.

25. Ferry B, Roozendaal B, and McGaugh JL. Basolateral amygdala noradrenergic influences on memory storage are mediated by an interaction between beta- and alpha1-adrenoceptors. J Neurosci. 1999;19:5119-23.

26. Brioni JD, Nagahara AH, and McGaugh JL. Involvement of the amygdala GABAergic system in the modulation of memory storage. Brain Res. 1989;487:105-12.

27. Campolongo P, Roozendaal B, Trezza V, Hauer D, Schelling G, McGaugh JL, et al. Endocannabinoids in the rat basolateral amygdala enhance memory consolidation and enable glucocorticoid modulation of memory. Proc Natl Acad Sci U S A. 2009;106:4888-93.

28. Roozendaal B and McGaugh JL. Glucocorticoid receptor agonist and antagonist administration into the basolateral but not central amygdala modulates memory storage. Neurobiology of Learning and Memory. 1997;67:176-179.

29. Donley MP, Schulkin J, and Rosen JB. Glucocorticoid receptor antagonism in the basolateral amygdala and ventral hippocampus interferes with long-term memory of contextual fear. Behavioural Brain Research. 2005;164:197-205.

30. Shen MM, Song ZH, and Wang JH. microRNA and mRNA profiles in the amygdala are associated with stress-induced depression and resilience in juvenile mice. Psychopharmacology. 2019;236:21192142.

31. Si YW, Song ZH, Sun XY, and Wang JH. microRNA and mRNA profiles in nucleus accumbens underlying depression versus resilience in response to chronic stress. American Journal of Medical Genetics Part B-Neuropsychiatric Genetics. 2018;177:563-579.

32. Sun XY, Song ZH, Si YW, and Wang JH. microRNA and mRNA profiles in ventral tegmental area relevant to stress-induced depression and resilience. Progress in Neuro-Psychopharmacology \& Biological Psychiatry. 2018;86:150-165.

33. Janak PH and Tye KM. From circuits to behaviour in the amygdala. Nature. 2015;517:284-92.

34. van den Bulk BG, Meens PH, van Lang ND, de Voogd EL, van der Wee NJ, Rombouts SA, et al. Amygdala activation during emotional face processing in adolescents with affective disorders: the role of underlying depression and anxiety symptoms. Front Hum Neurosci. 2014;8:393.

35. Muhie S, Gautam A, Chakraborty N, Hoke A, Meyerhoff J, Hammamieh R, et al. Molecular indicators of stress-induced neuroinflammation in a mouse model simulating features of post-traumatic stress disorder. Transl Psychiatry. 2017;7:e1135.

36. Muscatell KA, Dedovic K, Slavich GM, Jarcho MR, Breen EC, Bower JE, et al. Greater amygdala activity and dorsomedial prefrontal-amygdala coupling are associated with enhanced inflammatory responses to stress. Brain Behav Immun. 2015;43:46-53. 
37. Swartz JR, Prather AA, and Hariri AR. Threat-related amygdala activity is associated with peripheral CRP concentrations in men but not women. Psychoneuroendocrinology. 2017;78:93-96.

38. Li K, Yan L, Zhang Y, Yang Z, Zhang C, Li Y, et al. Seahorse treatment improves depression-like behavior in mice exposed to CUMS through reducing inflammation/oxidants and restoring neurotransmitter and neurotrophin function. J Ethnopharmacol. 2019;250:112487.

39. Berton O, McClung CA, Dileone RJ, Krishnan V, Renthal W, Russo SJ, et al. Essential role of BDNF in the mesolimbic dopamine pathway in social defeat stress. Science. 2006;311:864-8.

40. Krishnan V, Han MH, Graham DL, Berton O, Renthal W, Russo SJ, et al. Molecular adaptations underlying susceptibility and resistance to social defeat in brain reward regions. Cell. 2007;131:391404.

41. Karatsoreos IN and McEwen BS. Annual Research Review: The neurobiology and physiology of resilience and adaptation across the life course. J Child Psychol Psychiatry. 2013;54:337-47.

42. Bjorkqvist K. Social defeat as a stressor in humans. Physiology \& Behavior. 2001;73:435-442.

43. Hammels C, Pishva E, De Vry J, van den Hove DLA, Prickaerts J, van Winkel R, et al. Defeat stress in rodents: From behavior to molecules. Neuroscience \& Biobehavioral Reviews. 2015;59:111-140.

44. Martinez M, Calvo-Torrent A, and Pico-Alfonso MA. Social defeat and subordination as models of social stress in laboratory rodents: A review. Aggressive Behavior. 1998;24:241-256.

45. Tsankova NM, Berton O, Renthal W, Kumar A, Neve RL, and Nestler EJ. Sustained hippocampal chromatin regulation in a mouse model of depression and antidepressant action. Nature Neuroscience. 2006;9:519-525.

46. Vasconcelos M, Stein DJ, and de Almeida RMM. Social defeat protocol and relevant biomarkers, implications for stress response physiology, drug abuse, mood disorders and individual stress vulnerability: a systematic review of the last decade. Trends in Psychiatry and Psychotherapy. 2015;37:51-66.

47. Ma K, Guo L, Xu A, Cui S, and Wang JH. Molecular Mechanism for Stress-Induced Depression Assessed by Sequencing miRNA and mRNA in Medial Prefrontal Cortex. PLoS One. 2016;11:e0159093.

48. Ma K, Xu A, Cui S, Sun MR, Xue YC, and Wang JH. Impaired GABA synthesis, uptake and release are associated with depression-like behaviors induced by chronic mild stress. Transl Psychiatry. 2016;6:e910.

49. Smoller J. The Genetics of Stress-Related Disorders: PTSD, Depression and Anxiety Disorders. Neuropsychopharmacology : official publication of the American College of Neuropsychopharmacology. 2016;41.

50. Golden SA, Covington HE, 3rd, Berton O, and Russo SJ. A standardized protocol for repeated social defeat stress in mice. Nat Protoc. 2011;6:1183-91.

51. Kilkenny C, Browne WJ, Cuthill IC, Emerson M, and Altman DG. Improving bioscience research reporting: the ARRIVE guidelines for reporting animal research. PLoS Biol. 2010;8:e1000412. 
52. Love MI, Huber W, and Anders S. Moderated estimation of fold change and dispersion for RNA-seq data with DESeq2. Genome Biol. 2014;15:550.

53. Friedlander MR, Mackowiak SD, Li N, Chen W, and Rajewsky N. miRDeep2 accurately identifies known and hundreds of novel microRNA genes in seven animal clades. Nucleic Acids Research. 2012;40:37-52.

54. Friedlander M, Lizano E, Houben A, Bezdan D, Bañez-Coronel M, Kudla G, et al. Evidence for the biogenesis of more than 1,000 novel human microRNAs. Genome biology. 2014;15:R57.

55. Liu B, Feng J, and Wang JH. Protein kinase $\mathrm{C}$ is essential for kainate-induced anxiety-related behavior and glutamatergic synapse upregulation in prelimbic cortex. CNS Neurosci Ther. 2014;20:982-90.

56. Muir J, Lorsch ZS, Ramakrishnan C, Deisseroth K, Nestler EJ, Calipari ES, et al. In Vivo Fiber Photometry Reveals Signature of Future Stress Susceptibility in Nucleus Accumbens. Neuropsychopharmacology. 2018;43:255-263.

57. Ponnambalam S, Girotti M, Yaspo ML, Owen CE, Perry AC, Suganuma T, et al. Primate homologues of rat TGN38: primary structure, expression and functional implications. J Cell Sci. 1996;109 ( Pt 3):675-85.

58. Sequeira A, Gwadry FG, Ffrench-Mullen JM, Canetti L, Gingras Y, Casero RA, Jr., et al. Implication of SSAT by gene expression and genetic variation in suicide and major depression. Arch Gen Psychiatry. 2006;63:35-48.

59. Desbene C, Malaplate-Armand C, Youssef I, Garcia P, Stenger C, Sauvee M, et al. Critical role of cPLA2 in Abeta oligomer-induced neurodegeneration and memory deficit. Neurobiol Aging. 2012;33:1123 e17-29.

60. Everson TM, Marsit CJ, Michael O'Shea T, Burt A, Hermetz K, Carter BS, et al. Epigenome-wide Analysis Identifies Genes and Pathways Linked to Neurobehavioral Variation in Preterm Infants. Sci Rep. 2019;9:6322.

61. Morimoto Y, Shimada-Sugimoto M, Otowa T, Yoshida S, Kinoshita A, Mishima H, et al. Whole-exome sequencing and gene-based rare variant association tests suggest that PLA2G4E might be a risk gene for panic disorder. Transl Psychiatry. 2018;8:41.

62. Ohto T, Uozumi N, Hirabayashi T, and Shimizu T. Identification of novel cytosolic phospholipase $A(2)$ s, murine $\operatorname{cPLA}(2)\{d e l t a\},\{e p s i l o n\}$, and \{zeta\}, which form a gene cluster with cPLA(2)\{beta\}. J Biol Chem. 2005;280:24576-83.

63. Sun GY, Shelat PB, Jensen MB, He Y, Sun AY, and Simonyi A. Phospholipases A2 and inflammatory responses in the central nervous system. Neuromolecular Med. 2010;12:133-48.

64. Cestari V, Rossi-Arnaud C, Saraulli D, and Costanzi M. The MAP(K) of fear: From memory consolidation to memory extinction. Brain Research Bulletin. 2014;105:8-16.

65. Johansen Joshua P, Cain Christopher K, Ostroff Linnaea E, and LeDoux Joseph E. Molecular Mechanisms of Fear Learning and Memory. Cell. 2011;147:509-524. 
66. Kyrke-Smith M and Williams JM. Bridging Synaptic and Epigenetic Maintenance Mechanisms of the Engram. Front Mol Neurosci. 2018;11:369.

67. Otis JM, Werner CT, and Mueller D. Noradrenergic regulation of fear and drug-associated memory reconsolidation. Neuropsychopharmacology. 2015;40:793-803.

\section{Figures}
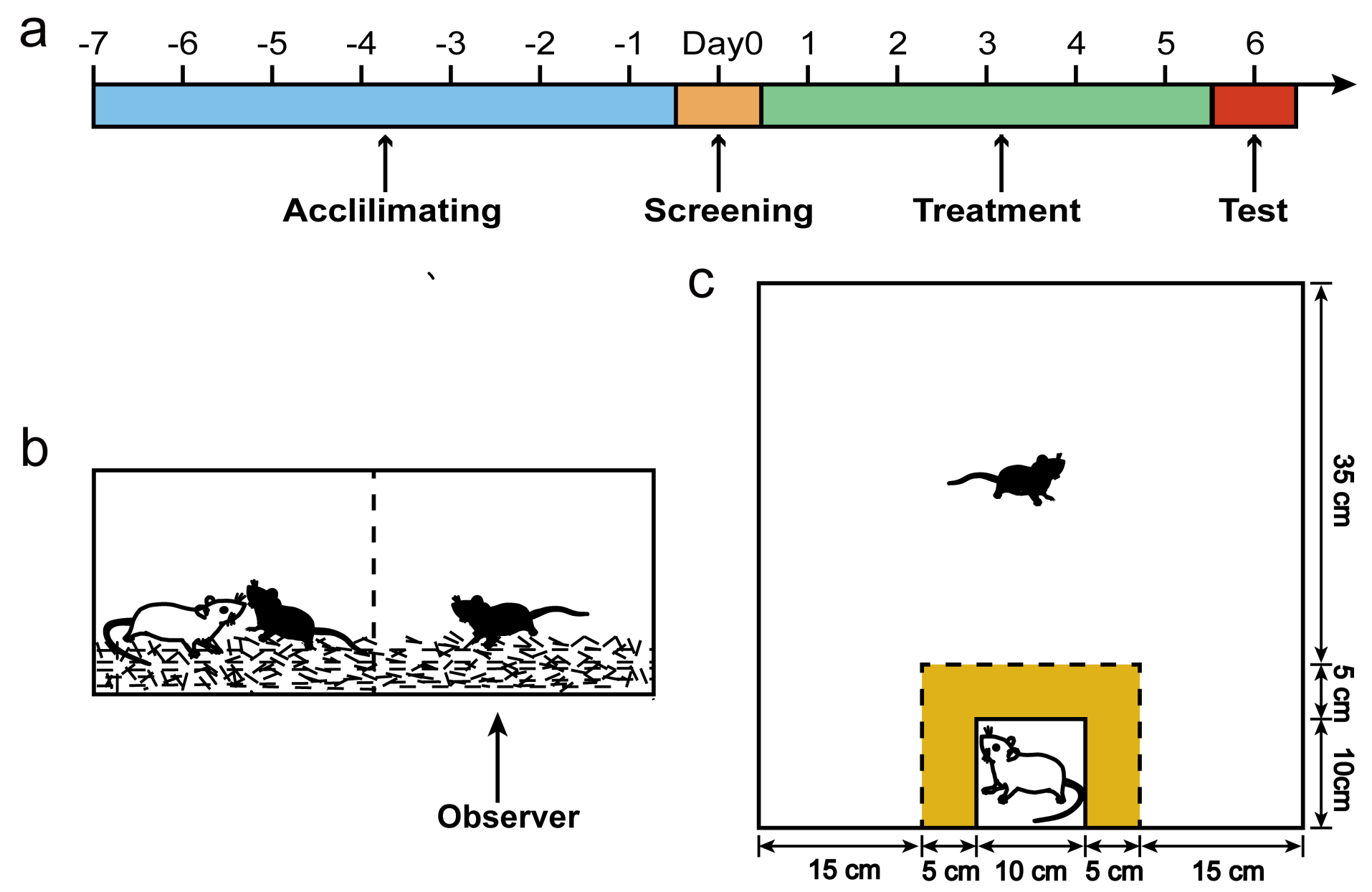

Figure 1

Psychological stress-induced social frustration and evasion detection in Susceptible mice and Resilient mice. a Seven days after acclimation, the elevated cross-maze detection and social avoidance detection were used to screen $\mathrm{C} 57$ mice before psychological stress treatment. Then, five consecutive days of psychological stress experiments were performed, one in the morning and one in the afternoon. The elevated cross-maze test and social avoidance test were used again to detect anxiety and fear memory in C57 mice, followed by genetic sequencing. $b$ The same kind of $C 57$ mice were placed in the CD1 cage. The observe mice were placed in the cage next to the CD1 cage. When the observe mice were able to observe the aggressive behavior of CD1 mice through the transparent partition, psychological stress was generated. c Social avoidance detection is performed in an interactive social area $(50 * 50 \mathrm{~cm})$, with 10 * 
$10 \mathrm{~cm}$ transparent and perforated small cages on the edges. The area around the small cage is defined as the communication area.
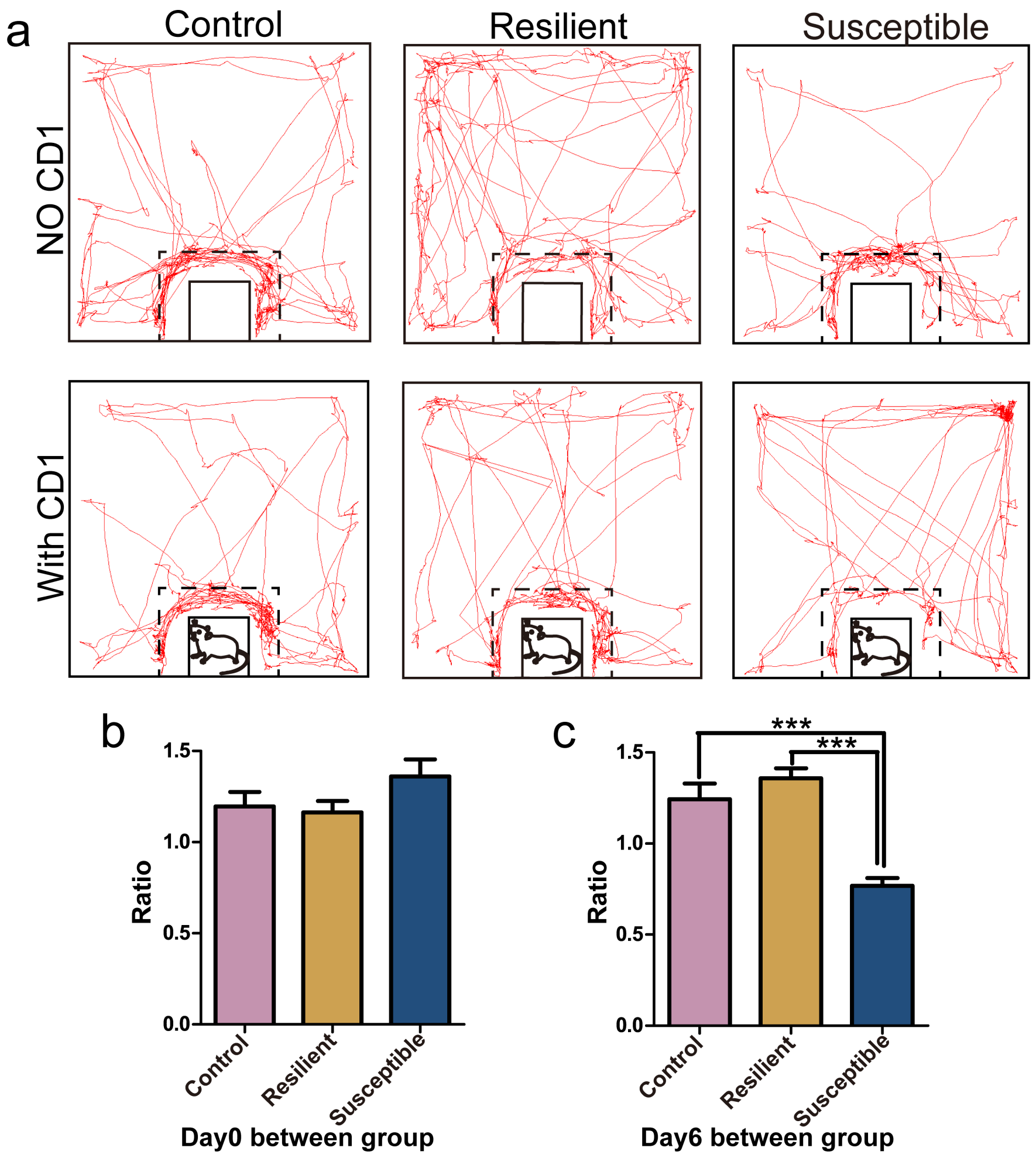

Figure 2

Results of social avoidance test in mice after psychological stress treatment. Control $n=15$, Resilient $n=13$, Susceptible $n=10$. a shows the movement trajectories of the Control, Resilient and Susceptible mice in the open field with and without CD1 on day 6 . b shows the ratio (\%) of the residence time of the 
Control, Resilient and Susceptible mice on the 0th days in the communication area when there is a CD1 attacker in the small container and when there is no CD1 attacker. c shows the ratio (\%) of the residence time of the Control, Resilient and Susceptible mice on the 6th days in the communication area when there is a CD1 attacker in the small container and when there is no CD1 attacker. One-way ANOVA was used for the comparisons among Control, Resilient and Susceptible mice, while three asterisks show $p<0.001$, two asterisks show $p<0.01$, one asterisk show $p<0.05$.
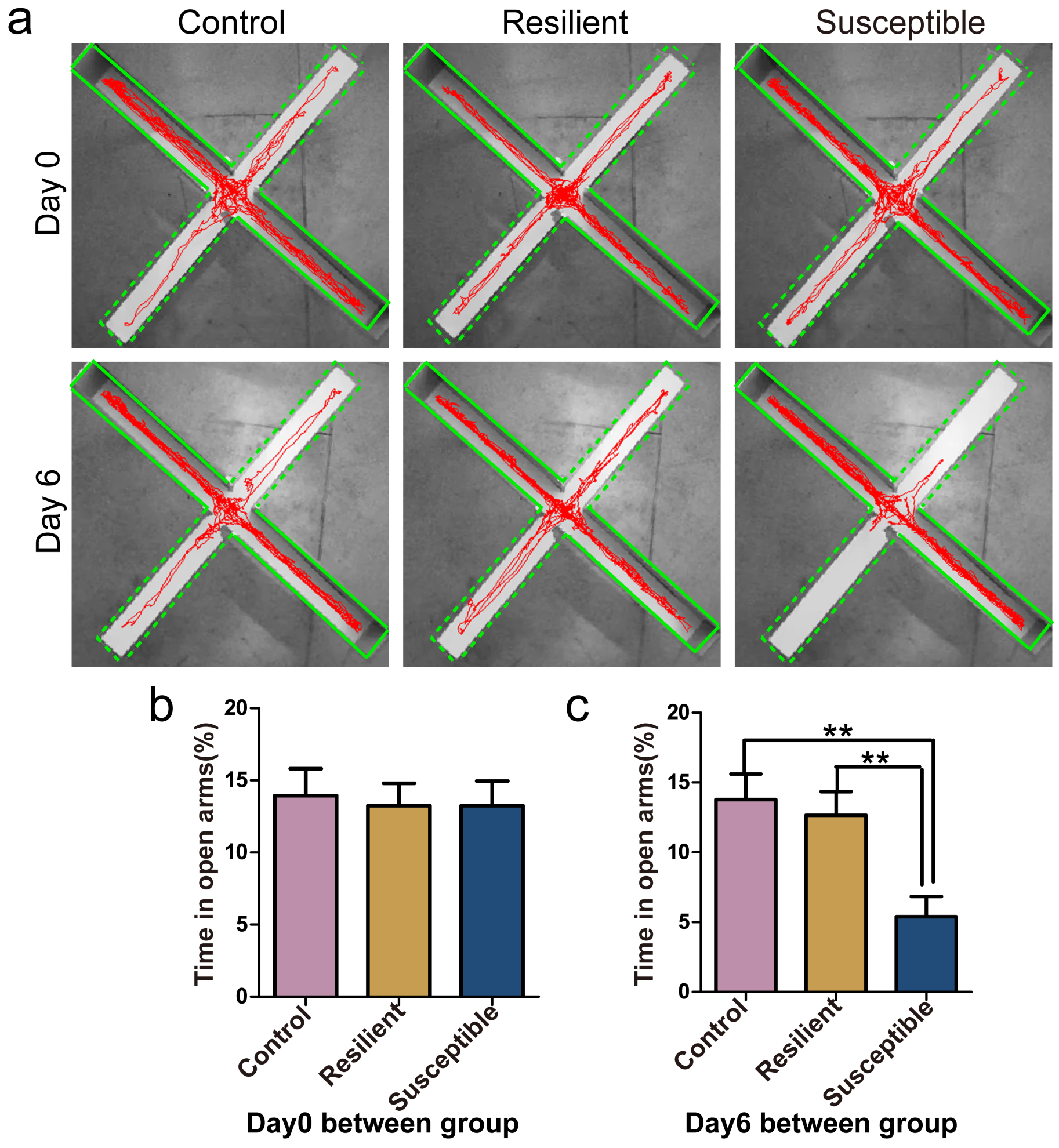

Figure 3 
Test results of the elevated cross labyrinth of mice after psychological stress treatment. Control $n=15$, Resilient $n=13$, Susceptible $n=10$. a shows the motion trajectories of the Control, Resilient and Susceptible mice before the psychological stress (day 0 ) and after the psychological stress (day 6) on the elevated cross-maze. b shows the time (\%) of the Control, Resilient and Susceptible mice in the open zone on day 0 , and there was no significant difference between groups on day 0. c shows the time (\%) of the Control, Resilient and Susceptible mice in the open area on day 6. One-way ANOVA was used for the comparisons among Control, Resilient and Susceptible mice, while two asterisks show $p<0.01$.
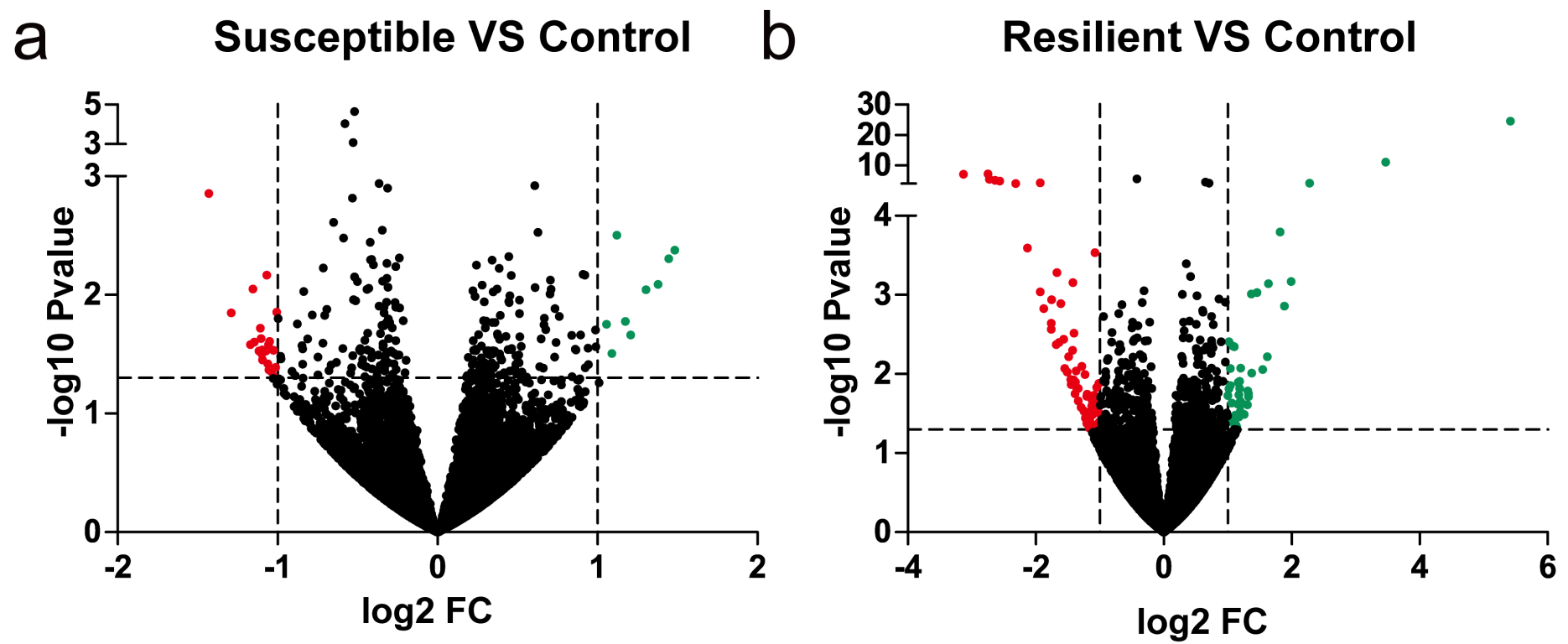

\section{Susceptible VS Resilient}

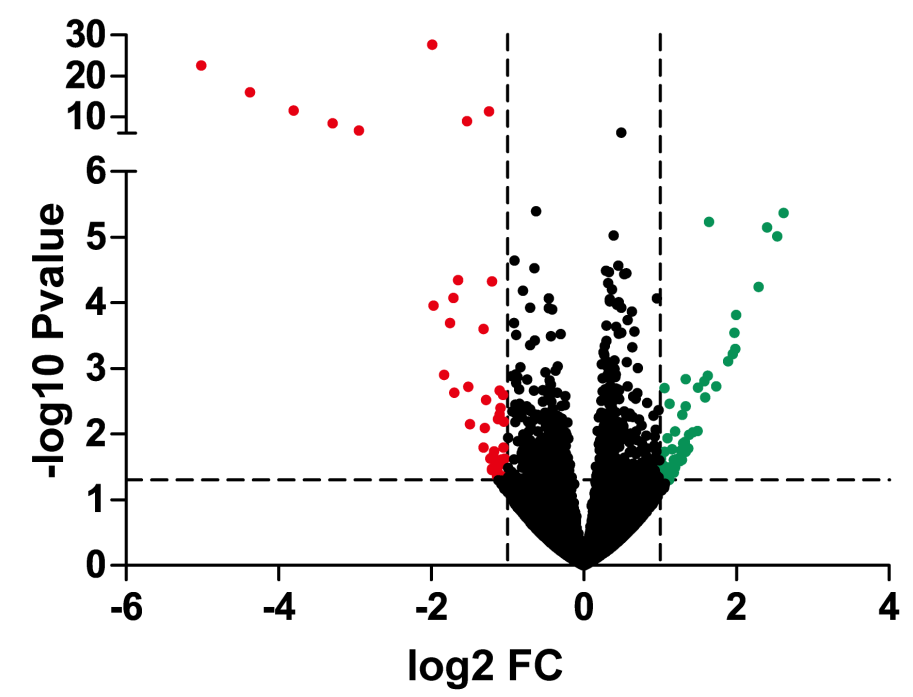

Figure 4

Volcano plot for mRNA differential expression analysis. a shows the Volcano plot for amygdala mRNA differential expression analysis in Susceptible and Control mice. b shows the Volcano plot for amygdala mRNA differential expression analysis in Resilient and Control mice. c shows the Volcano plot for amygdala mRNA differential expression analysis in Susceptible and Resilient mice. Red indicates that the 
gene is down-regulated more than 2 times and $P$ value is less than 0.05 . Green indicates that the gene is up-regulated more than 2 times and $P$ value is less than 0.05 .

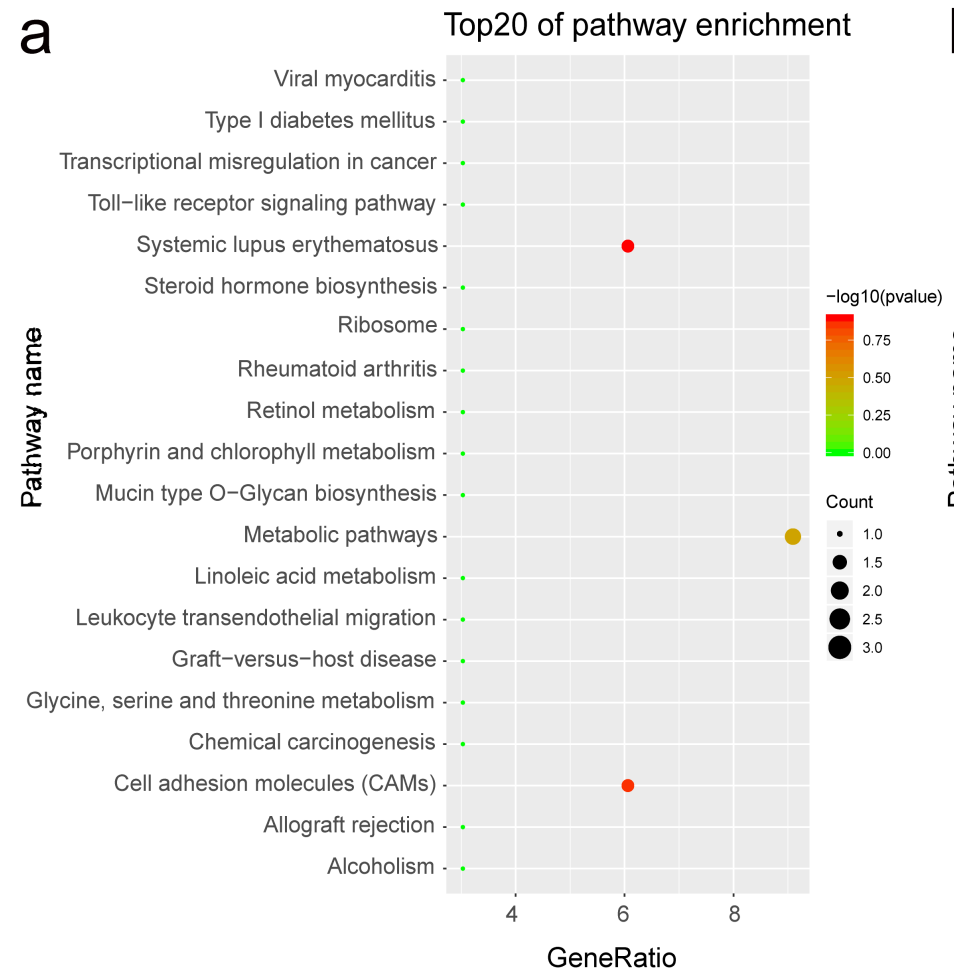

b Top20 of pathway enrichment

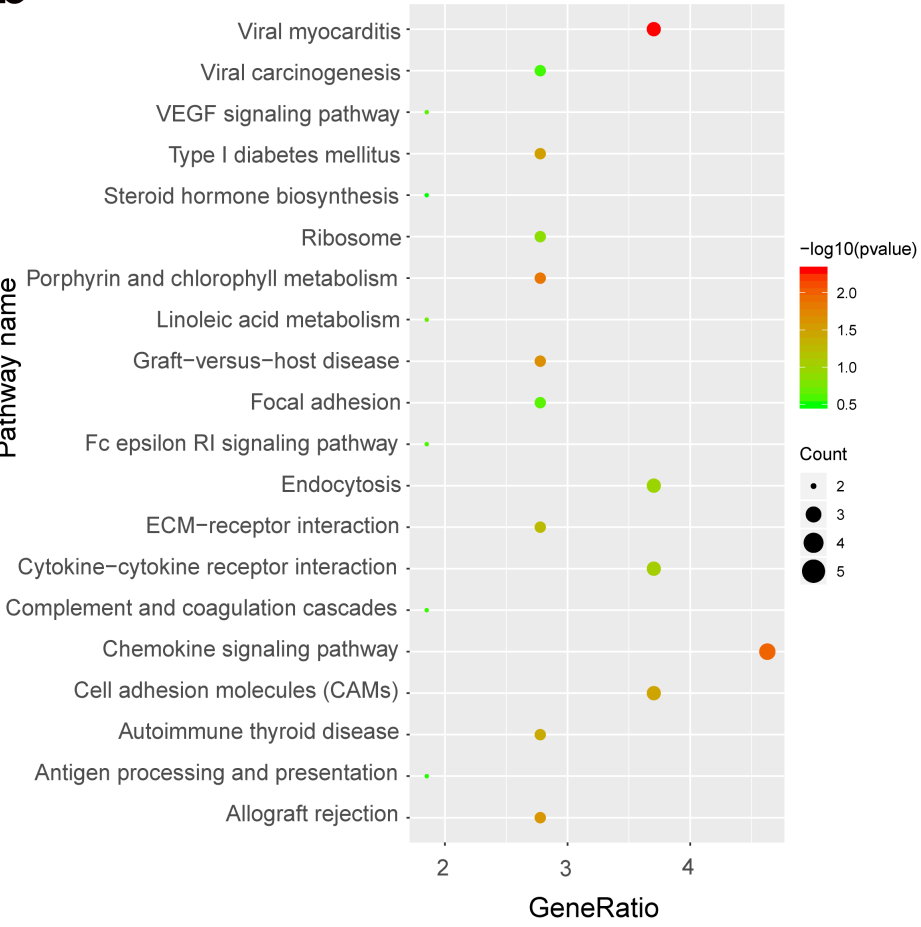

C Top20 of pathway enrichment

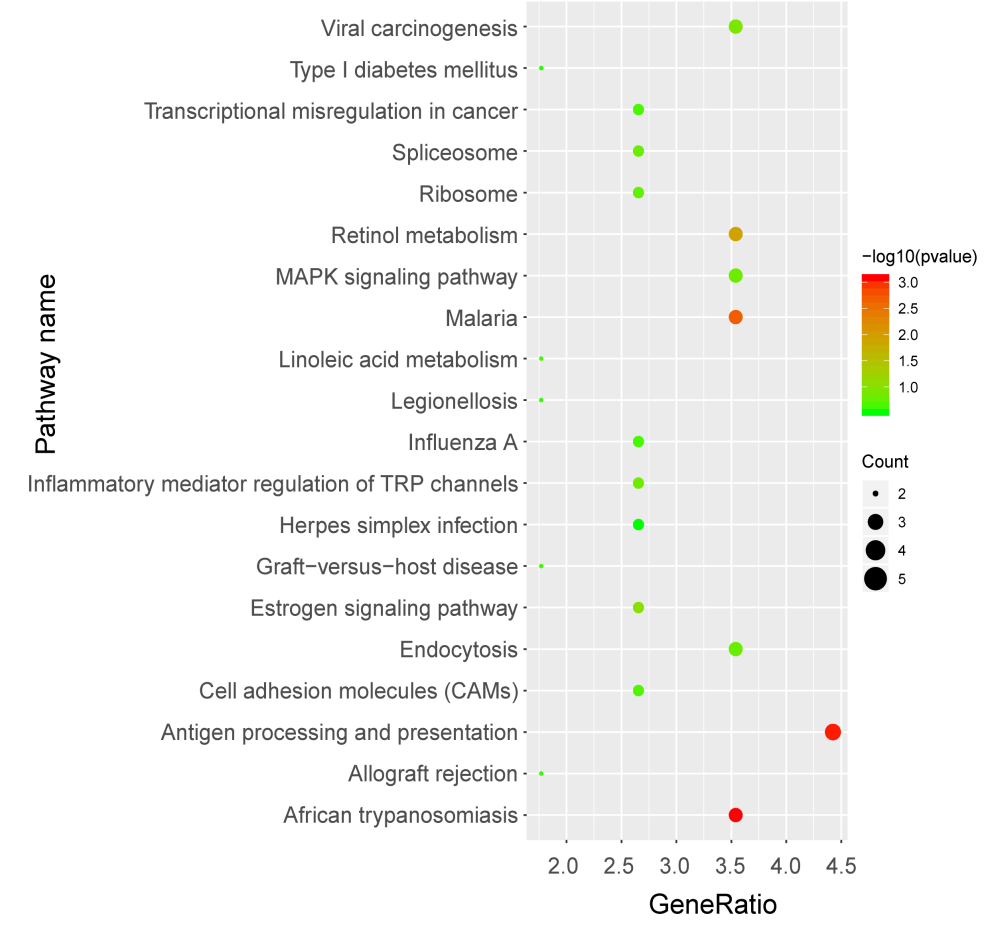

Figure 5

Bubble chart of KEGG pathway enrichment analysis of differentially expressed genes. a shows a Bubble chart of KEGG pathway enrichment analysis of differentially expressed genes in the amygdala of Susceptible and Control mice. b shows a Bubble chart of KEGG pathway enrichment analysis of 
differentially expressed genes in the amygdala of Resilient and Control mice. c shows a Bubble chart of KEGG pathway enrichment analysis of differentially expressed genes in the amygdala of Susceptible and Resilient mice. The size of the bubble presents the type of pathway gene. The larger the bubble, the more gene types of the pathway. The color of the bubble presents the $P$ value of the pathway. The redder the color, the more likely the genes are concentrated in the pathway.

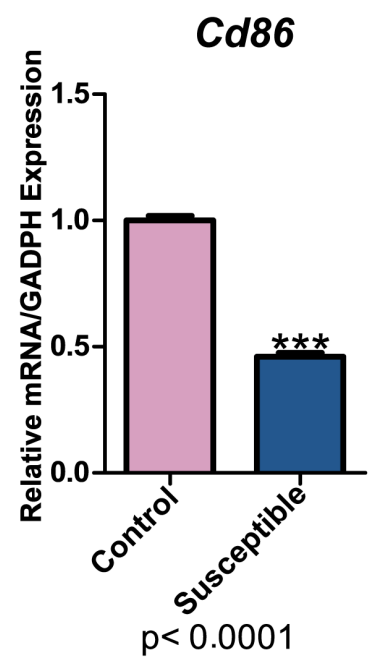

Fibcd1

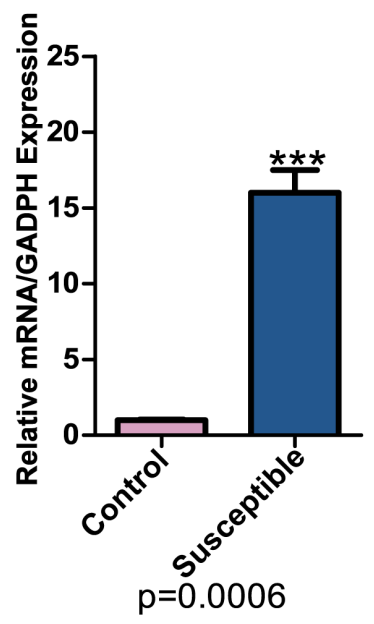

Lst1

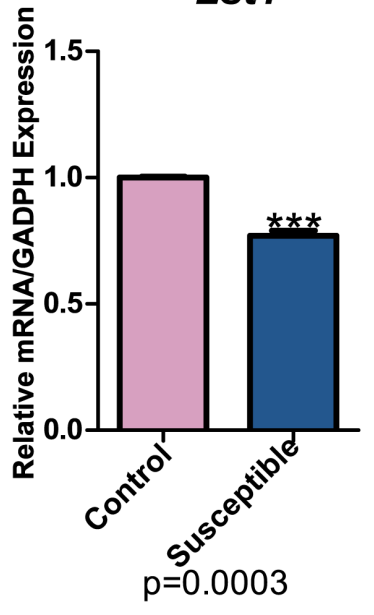

lqgap3

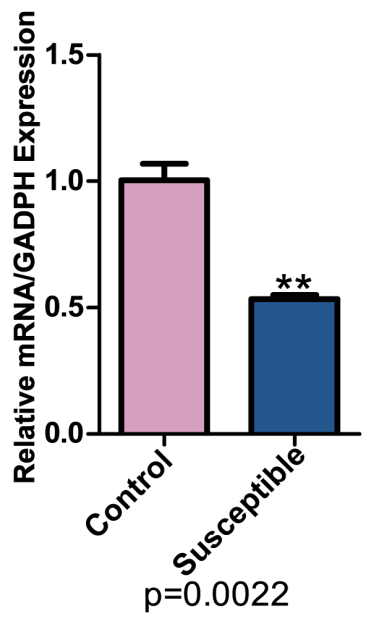

Gimap9

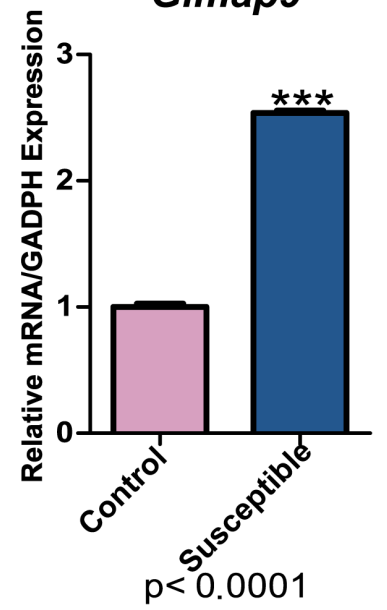

Rp/10a

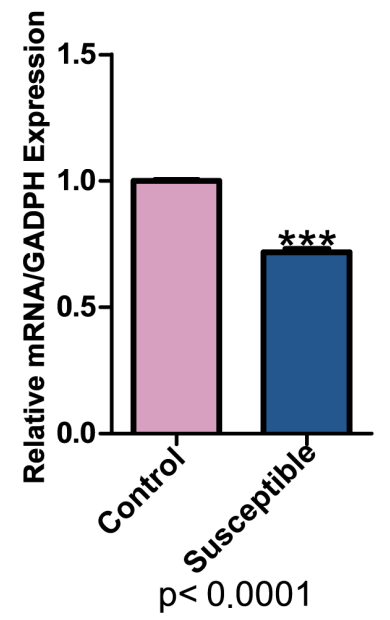

$\operatorname{Lh} \times 9$

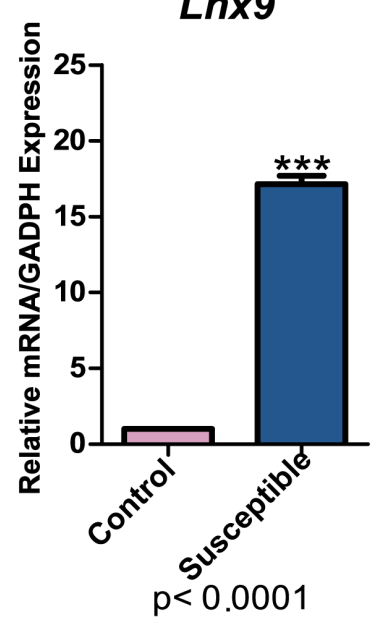

Lrrcc1

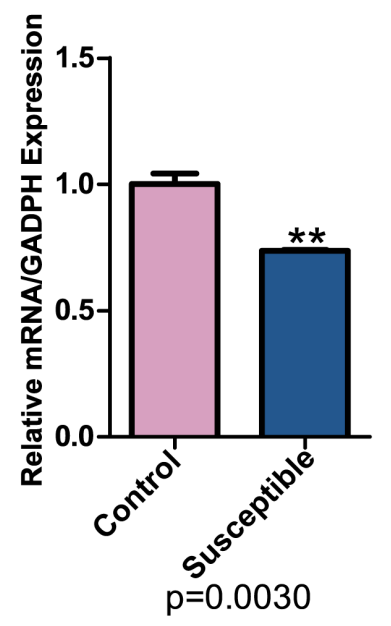

Figure 6

The validation of differentially expressed mRNAs in the amygdala from Control mice versus Susceptible mice. Three asterisks show $p<0.001$, two asterisks show $p<0.01$, in which two-sample t-test was used for the comparisons between Control mice versus Susceptible mice. 

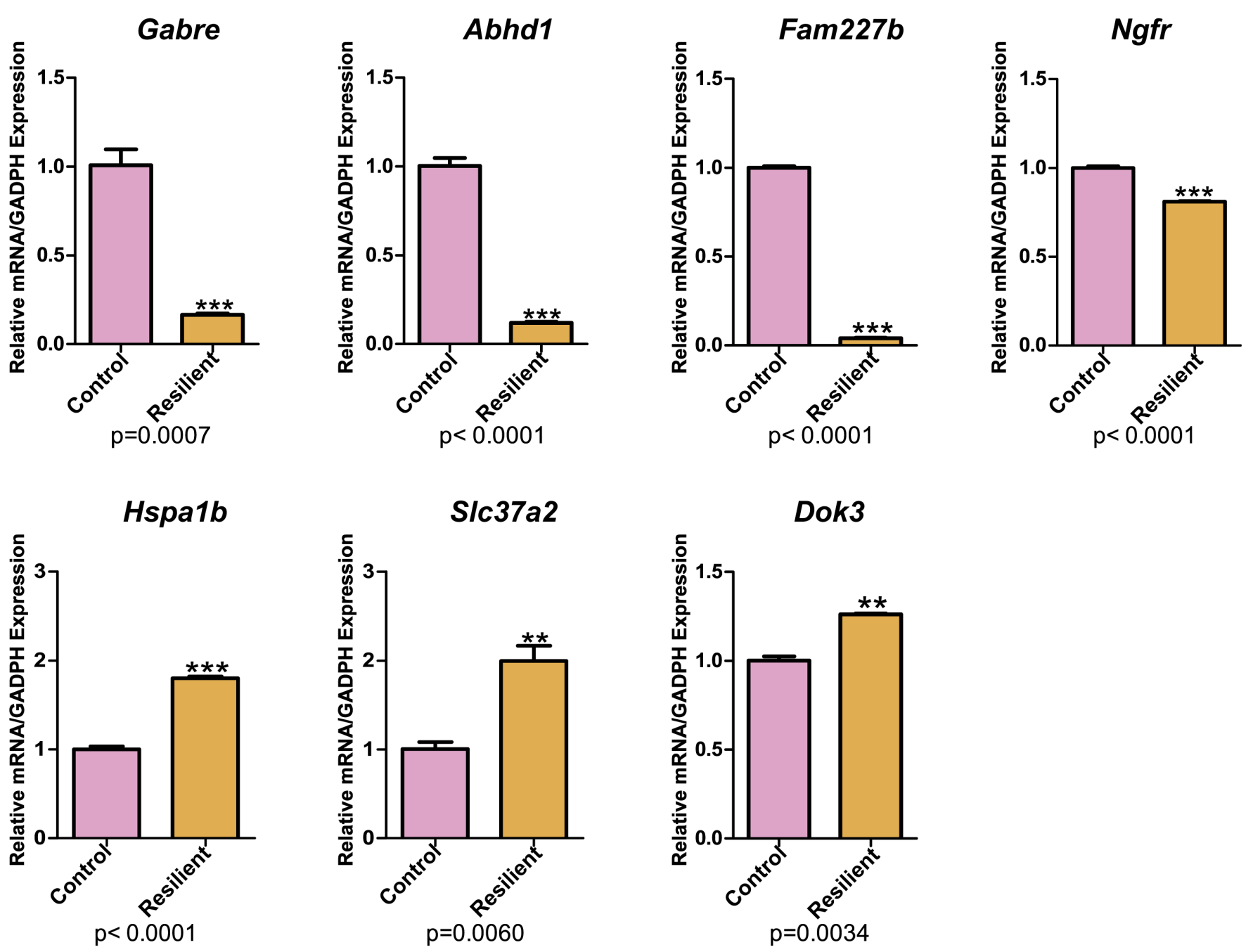

Figure 7

The validation of differentially expressed mRNAs in the amygdala from Control mice versus Resilient mice. Three asterisks show $p<0.001$, two asterisks show $p<0.01$, in which two-sample t-test was used for the comparisons between Control mice versus Resilient mice. 

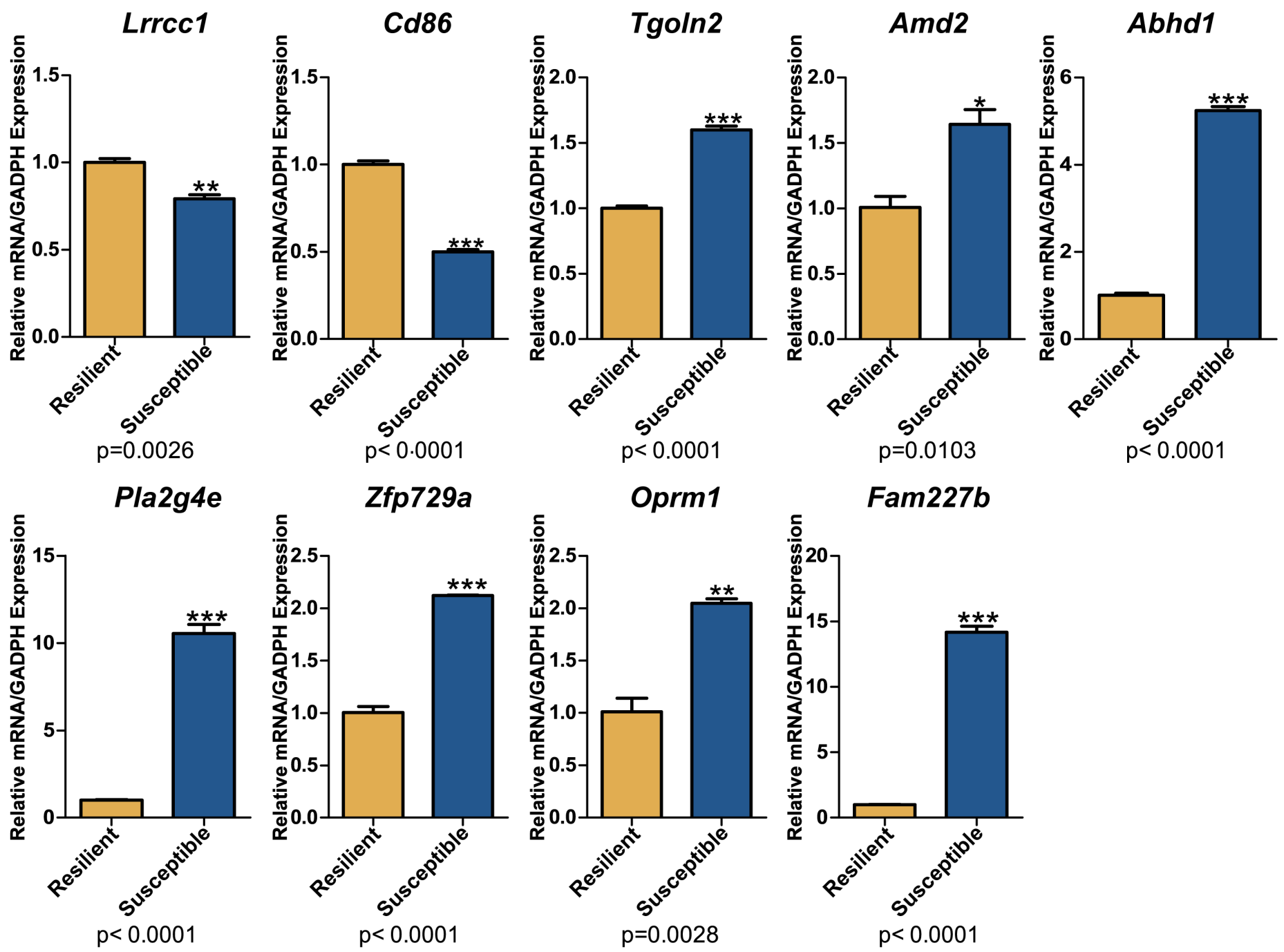

Fam227b

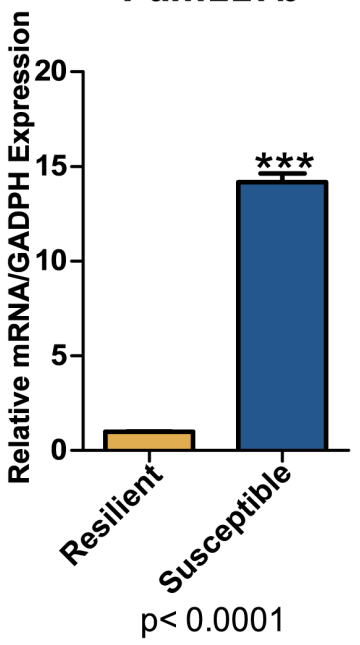

Figure 8

The validation of differentially expressed mRNAs in the amygdala from Resilient mice versus Susceptible mice. Three asterisks show $p<0.001$, two asterisks show $p<0.01$, one asterisk show $p<0.05$, in which two-sample t-test was used for the comparisons between Resilient mice versus Susceptible mice. 

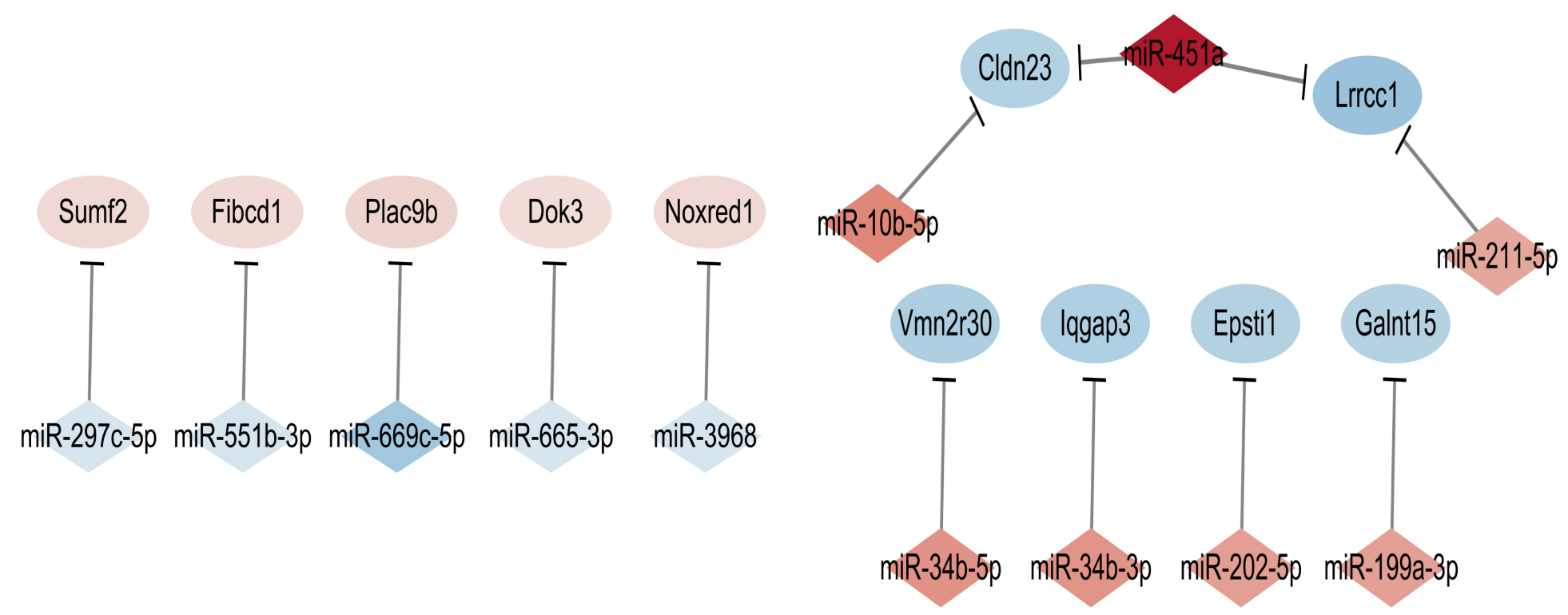

\section{Figure 9}

MicroRNA-mRNA network in Susceptible mice versus Control mice. microRNA/mRNA networks were constructed between the 12 microRNAs and 11 overlapped mRNAs with using transcriptome expression data and predicted target genes from RNAhybrid, Targetscan and miRanda databases. Diamonds present microRNAs and ovals present mRNAs. Red symbols present the elevated expression of microRNAs or mRNAs and the deeper the red, the more up-regulated. Blue symbols present the down-regulated microRNAs or mRNAs and the deeper the blue, the more down-regulated. The picture on the left shows the down-regulation of microRNA, and its corresponding mRNA is up-regulated. The more microRNA is downregulated, the more mRNA is up-regulated. The figure on the right shows that microRNA is up-regulated, and its corresponding mRNA is down-regulated. 

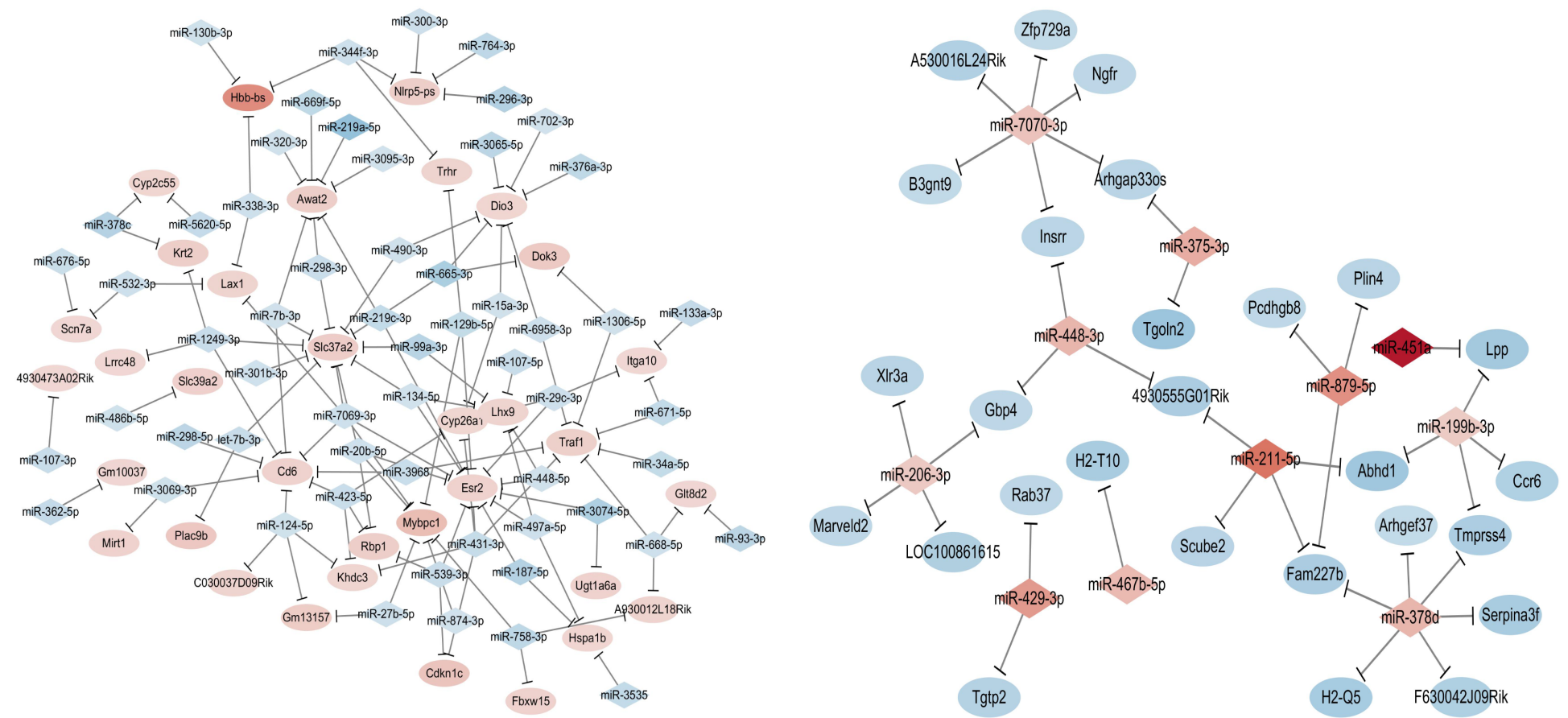

Figure 10

MicroRNA-mRNA network in Resilient mice versus Control mice. microRNA/mRNA networks were constructed between the 69 microRNAs and 61 overlapped mRNAs with using transcriptome expression data and predicted target genes from RNAhybrid, Targetscan and miRanda databases. Diamonds present microRNAs and ovals present mRNAs. Red symbols present the elevated expression of microRNAs or mRNAs and the deeper the red, the more up-regulated. Blue symbols present the down-regulated microRNAs or mRNAs and the deeper the blue, the more down-regulated. The picture on the left shows the down-regulation of microRNA, and its corresponding mRNA is up-regulated. The more microRNA is downregulated, the more mRNA is up-regulated. The figure on the right shows that microRNA is up-regulated, and its corresponding mRNA is down-regulated. 

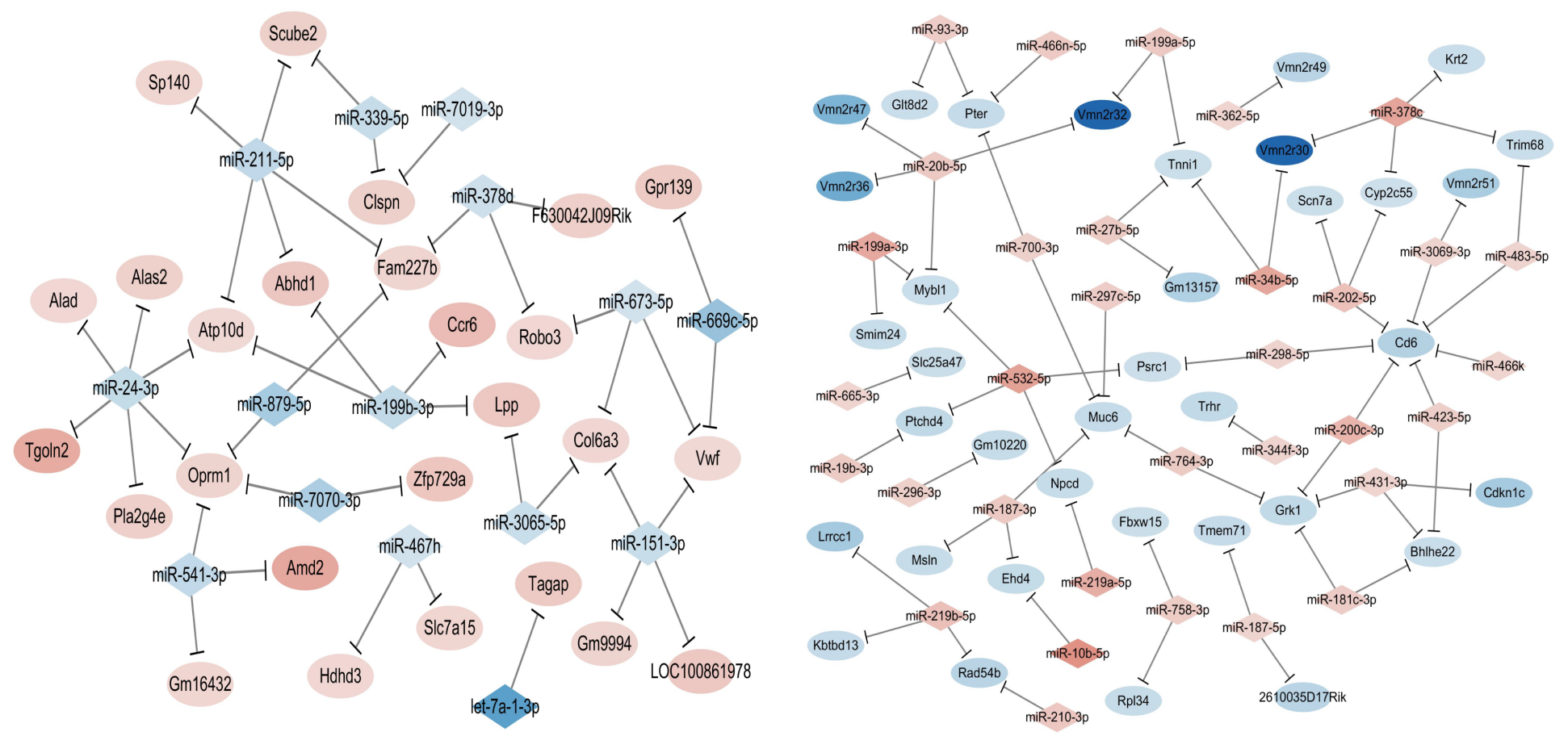

Figure 11

MicroRNA-mRNA network in Susceptible mice versus Resilient mice. microRNA/mRNA networks were constructed between the 48 microRNAs and 62 overlapped mRNAs with using transcriptome expression data and predicted target genes from RNAhybrid, Targetscan and miRanda databases. Diamonds present microRNAs and ovals present mRNAs. Red symbols present the elevated expression of microRNAs or mRNAs and the deeper the red, the more up-regulated. Blue symbols present the down-regulated microRNAs or mRNAs and the deeper the blue, the more down-regulated. The picture on the left shows the down-regulation of microRNA, and its corresponding mRNA is up-regulated. The more microRNA is downregulated, the more mRNA is up-regulated. The figure on the right shows that microRNA is up-regulated, and its corresponding mRNA is down-regulated. 

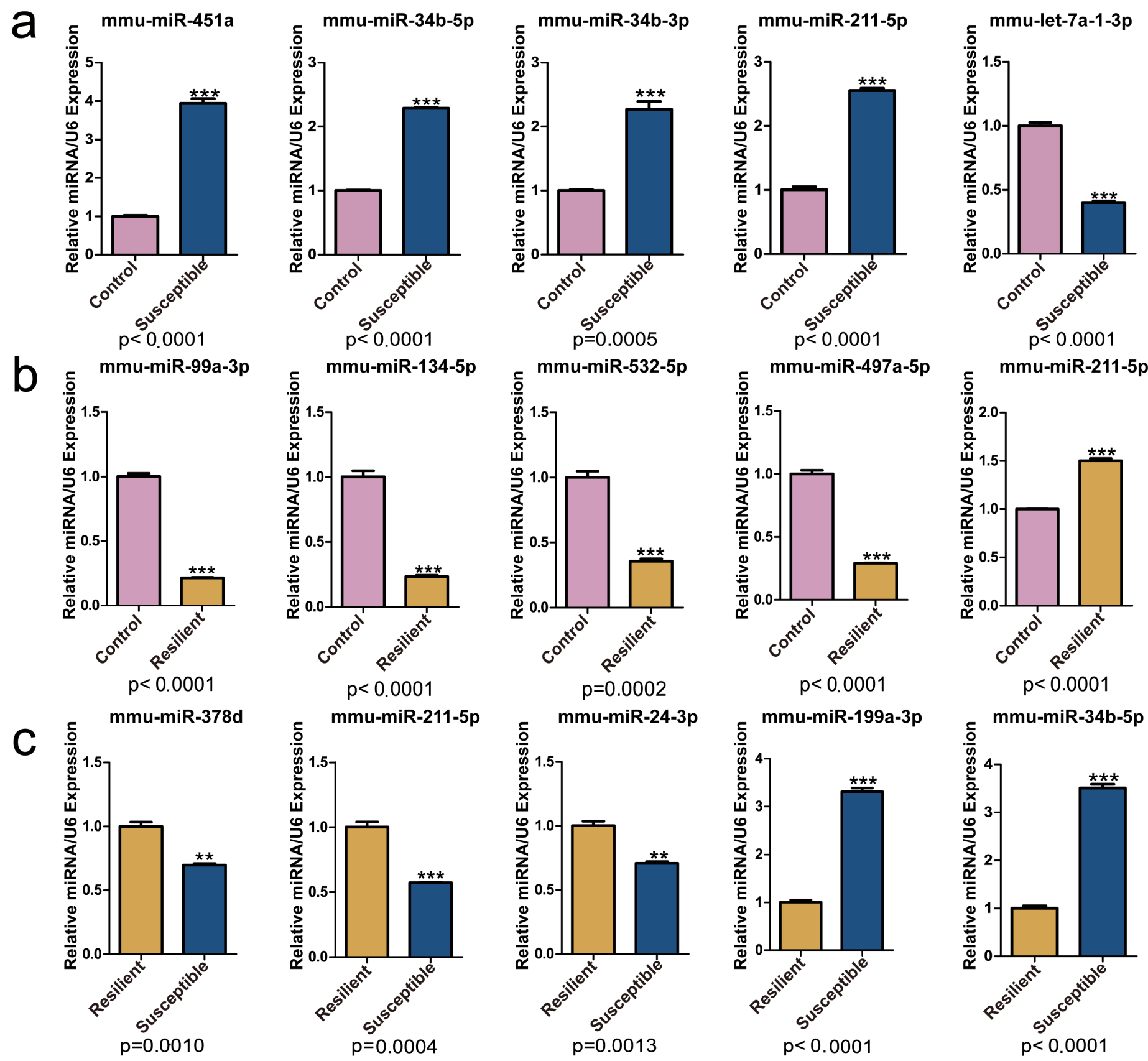

Figure 12

The validation of differentially expressed microRNAs in the amygdala from three groups of mice. a shows the validation of differentially expressed microRNAs in the amygdala from Control mice versus Susceptible mice. b shows the validation of differentially expressed microRNAs in the amygdala from Control mice versus Resilient mice. c shows the validation of differentially expressed microRNAs in the amygdala from Resilient mice versus Susceptible mice. Three asterisks show $p<0.001$, two asterisks show $p<0.01$, two-sample t-test was used for the comparisons. 
a

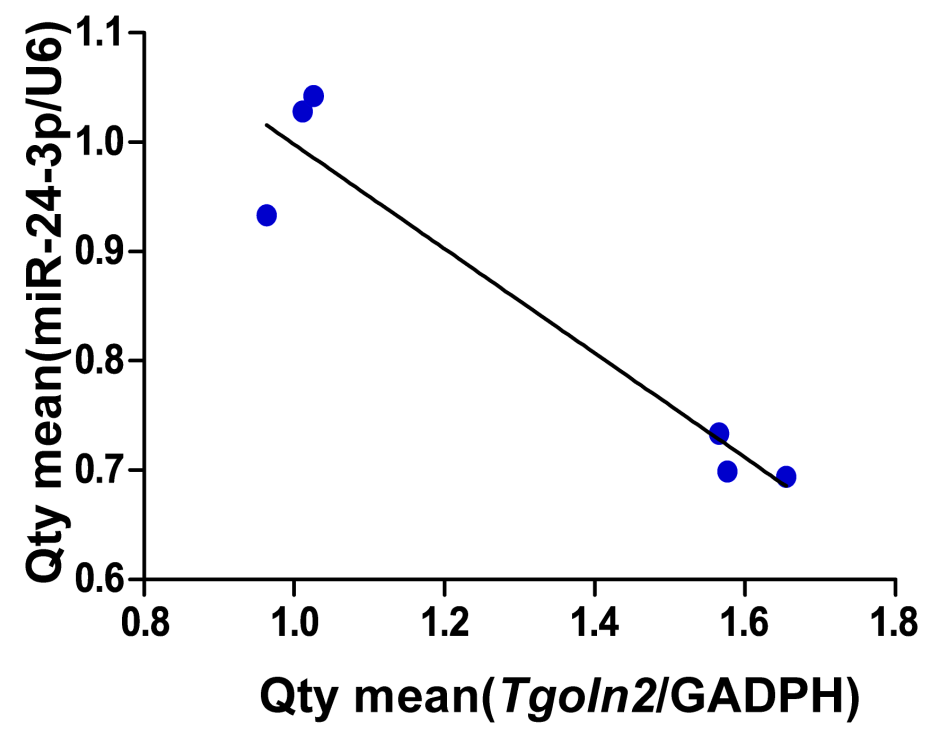

b

Tgoln2

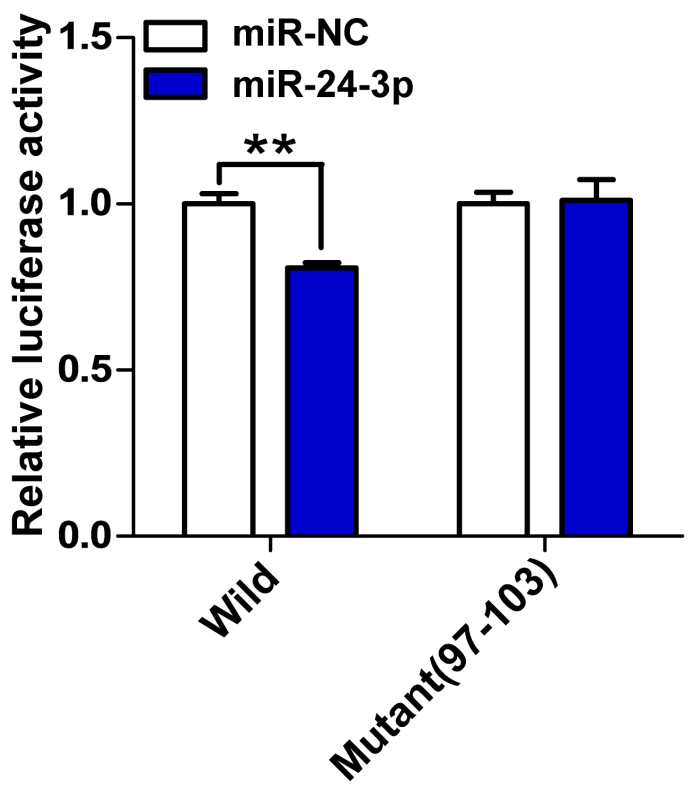

C

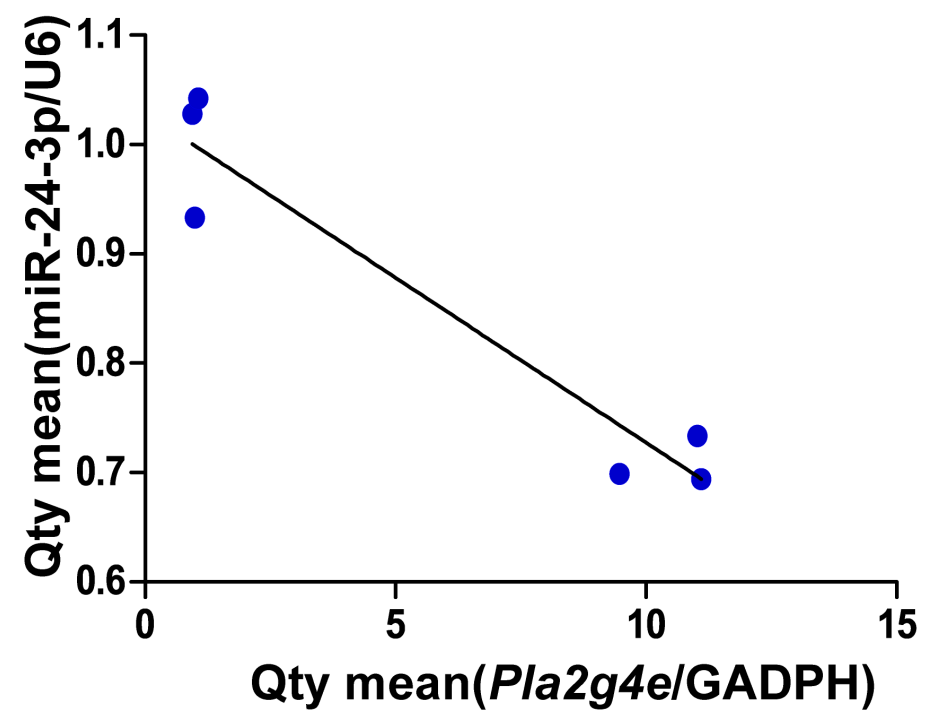

d
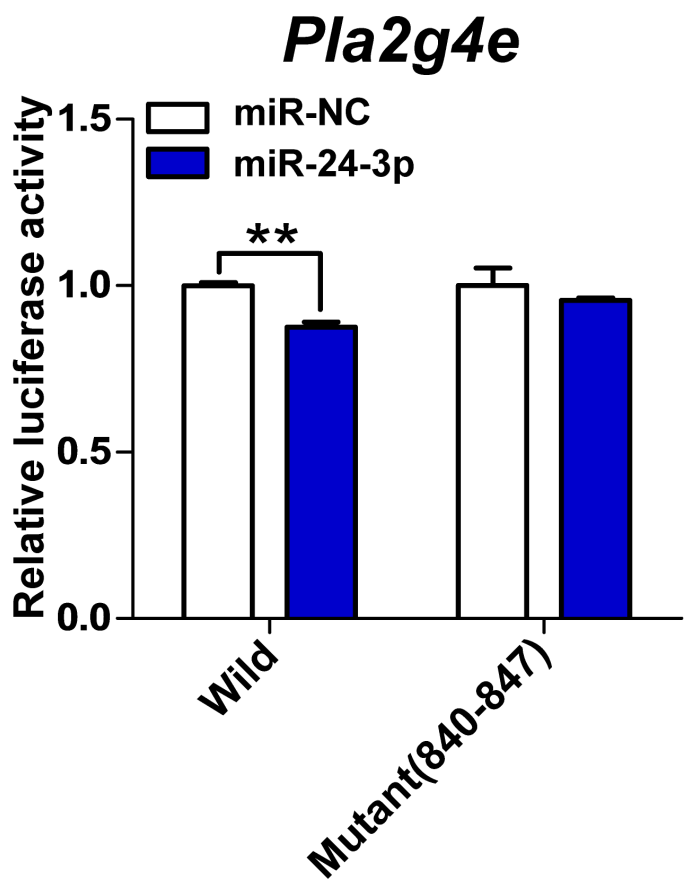

Figure 13

The microRNAs targeted mRNAs were validated by qRT-PCR and Luciferase reporter assay. a The correlation between miR-24-3p and its prediction target Tgoln2 expression by qRT-PCR in amygdala tissue $(r=-0.9225 ; P=0.0023)$. $b$ Luciferase reporter assay performed by constructed luciferase reporter plasmids, which contained the wild-type or the mutant of the predicted binding sites of miR-24-3p in Tgoln2. Then co-transfection of wild or mutant type vectors with miR-24-3p mimic or negative control (NC) into HEK293T cells ( $P=0.0051$, two-sample t-test). $c$ The correlation between miR-24-3p and its prediction target Pla2g4e expression by $q R T-P C R$ in amygdala tissue $(r=-0.9123 \otimes P=0.0030)$. $d$ Luciferase reporter assay performed by constructed luciferase reporter plasmids, which contained the wild-type or the mutant 
of the predicted binding sites of miR-24-3p in Pla2g4e. Then co-transfection of wild or mutant type vectors with miR-24-3p mimic or negative control (NC) into HEK293T cells ( $P=0.0021$, two-sample t-test).

\section{Supplementary Files}

This is a list of supplementary files associated with this preprint. Click to download.

- Additionalfile.doc

- ChecklistS1.docx 